\title{
Modelagem Computacional de Estruturas Anatômicas em 3D e Simulação de suas Imagens Radiográficas
}

Tese apresentada à Escola de Engenharia de São Carlos da Universidade de São Paulo, como parte dos requisitos para obtenção do título de Doutor em Engenharia Elétrica.

Orientadora: $\operatorname{Prof}^{\mathrm{a}} \mathrm{Dr}^{\mathrm{a}}$ Annie France Frère Slaets 
Dedico este trabalho aos meus pais, Antônio e Maria Aparecida, ao meu irmão Cledson e a todos que de alguma forma contribuíram para a sua realização, em especial à Prof ${ }^{\mathrm{a}}$. Annie. 


\section{AGRADECIMENTOS}

À Prof ${ }^{\mathrm{a}}$. Annie France Frère Slaets, pela oportunidade, dedicação, colaboração e competência como orientadora, fatores indispensáveis para a realização desse trabalho.

Ao professor e amigo Márcio Alexandre Marques, principal responsável pelo início da minha vida acadêmica na cidade de São Carlos.

À Coordenação de Aperfeiçoamento de Pessoal de Nível Superior - CAPES, pelo apoio financeiro.

Aos meus pais, Antônio e Maria Aparecida, agradeço por tudo, a começar por minha existência e a de meu irmão. Por uma vida dedicada ao trabalho e a família, pelas inúmeras oportunidades proporcionadas, pelos exemplos de conduta, amor e dedicação demonstrados durante todos os anos da minha vida, valores essenciais e determinantes na formação do meu caráter e personalidade.

Ao meu querido irmão Cledson, pessoa de fundamental importância em minha vida, pela amizade e lealdade, sempre pronto e disposto a me ouvir a qualquer momento, hora ou lugar.

Aos meus grandes amigos Adriano Horas, Celso, Cirano, Fabiana, Fabrício, Fernando, Flávio, Guilherme, Jackeline, João, Marcelo, Renan, Robson, Rodolfo e Sabrina por estarem sempre tão presentes em minha vida ao longo de tantos anos e por tornarem a distância um detalhe insignificante e imperceptível.

Aos inúmeros e sinceros amigos que fiz durante as viagens entre São Carlos e São José do Rio Preto, em especial: Cléber, Everthon, Karina, Luciano (Ruivo), Priscila e Samira.

Aos atuais e antigos membros do Laboratório de Imagens Médicas da USP de São Carlos, do Centro Hospitalar de Processamento de Imagens da USP de Ribeirão Preto e do Núcleo de Pesquisas Tecnológicas da Universidade de Mogi das Cruzes pela amizade, receptividade e em especial, pelos bons momentos compartilhados.

Aos amigos, professores e funcionários do CEFET Bragança Paulista e do Departamento de Engenharia Elétrica da USP de São Carlos pela amizade e disponibilidade.

Por fim, mas em primeiro lugar, agradeço a Deus, por tornar tudo isso possível e pela presença constante em minha vida. 


\section{RESUMO}

SANTOS, C. E. (2008). Modelagem Computacional de Estruturas Anatômicas em 3D e Simulação de suas Imagens Radiográficas. Tese de Doutorado. E.E.S.C., Universidade de São Paulo, São Carlos (2008).

Os métodos de controle de qualidade tradicionais aplicados ao radiodiagnóstico, são a melhor maneira de garantir a boa qualidade das imagens produzidas. No entanto, a investigação de particularidades oriundas do processo de formação de imagens radiológicas requer ferramentas computacionais complementares, em função do número de variáveis envolvidas. Entretanto, os fantomas computacionais baseados em voxels não conseguem representar as variações morfométricas necessárias para a simulação de exames cujo diagnóstico é baseado em imagem. Neste trabalho foi desenvolvido um novo tipo de fantoma computacional, baseado em modelagem 3D, que possui as vantagens apresentadas pelos fantomas computacionais tradicionais sem os problemas encontados nestes. A ferramenta de modelagem utilizada, o Blender, é disponibilizado gratuitamente na internet. A técnica utilizada foi a "box modeling", que consiste na deformação de uma primitiva básica, nesse caso um cubo, até que apresente a forma da estrutura que se deseja modelar. Para tanto, foram utilizadas como referência, imagens obtidas de atlas de anatomia e fotografias de um esqueleto fornecido pela Universidade de Mogi das Cruzes. Foram modelados o sistema ósseo, os órgãos internos e a anatomia externa do corpo humano. A metodologia empregada permitiu a alteração de parâmetros do modelo dentro da ferramenta da modelagem. Essa possibilidade foi mostrada através da variação dos formatos do intestino e do aumento da quantidade de tecido adiposo da malha referente à pele. A simulação das imagens radiológicas foi realizada a partir de coeficientes de atenuação de massa de materiais, ossos e tecidos e de modelos com diversas características físicas. Essa versatilidade, permite prever a influência que as diferenças morfométricas entre os indivíduos provocam nas imagens, propriciando dessa forma, uma ferramenta relevante complementar aos métodos de controle de qualidade tradicionais.

Palavras chave: Modelagem computacional; Simulação Radiográfica; Estruturas Anatômicas; Fantoma Computacional. 


\section{ABSTRACT}

SANTOS, C. E. (2008). Computational 3D Modelling of Anatomic Structures and Simulation of its Radiography Images. PhD Thesis. E.E.S.C. - University of São Paulo, São Carlos (2008).

The conventional methods of quality control applied to radio diagnosis are the best way to have assured good quality of the produced images. Due the amount of variables to consider, the study of particular issues of the process of formation of radiological images requires complementary computational tools. However, the computational voxel based phantoms are not suitable to represent the morphometrical variations, intended for test simulations with image based diagnosis. This work developed a new type of computational phantom, based on 3D modelling. It has the same advantages of the conventional ones, without some of their restrictions. The modelling tool employed, Blender, is available on internet for free download. The project uses the technique called "box modeling", which consists in the deformation of a primitive form (a cube, in this case) until it presents a similar form to that it is wanted to model. In order to achieve it, some images, obtained from anatomy atlas and a skeleton pictures obtained from University of Mogi das Cruzes, were used as reference. Were built models from skeletal system, internal organs and external human body anatomy. The applied methodology allowed model's parameter settings on the modelling tool. This option was presented by means of intestine format variation and increase of adipose tissue on the mesh that represents skin. The simulation of radiological images was done by means of X-Ray Mass Attenuation Coefficients, bones and tissues and models with diferent physical characteristics. This flexibility allows the analysis and forecasting of the influences that morphometrical differences of individual implies on images, revealing an important tool that complements the conventional quality control tools.

Keywords: Computational Modelling; Radiography Simulation; Anatomic Structures; Computational Phantom. 


\section{Lista de Figuras}

2.1 Fantoma analítico estilizado de um adulto [Gualdrini, 2005] . . . . . . . . . . 12

2.2 Visualização tridimensional da disposição interna dos órgãos e do esqueleto do fantoma analítico [Gualdrini, 2005] . . . . . . . . . . . . . . . . . 12

2.3 Representação do estômago e do sistema gastro-intestinal [Gualdrini, 2005]. . . 12

2.4 Os fantomas analíticos Adam e Eva [Gualdrini, 2005]. . . . . . . . . . . . . . 13

2.5 Resultados obtidos com a utilização de um fantoma analítico - (a) e um fantoma baseado em "voxels" - (b), [Xu, 2005c]. . . . . . . . . . . . . . . . . . . . 14

2.6 Série de imagens tomográficas pertencentes ao projeto "The Visible Human" [Spitzer, 2008] . . . . . . . . . . . . . . . . . . . . . . . 15

2.7 Fantoma analítico (a), uma representação 2D (b) e uma representação 3D (c) do fantoma baseado em voxels "Vip-Man" [Gualdrini, 2005] . . . . . . . . . . . . . 16

2.8 Visualizações frontal e lateral e disposição interna dos órgãos e do esqueleto do fantoma femino $F A X$ [Kramer et al., 2004]. . . . . . . . . . . . . . . . . . 16

2.9 Projeções 3D do fantoma femino FAX a partir de diferentes perspectivas [Kramer et al., 2004]. 17

2.10 Visualizações baseadas em reconstruções 3D do voxel-phantom GOLEM [Zankl and Wittmann, 20

2.11 Visualizações baseadas em reconstruções 3D dos voxel-phantoms femininos Helga, Donna e Irene [Gualdrini, 2005] . . . . . . . . . . . . . . . . . . . . 20

2.12 Visualizações bidimensionais de um voxel-phantom do joelho [Gualdrini, 2005]. 20

3.1 Tela principal do software de modelagem blender. . . . . . . . . . . . . . . 27

3.2 Quatro modos de visualização simultâneos. . . . . . . . . . . . . . . . . . 28

3.3 (a)Uma primitiva básica, o cubo; (b)A mesma primitiva após a realização de operações de extrusão; (c)O modelo final. . . . . . . . . . . . . . . . . . . . . 29

3.4 Selecionando uma imagem de referência. . . . . . . . . . . . . . . . . . . . 29

3.5 Imagem de referência selecionada. . . . . . . . . . . . . . . 30 


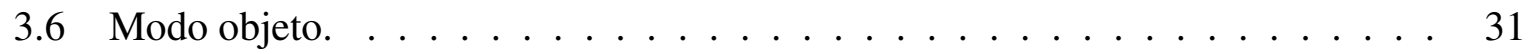

3.7 Modo de edição. . . . . . . . . . . . . . . . . . . . . . . . . . 32

3.8 Trabalhando com múltiplas camadas. . . . . . . . . . . . . . 33

3.9 Demonstração do processo de escala. . . . . . . . . . . . . . . . . . . . . 34

3.10 Demonstração do processo de translação. . . . . . . . . . . . . . . . . 34

3.11 Demonstração do processo de extrusão. . . . . . . . . . . . . . . . 35

3.12 Demonstração do processo de extrusão. . . . . . . . . . . . . . . 36

3.13 A primitiva inicial, um cubo, ainda não posicionada de maneira correta sobre a imagem de referência. . . . . . . . . . . . . . . . 37

3.14 Cubo posicionado sobre a imagem de referência. . . . . . . . . . . . 37

3.15 Extrusão a partir da primitiva inicial. . . . . . . . . . . . . . 38

3.16 Visão tridimensional do modelo. . . . . . . . . . . . . . . . . . . . 39

3.17 Aplicação de subdivisão de superfície. . . . . . . . . . . . . . . . . . 39

3.18 Malha do modelo em wireframe. . . . . . . . . . . . . . . . . . 40

3.19 Malha do modelo em wireframe sobre a imagem de referência. . . . . . . . . . 40

3.20 Aplicação de textura ao modelo. . . . . . . . . . . . . . . . . . . . 41

3.21 Localização dos pontos (a) e (b) em relação ao modelo proporcional para posterior realização da operação de seccionamento. . . . . . . . . . . . . . . . 47

3.22 Seccionamento do modelo proporcional em vinte e três fatias, utilizando uma espessura de corte cinco vezes maior do que a espessura usada na simulação. 48

3.23 Fluxograma do algoritmo de simulação de imagens radiológicas. . . . . . . . . 51

4.1 Visualização anterior, posterior e lateral do modelo tridimensional da caixa

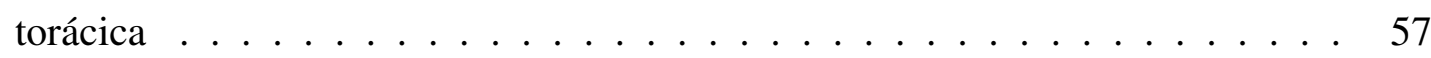

4.2 Visualização anterior e posterior do modelo tridimensional dos membros supe-

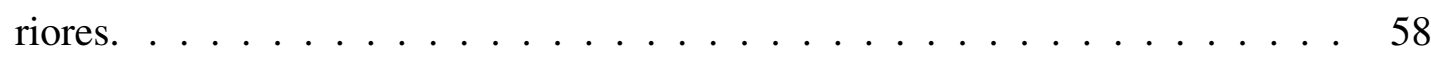

4.3 Visualização anterior, posterior e lateral do modelo tridimensional dos membros

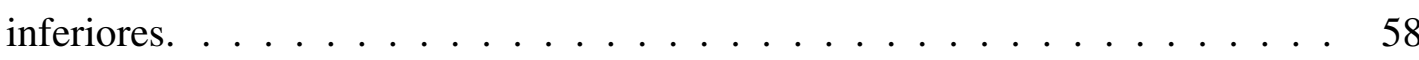


4.4 Visualização anterior, posterior e lateral do modelo tridimensional da espinha dorsal. . . . . . . . . . . . . . . . . . . . . 59

4.5 Visualização anterior, posterior e lateral do modelo tridimensional completo do esqueleto. ......................... 59

4.6 Visualização anterior, posterior e lateral do modelo tridimensional da pele de um indivíduo com altura e peso proporcionais. . . . . . . . . . . . . . . . 60

4.7 Visualização anterior, posterior e lateral do modelo tridimensional da pele de um indivíduo com altura e peso desproporcionais em função da quantidade de tecido adiposo. . . . . . . . . . . . . . . . . . . 61

4.8 Visualização anterior, posterior e lateral do modelo tridimensional do pulmão. . 62

4.9 Visualização anterior, posterior e lateral do modelo tridimensional do sistema gastro-intestinal. . . . . . . . . . . . . . . . . 62

4.10 Visualização anterior, posterior e lateral dos modelos tridimensionais dos órgãos presentes no corpo humano. . . . . . . . . . . . . . . . . 63

4.11 Visualização frontal do modelo do intestino em formato "normal". . . . . . . . 64

4.12 Visualização frontal, lateral e posterior do modelo tridimensional completo do corpo humano com peso e altura proporcionais. . . . . . . . . . . . . . . . . . 65

4.13 Visualização frontal, lateral e posterior do modelo tridimensional completo do corpo humano com peso e altura desproporcionais em função da quantidade de tecido adiposo. . . . . . . . . . . . . . . . . . . . 66

4.14 Visualização frontal do modelo tridimensional completo do corpo humano com peso e altura proporcionais e intestino em formato de serpente. . . . . . . . . .

4.15 Visualização frontal do modelo tridimensional completo do corpo humano com peso e altura proporcionais e intestino em formato de "U". . . . . . . . . . . . 68

4.16 Visualização frontal/s do modelo tridimensional completo do corpo humano com peso e altura proporcionais e intestino em formato de "V". . . . . . . . . .

4.17 Visualização frontal do modelo tridimensional completo do corpo humano com peso e altura desproporcionais em função da quantidade de tecido adiposo e intestino em formato de serpente. . . . . . . . . . . . . . . . . . . . . . . 70 
4.18 Visualização frontal do modelo tridimensional completo do corpo humano com peso e altura desproporcionais em função da quantidade de tecido adiposo e intestino em formato de "U". . . . . . . . . . . . . . . . . . . . . . 71

4.19 Visualização frontal do modelo tridimensional completo do corpo humano com peso e altura desproporcionais em função da quantidade de tecido adiposo e intestino em formato de "V". . . . . . . . . . . . . . . . . . . . . . . . . . 72

4.20 (a) Imagem frontal da caixa torácica obtida em um atlas anatômico sobreposta à malha que a representa em nosso modelo. (b) Operação de subtração entre a imagem obtida em um atlas anatômico e a imagem da malha de nosso modelo. . 73

4.21 (a) Imagem posterior da caixa torácica obtida em um atlas anatômico sobreposta à malha que a representa em nosso modelo. (b) Operação de subtração entre a imagem obtida em um atlas anatômico e a imagem da malha de nosso modelo. . 73

4.22 (a) Imagem frontal dos membros superiores obtida em um atlas anatômico sobreposta à malha que a representa em nosso modelo. (b) Operação de subtração entre a imagem obtida em um atlas anatômico e a imagem da malha de nosso modelo. ......................... 74

4.23 (a) Imagem frontal dos membros inferiores obtida em um atlas anatômico sobreposta à malha que a representa em nosso modelo. (b) Operação de subtração entre a imagem obtida em um atlas anatômico e a imagem da malha de nosso modelo. ........................... 74

4.24 Imagem frontal e posterior do torso obtida em um atlas anatômico [Sobotta, 2000]. 76

4.25 Imagem frontal e posterior da malha que representa o torso obtida em nosso modelo. . . . . . . . . . . . . . . . . . 76

4.26 Imagem lateral do torso obtida em um atlas anatômico [Sobotta, 2000]. . . . . 77

4.27 Imagem lateral da malha que representa o torso obtida em nosso modelo. . . . 77

4.28 Imagem frontal e posterior do torso obtida em um atlas anatômico [Sobotta, 2000]. 78

4.29 Imagem frontal e posterior da malha que representa o torso obtida em nosso modelo obeso. . . . . . . . . . . . . . . . . . . . . . . 78

4.30 Imagem lateral do torso obtida em um atlas anatômico [Sobotta, 2000]. . . . . 79

4.31 Imagem lateral da malha que representa o torso obtida em nosso modelo obeso. 79 
4.32 Imagem radiográfica simulada de um indivíduo com peso e altura proporcionais e imagem radiográfica real de um indivíduo com características semelhantes. . 80

4.33 Imagem radiográfica simulada de um indivíduo com peso e altura desproporcionais e imagem radiográfica real de um indivíduo com características semelhantes. 81 


\section{Lista de Tabelas}

2.1 Tabela comparativa dos principais fantomas computacionais encontrados na literatura . . . . . . . . . . . . . . . . . . . . . 10

3.1 Coeficientes de atenuação de massa de materiais. . . . . . . . . . . . . . . . . 43

3.2 Coeficientes de atenuação de massa de ossos e sua composição em função dos elementos básicos. . . . . . . . . . . . . . . . . . . 43

3.3 Coeficientes de atenuação de massa de tecidos e sua composição em função dos elementos básicos. . . . . . . . . . . . . . . . . . . . 43

3.4 Valores de massa para órgãos e tecidos segundo o "Homem de Referência" do

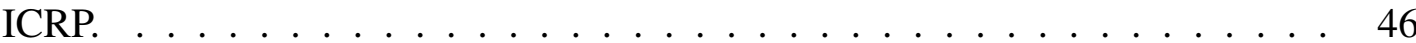

4.1 Dados referentes à análise quantitativa baseada em contagem de pixels realizada em nossos modelos. . . . . . . . . . . . . . . . . . . . . 75 


\section{Sumário}

1 Introdução 1

1.1 Considerações Iniciais $\ldots \ldots \ldots \ldots$. . . . . . . . . . . . . . 1

1.2 Motivação e Justificativa . . . . . . . . . . . . . . . . . . . 3

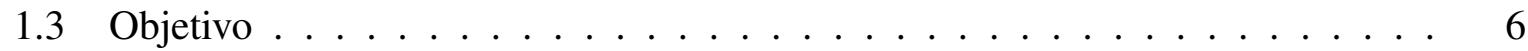

1.4 Organização da Tese $\ldots \ldots \ldots \ldots \ldots \ldots$

2 Revisão Bibliográfica 9

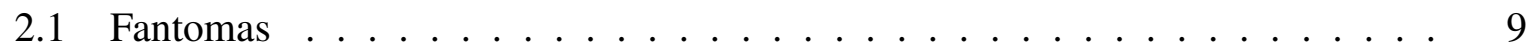

$2.1 .1 \quad$ Fantomas Analíticos . . . . . . . . . . . . . . . . 11

2.1 .2 Voxel phantoms . . . . . . . . . . . . . . . . 13

2.1.3 Modelos baseados em Simulações Computacionais . . . . . . . . . . 22

3 Materiais, Métodos e Algoritmos Desenvolvidos $\quad 25$

3.1 Etapas do Trabalho . . . . . . . . . . . . . . . . . . 25

3.1 .1 A Escolha do Software . . . . . . . . . . . . . . . . 25

3.2 Modelagem 3D . . . . . . . . . . . . . . . . . . 26

3.2.1 A Interface de Trabalho do Blender . . . . . . . . . . . . . . 26

3.2.2 Aquisição das Imagens de Referência . . . . . . . . . . . . . . 28

3.2.3 Modos de Utilização . . . . . . . . . . . . . . . . . . . . . . . . 31

3.2.4 Iniciando o Processo de Modelagem . . . . . . . . . . . . . . 36

3.3 A Ferramenta . . . . . . . . . . . . . . . . . . . 41

3.4 Determinação dos Parâmetros Necessários para Simulação das Imagens Radiológicas ................................ 42 
3.4.1 Coeficientes de Atenuação de Massa . . . . . . . . . . . . . . . . . . . 42

3.4 .2 Características Físicas $\ldots \ldots \ldots \ldots$. . . . . . . . . . 46

3.4.3 Seccionamento dos Modelos . . . . . . . . . . . . . . . . . . . 47

3.4.4 Algoritmo de Simulação das Imagens Radiológicas . . . . . . . . . . . 49

3.5 Validação dos Modelos Desenvolvidos . . . . . . . . . . . . . . . 52

3.5.1 Validação por Subtração de Imagens . . . . . . . . . . . . . . . . . 52

3.5.2 Validação por Comparação Visual dos Modelos . . . . . . . . . . . . . 52

3.5.3 Cálculo da Média dos Níveis de Cinza . . . . . . . . . . . . . . 54

3.5.4 Validação por Comparação Visual das Imagens Radiográficas . . . . . 54

4 Resultados $\quad 57$

4.1 Modelo Tridimensional do Sistema Ósseo Humano $\ldots . . . \ldots$

4.2 Modelo Tridimensional da Pele . . . . . . . . . . . . . . . . . 60

4.3 Modelos Tridimensionais dos Órgãos . . . . . . . . . . . . . . . 61

4.3.1 Pulmões, Coração, Fígado, Estômago, Pâncreas, Rins, Intestino Grosso, Intestino Delgado e Bexiga . . . . . . . . . . . . . . . 63

4.4 Variações Anatômicas . . . . . . . . . . . . . . . . . . . . 63

4.5 Modelos Completos . . . . . . . . . . . . . . . . . . . 64

4.6 Validação dos Modelos por Subtração de Imagens . . . . . . . . . . . . . . . 73

4.7 Validação dos Modelos por Comparação com Atlas Anatômico . . . . . . . . . 76

4.7.1 Avaliação dos Modelos por Especialistas . . . . . . . . . . . . . 80

4.8 Validação das Imagens Simuladas por comparação com Imagens Radiográficas 80

4.8.1 Avaliação das Imagens Radiológicas por Médicos . . . . . . . . . . . . 81

4.9 Discussões . . . . . . . . . . . . . . . . . . . . 82

5 Conclusões $\quad 85$

5.1 Sugestões para Trabalhos Futuros . . . . . . . . . . . . . . 87 
Referências Bibliográficas 


\section{Introdução}

\subsection{Considerações Iniciais}

De uma maneira geral, exames clínicos baseados em imagem são comuns na rotina médica e hospitalar. Dentre os principais tipos de exame que se enquadram nessa categoria, o exame radiológico é o realizado com maior frequência. Além do custo significativamente menor em relação aos exames de tomografia computadorizada e de ressonância magnética, os equipamentos de raios $\mathrm{X}$ possuem uma base instalada superior em relação aos equipamentos que utilizam tecnologia mais moderna, embora esse número ainda esteja longe do ideal.

Os equipamentos radiológicos podem ser utilizados para a realização de exames cujo diagnóstico é considerado simples, como fraturas, por exemplo, até exames mais detalhados e de difícil diagnóstico, como a detecção de microcalcificações de mama. A detecção de microcalcificações de mama é mais difícil em função do tamanho reduzido destas, sendo portanto, dependente da qualidade da imagem e de técnicas de exposição adequadas. Mesmo um médico experiente necessita de imagens com um padrão de qualidade suficiente para evidenciar as informações necessárias a um diagnóstico confiável.

Em geral, são utilizadas técnicas de exposição específicas para cada tipo de exame, que variam de acordo com a estrutura investigada e com as características do paciente. No entanto, somente a utilização da técnica correta não é suficiente para solucionar todos os problemas decorrentes do processo de formação de imagens radiológicas. O controle de qualidade aplicado ao radiodiagnóstico é a maneira mais eficiente de garantir a qualidade das imagens produzidas por um equipamento de raios $\mathrm{X}$. Os equipamentos radiológicos podem apresentar diferenças entre os valores nominais determinados como técnica de exposição e os valores produzidos efetivamente pelo equipamento, em função do desgaste natural do tubo ou mesmo por problemas de calibração do mesmo. Desse modo, os exames podem não retratar informações radiológicas importantes, ou ainda, submeter os pacientes a exposição desnecessária à radiação, uma vez que o primeiro exame pode não produzir os resultados esperados pelo radiologista tornando necessária a realização de pelo menos mais um exame. Um programa de controle de qualidade 
traz também outros benefícios além da qualidade das imagens radiográficas produzidas pelo aparelho, como por exemplo, a economia. Um equipamento operado corretamente e em perfeitas condições, irá gerar boas imagens já na primeira exposição, eliminando dessa forma, o custo de produção de novas imagens. Além disso, a vida útil do tubo de raios X será prolongada, devido a menor quantidade de disparos efetuados. Entretanto, a principal vantagem da utilização de métodos e técnicas de controle de qualidade é a redução da radiação, desnecessária, recebida pelo paciente.

Alguns fenômenos físicos que ocorrem durante o processo de formação de imagens são fundamentais na nitidez das imagens e não são considerados nos métodos de controle de qualidade tradicionais. Fatores como o efeito heel, o efeito Compton e a sensibilidade do sistema tela-filme utilizado para o registro das radiografias, podem provocar resultados diferentes dos esperados pelo radiologista. No caso do sistema de registro, como muitas vezes os hospitais estão sujeitos a receber materiais de menor custo e de menor qualidade, esse é um problema que deve ser considerado. Em alguns casos, são necessárias compensações nas técnicas de exposição que eram utilizadas nos sistemas tela-filme anteriores. Isso ocorre porque os sistemas de registro tem sensibilidades diferentes e por esse motivo são mais ou menos eficientes durante o processo de absorção de fótons, caracterizando dessa forma, um sistema de registro mais ou menos adequado.

A maior parte dos métodos de controle de qualidade utilizados atualmente, analisam os parâmetros fisicos presentes no processo de formação das radiografias somente em uma posição do campo, normalmente o centro, não considerando os efeitos que estes provocam. Dessa forma, como o campo de radiação não é isotrópico, o equipamento pode produzir uma imagem adequada no centro e apresentar características inadequadas em outras regiões, sem que este fenômeno seja detectado. Em função desse tipo de limitação, a adoção de um método complementar baseado em uma ferramenta computacional que efetue o controle de qualidade em todas as posições do campo e principalmente considere os efeitos que os fenômenos físicos provocam, tornaria o controle de qualidade mais eficiente. Em um trabalho anterior, desenvolvemos um Sistema Radiológico Virtual [Santos, 2003] que contempla todos esses fenômenos e portanto, complementa o controle de qualidade tradicional, mas utilizamos como objeto virtual uma matriz de esferas.

Um outro fator que merece atenção é a importância da avaliação dos efeitos que as diferenças morfométricas e anatômicas entre pacientes podem provocar nas imagens radiológicas. Em muitos casos, esses fatores combinados com os efeitos provocados pelos fenômenos físicos presentes no processo de formação de imagens radiológicas, podem tornar uma técnica de 
exposição ineficiente e por esse motivo, fazer com que estruturas importantes não sejam representadas, exigindo dessa forma, novos exames caso esse problema seja detectado, ou ainda, caso não seja, prejudicar o processo de diagnóstico. No entanto, a avaliação desse tipo de característica é inviável experimentalmente, sendo assim, os métodos de controle de qualidade convencionais necessitam que ferramentas computacionais auxiliares sejam desenvolvidas.

\subsection{Motivação e Justificativa}

O avanço da ciência e da medicina proporcionou, entre outras coisas, a possibilidade de detecção precisa de várias doenças, em especial nas áreas de ortopedia e oncologia. Os equipamentos radiológicos e os baseados em medicina nuclear desempenham um papel importante nesse aspecto. A precisão dos resultados obtidos, permite que diagnósticos precoces realizados em uma fase inicial da doença evitem que o quadro do paciente se agrave, fato que, em muitos casos, pode salvar vidas.

Por outro lado, pesquisas referentes ao estudo e quantificação das doses de radiação recebidas pelos indivíduos, são relevantes para o desenvolvimento de novas tecnologias nos campos da imageologia e da medicina nuclear ou no aperfeiçoamento das tecnologias já existentes. Essas doses, devem estar de acordo com os índices sugeridos pelos órgãos competentes. Além da quantidade de radiação, a periodicidade de exposição também deve ser controlada, desse modo, pesquisas que envolvam esse tipo de experimento, não podem utilizar pessoas "reais" como base de estudo. Segundo Xu [Xu et al., 2000], nas duas últimas décadas, as indústrias americanas que utilizam energia nuclear e as agências que regulamentam esse tipo de atividade tem demonstrado um interesse especial em questões que envolvem dosimetria.

Esses fatos fizeram com que "pacientes virtuais" com características anatômicas semelhantes a de um ser humano real fossem assunto de pesquisas recentes. Os "pacientes virtuais" devem representar de maneira correta e convincente a composição dos órgãos e tecidos presentes no corpo humano e consequentemente, dos coeficientes de atenuação de massa destes. De maneira geral, esse objetivo é perseguido com a simulação de características, textura e composição semelhantes aos materiais encontrados nas estruturas investigadas. Esses "pacientes virtuais" são denominados "phantom” ou fantomas. Segundo Kramer [Kramer et al., 2004], os fantomas são representações do corpo humano utilizadas na determinação da dose absorvida por órgãos e tecidos sensíveis à radiação.

A representação virtual da anatomia humana desempenha um papel importante em diversos aspectos diagnósticos e terapêuticos relacionados ao processamento de imagens. O nível de 
detalhamento dos fantomas é variado e normalmente está associado com o tipo de tecnologia empregada em seu desenvolvimento, o que resulta em imagens mais ou menos detalhadas e consequentemente, mais ou menos representativas.

Em geral, programas de controle de qualidade convencionais utilizam fantomas de calibração para verificar o funcionamento dos equipamentos radiológicos e a eficiência das técnicas de exposição utilizadas [Supertech, 2008]. Esse tipo de fantoma é composto internamente por materiais específicos que simulam estruturas anatômicas reais tanto em forma como em textura, propiciando a "simulação" de exames com resultados próximos aos obtidos radiografando-se estruturas reais, dispensando portanto, a exposição de um paciente. Infelizmente, o custo desses fantomas é alto, o que em muitos casos impossibilita sua aquisição. Além disso, sua articulação é limitada a pequenas variações de posicionamento. A liberdade de movimento do fantoma, caso existisse, poderia ilustrar na prática a importância da obediência às recomendações de posicionamento e técnicas de exposição estabelecidas por guias radiográficos, por exemplo. Outro fator é a impossibilidade prática de utilização desse tipo de fantoma em aplicações de grande escala, em função da necessidade de um número grande de equipamentos radiográficos e materiais para revelação dos filmes e principalmente, a quantidade de radiação a que os operadores estariam expostos.

$\mathrm{Na}$ literatura especializada existem também vários trabalhos [Chao et al., 2001], [Chao and Xu, 2004], [Kramer et al., 2003], [Kramer et al., 2004], [Wang et al., 2005], [Winslow et al., 2004], [Xu et al., 2000], [Xu, 2005c], [Xu, 2005a], [Zubal et al., 1995], que utilizam uma variante computacional de funcionalidade similar a de um fantoma convencional, denominada "voxel-phantom" ou fantoma tomográfico. Em geral, esse tipo de fantoma é utilizado com mais frequência em aplicações diferentes daquelas feitas para radiodiagnóstico. Os “voxel-phantoms", são normalmente utilizados em experimentos dosimétricos, onde são submetidos a uma série de cálculos referentes a radiação emitida por uma fonte pré-determinada, normalmente baseada em uma das variantes do método de Monte Carlo, calculando em seguida, as doses residuais depositadas nos órgãos/tecidos expostos à essa fonte de radiação. Os "voxelphantoms" são gerados a partir de um processo de reconstrução 3D, cujos dados são extraídos de um conjunto de imagens tomográficas de um ou mais pacientes. Uma representação tridimensional do modelo construído pode ser visualizada com o auxílio de um toolkit de visualização, em geral, VTK (The Visualization ToolKit) [Kitware, 2008].

Apesar da boa qualidade apresentada nas representações das estruturas anatômicas e dos órgãos internos dos "voxel-phantoms", como suas características são definidas a partir de imagens tomográficas de referência, alterações anatômicas não podem ser realizadas após a constru- 
ção do modelo inicial.

$\mathrm{Na}$ literatura existem ainda trabalhos baseados no desenvolvimento de modelos computacionais de estruturas anatômicas específicas [Kitaoka and Suki, 1999], [Kitaoka and Takaki, 2000], [Kitaoka, 2002], [Neves, 2005], [Oliveira, 1999] que simulam também, ainda que de maneira simplificada, a realização de exames baseados em imagem, normalmente radiológicos ou tomográficos. Os modelos utilizados nesses trabalhos são virtuais e são contruídos utilizando-se simulação computacional. A maior parte dos trabalhos desse tipo encontrados na literatura simulam a região torácica [Kitaoka and Suki, 1999], [Kitaoka and Takaki, 2000], [Kitaoka, 2002], [Neves, 2005], retratando estruturas como o pulmão e a mama [Oliveira, 1999]. Sua maior contribuição é a possibilidade de interação do usuário com o modelo, gerado em tempo de execução. Essa interação usuário-computador possibilita a variação de parâmetros referentes à composição anatômica, fornecendo dessa forma, possibilidades de alteração nas características do modelo utilizado, ainda que, de ordem microscópica, como a alteração dos padrões de ramificação dos alvéolos pulmonares e da composição dos tecidos mamários, por exemplo. No entanto, também são estáticos e representam somente uma perspectiva da estrutura simulada, normalmente a frontal. A tridimensionalidade desse tipo de modelo está relacionada com sua profundidade, no entanto, a representação gráfica da estrutura simulada é bidimensional. Desse modo, apesar da possibilidade de variação de parâmetros, os modelos baseados em simulação computacional apresentam os mesmos problemas de articulação presentes nos fantomas encontrados na literatura. Além disso, possuem algumas limitações graves, como a exibição em uma única perspectiva e a representação gráfica de qualidade relativamente inferior em relação aos fantomas de tecnologia mais recente.

Desse modo, dependendo da aplicação pretendida, o método utilizado na construção dos fantomas encontrados na literatura talvez apresente limitações significativas que poderão impossibilitar a utilização dos mesmos, sejam eles modelos gerados a partir de simulação computacional, analíticos ou baseados em reconstrução 3D. Entretanto, ferramentas computacionais podem ser utilizadas para a construção de fantomas com maior número de recursos e possibilidades de utilização.

Sendo assim, acreditamos que um novo tipo de fantoma concebido em três dimensões, com qualidade visual e representativa, semelhante a obtida com os voxel-phantoms e que cuja metodologia de desenvolvimento possibilite a inclusão futura de novas malhas, caracterizaria um fantoma funcional utilizável em qualquer tipo de aplicação e/ou exames. Além do maior número de recursos e possibilidades de uso, esse tipo de fantoma poderia ser utilizado em qualquer ambiente que possua um computador, sem custos adicionais. A geração de imagens 
radiológicas simuladas, utilizando o fantoma como paciente, proporcionaria uma ferramenta de simulação completa com inúmeras possibilidades de utilização e expansão. A possibilidade de variação de tamanho e espessura das estruturas retratadas em função da musculatura e gordura, utilizando para tanto a ferramenta de modelagem, são recursos relevantes e impraticáveis em modelos tradicionais.

\subsection{Objetivo}

Implementar modelos computacionais de estruturas anatômicas em três dimensões, proporcionando um fantoma virtual representativo, com possibilidades de variação de massa muscular e dos indíces de gordura corporal e a simulação de suas imagens radiográficas utilizando as técnicas de exposição correspondentes à região investigada.

\subsection{Organização da Tese}

Esta tese está dividida em 6 capítulos, organizados da seguinte maneira:

- Capítulo 1: Esta introdução;

- Capítulo 2: Neste capítulo descrevemos os trabalhos mais relevantes encontrados na literatura especializada relacionados ao desenvolvimento de fantomas. Inicialmente, apresentamos uma breve definição do termo seguida das principais aplicações onde os fantomas são utilizados. Na sequência, definimos os dois principais tipos de fantomas computacionais existentes, começando pelos menos representativos fantomas analíticos, e terminando com a evolução natural desses, os fantomas de última geração denominados "voxel-phantoms" ou fantomas tomográficos. Por fim, descrevemos os trabalhos baseados em simulação computacional que realizam a modelagem de estruturas anatômicas humanas desempenhando dessa forma, um papel semelhante ao de um fantoma baseado em voxels;

- Capítulo 3: Neste capítulo, apresentamos os materiais, métodos e algoritmos utilizados no desenvolvimento do trabalho;

- Capítulo 4: Neste capítulo, apresentamos os resultados obtidos em nossa pesquisa, à saber:

- Modelo tridimensional do sistema ósseo humano; 
- Modelos tridimensionais que representam a anatomia externa do corpo humano, atuando como "pele";

- Modelos tridimensionais dos órgãos internos do corpo humano;

- Modelos denominados "completos", que contemplam todos os modelos anteriores.

- Capítulo 5: Neste capítulo, apresentamos as conclusões referentes ao trabalho realizado.

- Anexo: Referências Bibliográficas. 


\section{Revisão Bibliográfica}

\subsection{Fantomas}

Kramer [Kramer et al., 2004] define os fantomas como representações físicas ou virtuais do corpo humano utilizadas na determinação da dose absorvida por órgãos e tecidos sensíveis à radiação. Em geral, os fantomas que possuem representação física são denominados fantomas físicos, ao passo que, os fantomas representados virtualmente com o auxílio de um computador, são classificados como fantomas analíticos ou fantomas tomográficos, de acordo com a técnica aplicada em seu desenvolvimento e consequentemente, na qualidade da representação das estruturas retratadas. As aplicações onde os fantomas são mais frequentemente utilizados são:

- Exames para radiodiagnóstico como paciente virtual [Santos, 2003], atuando no controle de qualidade ou auxiliando na validação de técnicas de exposição e na verificação da calibração dos equipamentos;

- Implementação de bancos de imagens para fins científicos, como por exemplo: utilização em sistemas $C A D$ [Fujita, 1995], validação de algoritmos de simulação de estruturas anatômicas [Neves, 2005], aplicação de técnicas de processamento de imagens para determinação de parâmetros e automatização de processos [Nascimento, 2005], entre outros;

- Experimentos dosimétricos, cujo objetivo é estimar a quantidade de radiação residual que determinados órgãos/tecidos retém após a exposição a uma fonte de radiação. Com esse tipo de aplicação, é possível evitar que órgãos e tecidos sejam prejudicados em função de períodos de exposição demasiadamente longos, durante um processo de tratamento, por exemplo.

Gualdrini, em [Gualdrini, 2005], apresenta um estudo comparativo dos principais fantomas descritos na literatura. O levantamento realizado pelo autor, mostra a evolução do processo de desenvolvimento de fantomas, em especial, dos utilizados em experimentos de dosimetria. 
Inicialmente, o autor apresenta diferentes modelos analíticos de primeira geração, pouco representativos e com estruturas simplificadas. Em seguida, cita vários trabalhos que são considerados pequenas evoluções dos primeiros, com melhorias relacionadas a representação de um maior número de estruturas internas e pequenas variações anatômicas, etárias e de posicionamento. Por fim, apresenta vários fantomas de última geração denominados "voxel-phantoms" ou fantomas tomográficos, cuja representação é rica em detalhes, permitindo dessa forma, a representação de órgãos e tecidos de geometria complexa, cuja representação não é possível em fantomas analíticos. A tabela 2.1 mostra os principais fantomas computacionais citados por Gualdrini:

Tabela 2.1: Tabela comparativa dos principais fantomas computacionais encontrados na literatura.

\begin{tabular}{|l|c|c|c|c|c|}
\hline Nome & Idade & Sexo & Altura (cm) & Massa (kg) & Região do Corpo \\
\hline & & $\mathrm{f}$ & & & Completo \\
\hline Baby & 8 semanas & $\mathrm{f}$ & 57 & 4.2 & Completo \\
\hline Child & 7 & $\mathrm{f}$ & 115 & 21.7 & Completo \\
\hline Voxelman & 35 & $\mathrm{~m}$ & 178 & 70 & Cabeça até a Coxa \\
\hline NORMAN & adulto & $\mathrm{m}$ & 170 & 70 & Completo \\
\hline Vip-Man & 38 & $\mathrm{~m}$ & 186 & 103 & Completo \\
\hline Adelaide & 14 & $\mathrm{f}$ & 157 & 48 & Busto \\
\hline Otoko & adulto & $\mathrm{m}$ & 170 & 65 & Completo \\
\hline Golem & 38 & $\mathrm{~m}$ & 176 & 69 & Completo \\
\hline UF newborn & 6 dias & $\mathrm{f}$ & & 3.8 & Completo \\
\hline UF 2-month & 2 meses & $\mathrm{m}$ & & 5.4 & Completo \\
\hline Donna & 40 & $\mathrm{f}$ & 170 & 79 & Completo \\
\hline Frank & 48 & $\mathrm{~m}$ & 174 & 95 & Cabeça e Tronco \\
\hline Helga & 26 & $\mathrm{f}$ & 170 & 81 & Cabeça até a Coxa \\
\hline Visible Human & 38 & $\mathrm{~m}$ & 186 & 103 & Cabeça até a Coxa \\
\hline MAX & 35 & $\mathrm{~m}$ & 175 & 75 & Completo \\
\hline Irene & 32 & $\mathrm{f}$ & 163 & 51 & Completo \\
\hline Onago & adulto & $\mathrm{f}$ & & & Completo \\
\hline
\end{tabular}

Outros autores [Caon, 2004], [Kramer et al., 2003], [Xu, 2005c], [Zubal et al., 1995], que realizaram estudos semelhantes aos de Gualdrini consideram que os fantomas analíticos perderam espaço em função da sua limitação na representação de estruturas anatômicas internas. Os fantomas tomográficos, ou "voxel-phantoms", baseados em imagens tomográficas reais, são muito mais representativos e por esse motivo, são considerados fantomas de última geração, servindo como referência para grande parte dos trabalhos produzidos atualmente. Apesar da diferença conceitual e representativa entre essas duas gerações de fantomas, as etapas envolvidas no processo de desenvolvimento de ambos são idênticas: Desenvolvimento do modelo; 
atribuição dos coeficientes de atenuação de massa; simulação da interação entre uma fonte de radiação e o modelo, sendo que a maioria dos autores utilizam uma das variações do método de Monte Carlo. Desse modo, para os diversos fantomas apresentados na literatura, a metodologia empregada no desenvolvimento de cada um deles é praticamente a mesma. Em geral, o que difere fantomas de mesma geração são somente variações anatômicas, etárias e de sexo. As variações foram obtidas com a alteração do tipo de material utilizado, no caso dos fantomas analíticos, e das imagens tomográficas de referência, no caso dos fantomas baseados em voxels. Um outro fator é a variação do tipo de fonte de radiação simulada.

\subsubsection{Fantomas Analíticos}

Os modelos analíticos estilizados foram originalmente desenvolvidos nos anos 70 para o "Medical Internal Radiation Dose (MIRD) Committee" da Sociedade de Medicina Nuclear. Essa primeira geração de fantomas, também conhecido como "MIRD phantom" serviu como base para o desenvolvimento de vários outros como crianças de várias idades [Cristy, 1980], fantomas adultos masculinos, femininos [Kramer et al., 1999], com ambos os sexos [Fisher and Snyder, 1967], [Fisher and Snyder, 1968] e um com as características de uma mulher gestante [Stabin et al., 1995].

O tamanho e a forma das representações do corpo e de seus órgãos são descritos por expressões matemáticas representando combinações e intersecções de planos, cilindros circulares e elípticos, esferas, cones, entre outros. Entretanto, a representação dos órgãos e dos ossos é uniforme, possibilitando dessa forma, apenas a simulação de estruturas com composição homogêneas. Esse tipo de abordagem tem como objetivo, gerar equações simples, minimizando desse modo, o custo computacional durante os cálculos das doses.

Durante 30 anos, esse tipo simplificado de fantoma tem sido usado como referência padrão, seguindo as recomendações sugeridas pelo "The Reference Man" [ICRP, 1975], nas áreas de proteção radiológica, medicina nuclear, física médica e imagens médicas. No entanto, em função da metodologia utilizada na construção desse tipo de modelo, as imagens obtidas nos experimentos não são realísticas quando comparadas com imagens reais.

A Figura 2.1 mostra um fantoma analítico estilizado de um adulto visualizado externamente [Gualdrini, 2005]. 

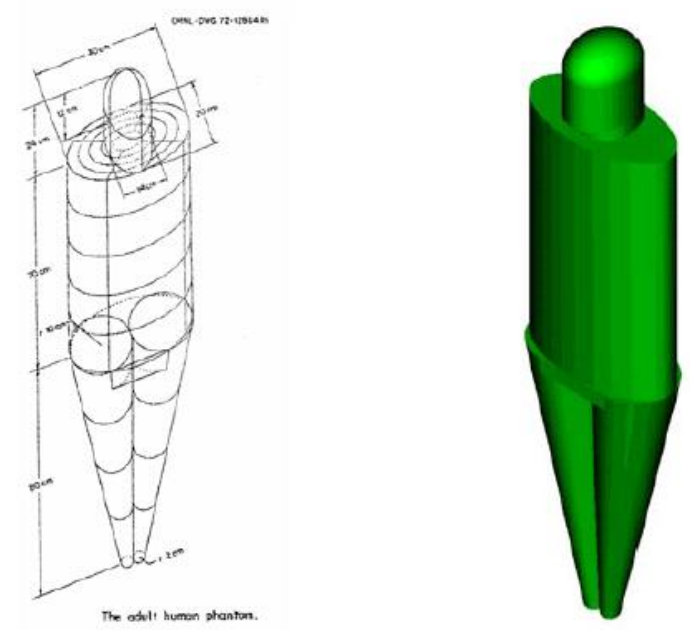

Figura 2.1: Fantoma analítico estilizado de um adulto [Gualdrini, 2005].

A Figura 2.2 mostra uma visualização tridimensional da disposição interna dos órgãos e do esqueleto do fantoma analítico [Gualdrini, 2005].

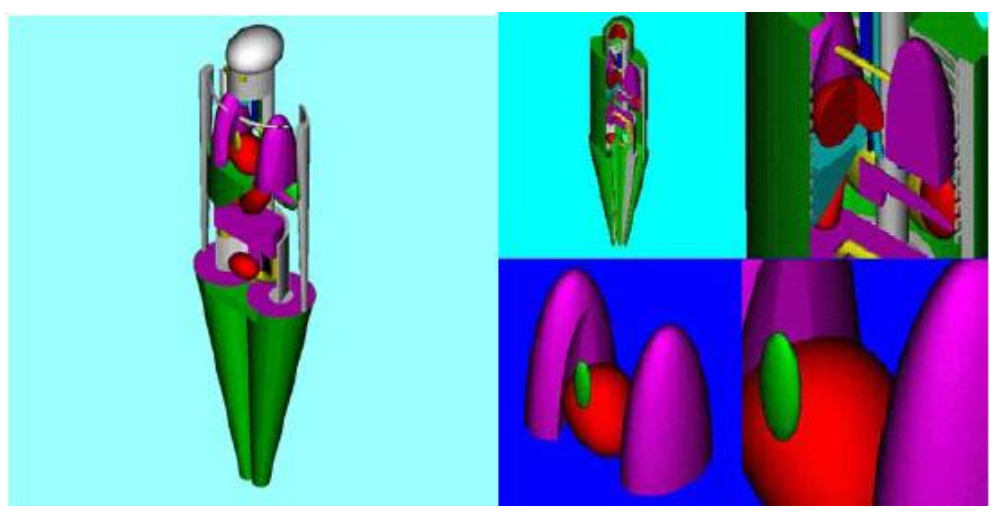

Figura 2.2: Visualização tridimensional da disposição interna dos órgãos e do esqueleto do fantoma analítico [Gualdrini, 2005].

A Figura 2.3 mostra a representação do estômago e do sistema gastro-intestinal [Gualdrini, 2005].

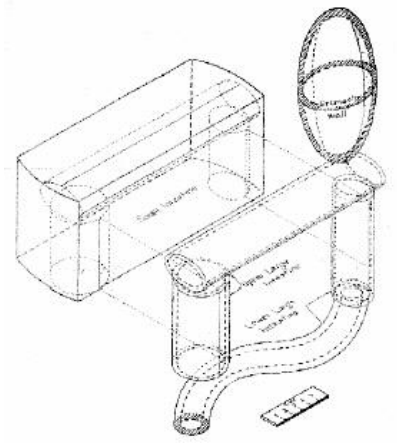

Figura 2.3: Representação do estômago e do sistema gastro-intestinal [Gualdrini, 2005]. 
A Figura 2.4 mostra a disposição interna dos órgãos dos fantomas analíticos Adam e Eva [Gualdrini, 2005].

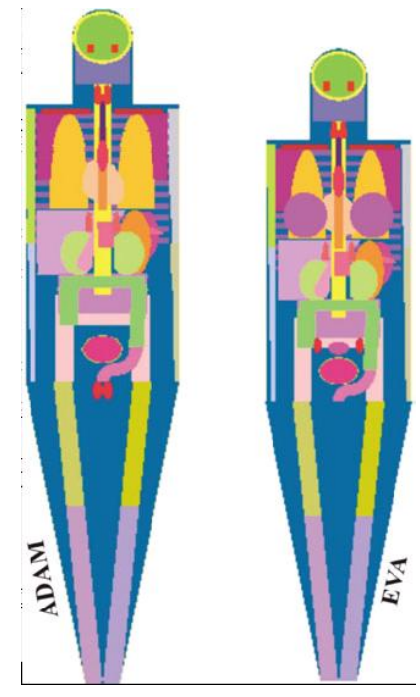

Figura 2.4: Os fantomas analíticos Adam e Eva [Gualdrini, 2005].

\subsubsection{Voxel phantoms}

A representação limitada das estruturas anatômicas e dos órgãos internos proporcionada pelos fantomas analíticos fez com que um novo tipo fosse desenvolvido. Esse novo tipo, denominado fantoma tomográfico ou "voxel phantom", é baseado em imagens digitais de exames tomográficos ou de ressonância magnética de pacientes reais. Cada imagem consiste em uma matriz bidimensional de pixels cujo tamanho varia em função da resolução utilizada durante os exames. Um conjunto consecutivo dessas imagens pode ser considerado uma matriz tridimensional composta por voxels, onde cada voxel representa um determinado órgão ou tecido. Comparados com fantomas analíticos, as imagens obtidas com a utilização de "voxel phantoms" são muito mais realísticas, pois conseguem representar órgãos e estruturas de geometria complexa.

A Figura 2.5 mostra uma fatia tomográfica que ilustra a diferença dos resultados obtidos com a utilização de um fantoma analítico e um fantoma baseado em “voxels” [Xu, 2005c].

Vários "voxel phantoms" foram desenvolvidos, sendo que a metodologia empregada em seu desenvolvimento também é praticamente a mesma em todos os trabalhos [Caon, 2004], com pequenas variações relacionadas às imagens tomográficas de referência [Kramer et al., 2004], [Xu et al., 2000], [Zankl and Wittmann, 2001], e ao método matemático utilizado para simular a interação de radiação com o modelo. 

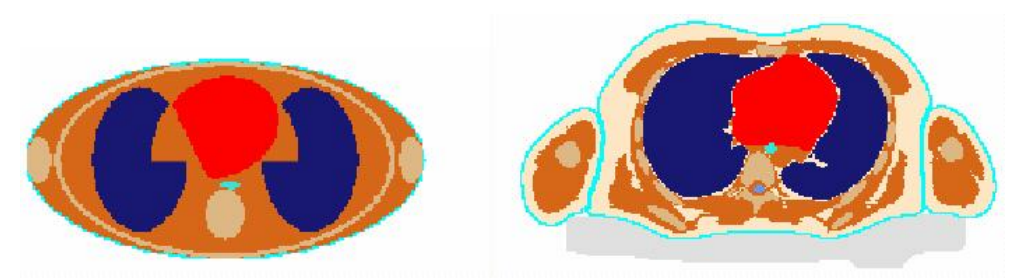

Figura 2.5: Resultados obtidos com a utilização de um fantoma analítico - (a) e um fantoma baseado em "voxels" - (b), [Xu, 2005c].

O primeiro passo na construção de um fantoma baseado em voxels consiste na seleção de uma série de imagens tomográficas referentes a um ou mais pacientes reais. O método mais comum utilizado para a obtenção dessas imagens é através do contato direto com hospitais que possuem imagens tomográficas dos exames realizados em suas instalações. Essas imagens não tinham sido processadas ou padronizadas na fase de aquisição, afinal, foram adquiridas para fins de diagnóstico e não para utilização em pesquisas científicas. Entretanto, existem exceções, o fantoma denominado "Vip-Man", desenvolvido por Xu [Xu et al., 2000], foi construído a partir das imagens tomográficas de uma série completa de um cadáver masculino e de um feminino, que fazem parte do projeto "The Visible Human" [Spitzer, 2008]. Cada imagem, disponibilizada em formato $R A W$, possui aproximadamente 7.5 megabytes. Como os corpos dos cadáveres utilizados foram seccionados em fatias de $1 \mathrm{~mm}$, estima-se que o tamanho da base de imagens referentes somente ao modelo masculino tenha por volta de 15 gigabytes. Esse tipo de abordagem proporcionou, pela padronização da aquisição e pela quantidade de imagens disponíveis, um modelo completo. Esse fato dificilmente ocorreria com as imagens disponibilizadas por hospitais, uma vez que, exames tomográficos realizados para fins de diagnóstico, não necessariamente representam todo o corpo humano. Desse modo, em grande parte dos casos, são necessárias as imagens de vários pacientes diferentes para a construção de um único fantoma. Um exemplo que ilustra essa dificuldade é a contrução do voxel-phantom feminino FAX - Female Adult voXel phantom [Kramer et al., 2004]. O fantoma FAX utilizou 151 imagens tomográficas sequenciais de uma paciente do sexo feminino de 37 anos de idade com altura de $165 \mathrm{~cm}$ e com $63.4 \mathrm{~kg}$ de peso. Esse conjunto inicial de imagens representa o tronco, o pescoço, e a parte inferior da cabeça, incluindo a mandíbula e os dentes inferiores. Um segundo conjunto com 206 imagens referente a exames realizados em uma paciente de 62 anos de idade, foi utilizado para representar as pernas e os pés do fantoma. Para complementar o modelo, foram utilizados ainda a cabeça e os braços de um outro fantoma e não de um paciente real. Segundo o autor, por questões de praticidade, a cabeça do fantoma $M A X$ - Male Adult voXel phantom [Kramer et al., 2003] - foi adicionada sobre o pescoço do fantoma $F A X$, após ser diminuída de acordo com as diferenças anatômicas existentes entre homens e mulhe- 
res, definidas no documento "Reference Adult" publicado pelo ICRP89 [ICRP, 2003]. O mesmo procedimento foi aplicado para adicionar os braços, que também foram extraídos do fantoma MAX[Kramer et al., 2003].

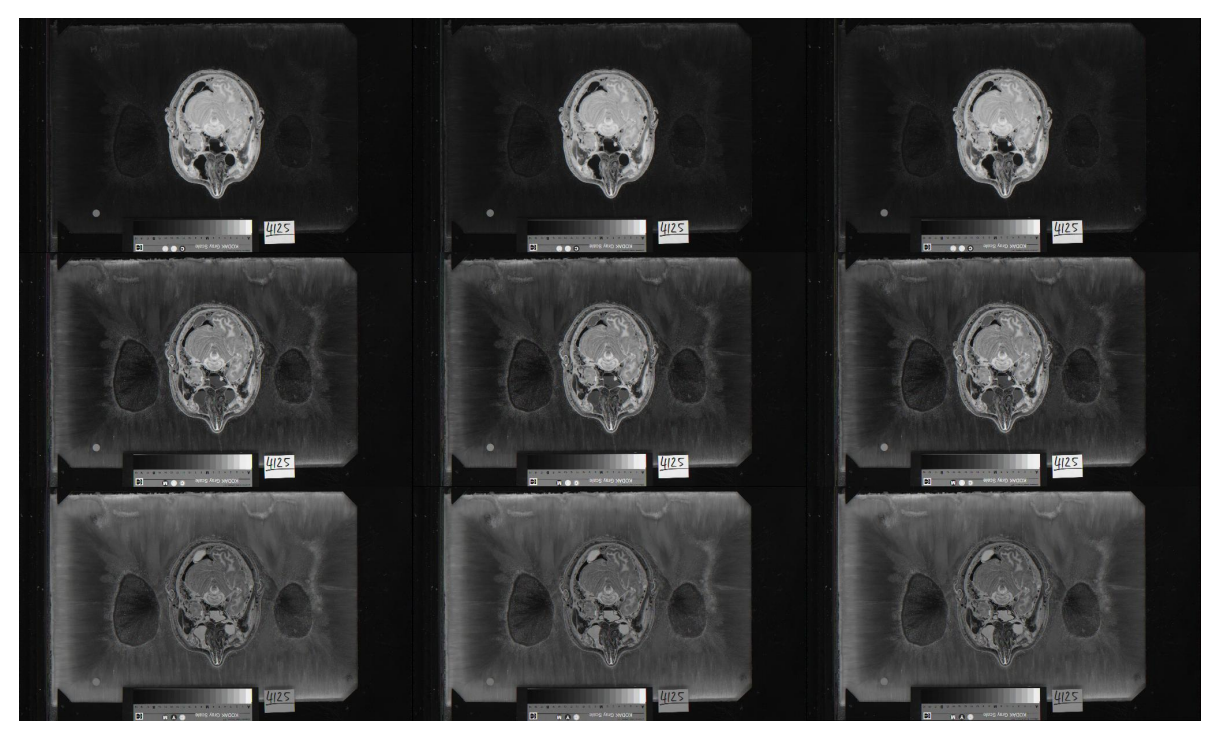

Figura 2.6: Série de imagens tomográficas pertencentes ao projeto "The Visible Human" [Spitzer, 2008].

Ainda segundo o autor, durante a aquisição das imagens utilizadas na construção do fantoma $M A X$, o paciente estava com os braços posicionados atrás da cabeça e desse modo, os ombros, as espátulas e a parte superior dos braços, tiveram de ser editados e reconstruídos de acordo com dados extraídos de atlas anatômicos. As imagens tomográficas do tronco, da cabeça, dos braços, e das pernas foram obtidas a partir de três pacientes diferentes. Então, para que as características do esqueleto pudessem ser representadas, mais alguns ajustes tiveram de ser realizados manualmente, utilizando novamente como referência, atlas anatômicos. Ao mesmo tempo, foram levados em conta as referências relacionadas à distribuição de massa dos ossos obtidas no ICRP89 [ICRP, 2003]. O formato das mamas do fantoma FAX também foi modificado utilizando esse processo, de modo que representasse de maneira correta a anatomia de uma mulher adulta jovem. Finalmente, todas as imagens foram redimensionadas de modo que os voxels passassem a possuir a mesma dimensão.

A Figura 2.7 mostra um fantoma analítico (a), uma representação 2D (b) e uma representação 3D (c) do fantoma baseado em voxels "Vip-Man" [Gualdrini, 2005]. 


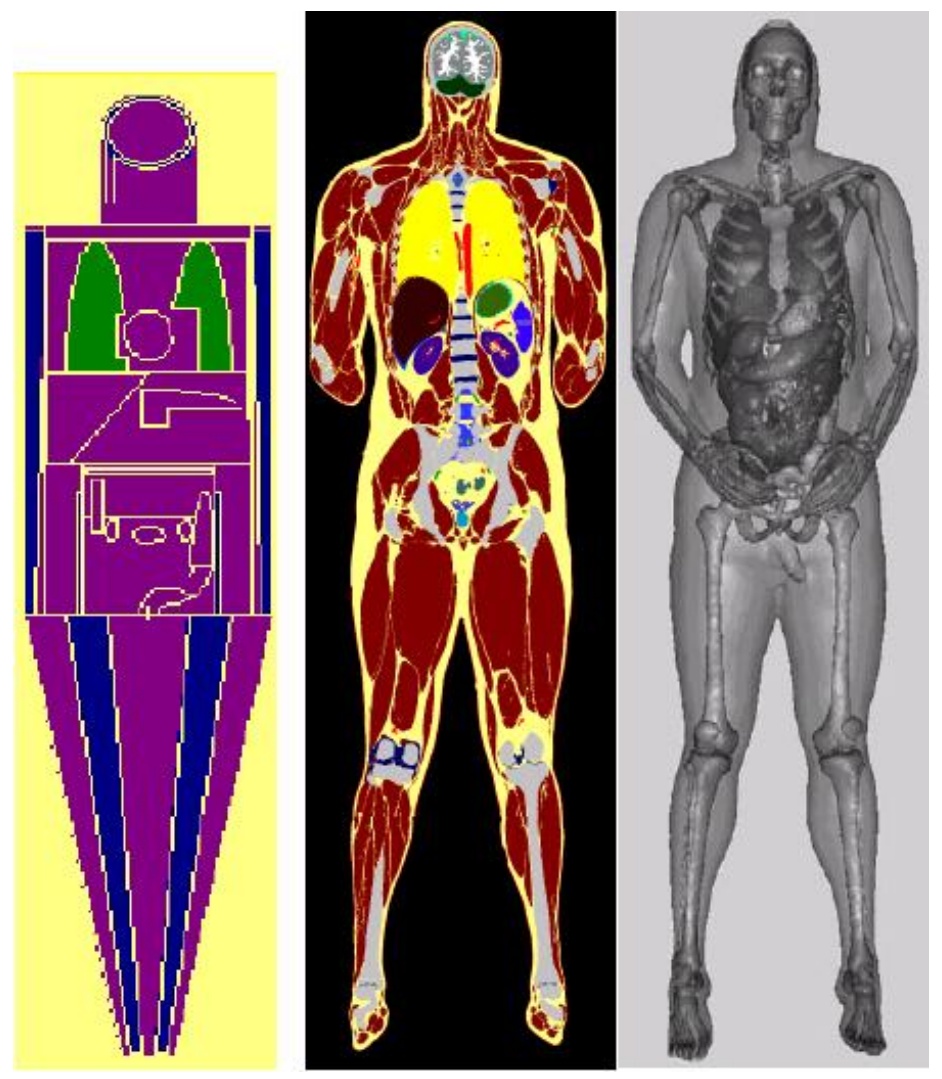

Figura 2.7: Fantoma analítico (a), uma representação 2D (b) e uma representação 3D (c) do fantoma baseado em voxels "Vip-Man" [Gualdrini, 2005].

A Figura 2.8 mostra as visualizações frontal e lateral e disposição interna dos órgãos e do esqueleto do fantoma femino FAX [Kramer et al., 2004].

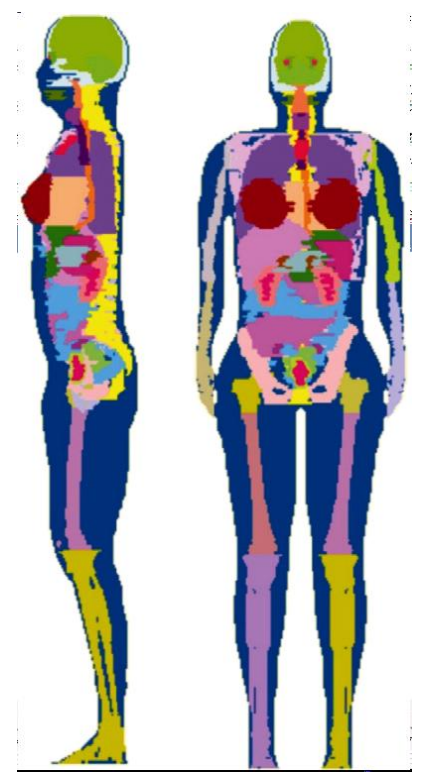

Figura 2.8: Visualizações frontal e lateral e disposição interna dos órgãos e do esqueleto do fantoma femino FAX [Kramer et al., 2004]. 
A Figura 2.9 mostra projeções 3D do fantoma femino $F A X$ a partir de diferentes perspectivas [Kramer et al., 2004].

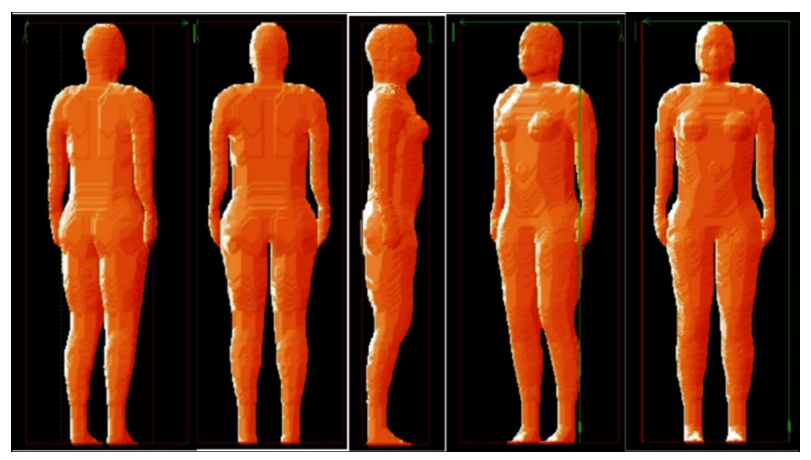

Figura 2.9: Projeções 3D do fantoma femino $F A X$ a partir de diferentes perspectivas [Kramer et al., 2004].

Para gerar os órgãos e os tecidos do fantoma, Kramer [Kramer et al., 2004] realizou operações de processamento sobre cada imagem tomográfica utilizada. As imagens tomográficas utilizadas para a construção do fantoma FAX estavam originalmente no formato DICOM (Digital Imaging and Communications in Medicine) e foram visualizadas com o software OSIRIS [Ligier et al., 1994], que pode ser obtido via internet. O software OSIRIS possui diversos filtros que podem ser aplicados para realçar o contraste das fronteiras entre os órgãos. Depois da aplicação dos filtros [Kramer et al., 2004], as imagens foram convertidas e editadas em formato bitmap (BMP) e em seguida, foi utilizado o software PAINT, disponível no sistema operacional Microsoft Windows para colorir manualmente, uma a uma, as 357 imagens que compoem o fantoma $F A X$. Nesse processo, cada órgão e tecido de interesse foi pintado com cores diferentes. Dessa forma, após o processo de segmentação e colorização das estruturas de interesse, cada nível de cinza da imagem foi substituído por uma cor, de acordo com o órgão ou tecido representado. Desse modo, cada órgão e tecido que compoem o modelo possui uma cor de identificação associada a um número específico. No final do processo, essa pilha de imagens foi representada numa matriz onde todos os voxels associados a um órgão ou tecido específico possui o mesmo número de identificação. Esse processo de segmentação e determinação de fronteiras, permite ao pesquisador separar as estruturas de interesse e identificá-las, uma a uma, para que através das cores e números de identificação, cada órgão, osso ou tecido, possa ser distinguido e tratado de maneira particular. Após a segmentação e identificação dos órgãos internos que irão compor o fantoma $F A X$, os autores relatam o processo de levantamento e determinação das massas referentes aos órgãos e tecidos do fantoma que são definidas de acordo com o ICRP89 [ICRP, 2003]. Em seguida, aplicam as densidades dos tecidos segundo as recomendações do ICRU44 [ICRU, 1989], para a determinação do volume dos órgãos do modelo. 
Ao contrário dos fantomas analíticos, onde apenas uma composição homogênea pode ser utilizada na composição das estruturas anatômicas, é possível criar nos "voxel phantoms" um esqueleto de composição heterogênea, onde todos os ossos recebem a aplicação de misturas específicas. Isso pode ser feito com o método do número CT, desenvolvido por Zankl e Wittmman [Zankl and Wittmann, 2001], que utiliza os níveis de cinza dos pixels representando os ossos nas imagens tomográficas originais do paciente, permitindo assim, misturar à composição desses elementos como cartilagem e tutano. Segundo dados do ICRP89 [ICRP, 2003], esses elementos correspondem a aproximadamente $17 \%$ da composição dos ossos. Desse modo os níveis de cinza entre 0 e 255 determinarão diferentes composições no interior dos ossos.

Por fim, Xu [Xu et al., 2000] aplica uma variação do método de Monte Carlo para realizar as simulações referentes à interação da radiação com o fantoma. Em geral, essas variações existem em função do tipo de fonte de radiação utilizada. Para simulações baseadas no método de Monte Carlo, algumas variações de propósito geral, como o método MCNP, por exemplo, oferecem interfaces amigáveis ao usuário que requerem pouquíssimas alterações do código fonte. Essa facilidade compromete a otimização do código e por esse motivo, pode causar problemas de desempenho e de alocação de memória em função da grande quantidade de voxels presentes nos modelos tomográficos. Os autores portanto recomendam que sejam realizadas implementações de rotinas visando a otimização do funcionamento do método, ou ainda que as imagens tomográficas, que servirão como base para a construção do fantoma, sejam redimensionadas. Para o funcionamento do método e a criação do modelo, implementaram rotinas que efetuam a leitura do número de identificação de cada órgão presente no voxel a partir das imagens segmentadas e coloridas pelo pesquisador. Em seguida, essas informações são convertidas para formato texto para gerar os arquivos de entrada exigidos como parâmetro pelo método de Monte Carlo e, após o processamento, os arquivos de saída com as doses resultantes e absorvidas pelo corpo.

Os quatro principais e mais utilizados tipos de aplicação do Método de Monte Carlo são:

- EGS4, originalmente desenvolvido pelo Stanford Linear Accelerator Center, conhecido pelo seu tratamento físico detalhado. Algoritmos de tranporte de elétrons como o PRESTA [Nelson et al., 1985] fazem do EGS4 um dos mais eficientes e sofisticados códigos de fóton-elétron já desenvolvidos;

- MCNP, originado no Laboratório Nacional de "Los Alamos"tem a capacidade de transportar fótons, neutrons e em sua versão mais recente, a 4B [Hendricks, 1997], elétrons;

- LAHET [Prael and Lichtenstein, 1989], é um código para transporte e interação de várias 
substâncias em uma geometria complexa;

- MCNPX [Hughes et al., 1997], Combina os modelos teóricos do LAI-IET Code System com modelos de propósito geral, como o MCNP.

A Figura 2.10 mostra diversas visualizações baseadas em reconstruções 3D do voxel-phantom GOLEM [Zankl and Wittmann, 2001].

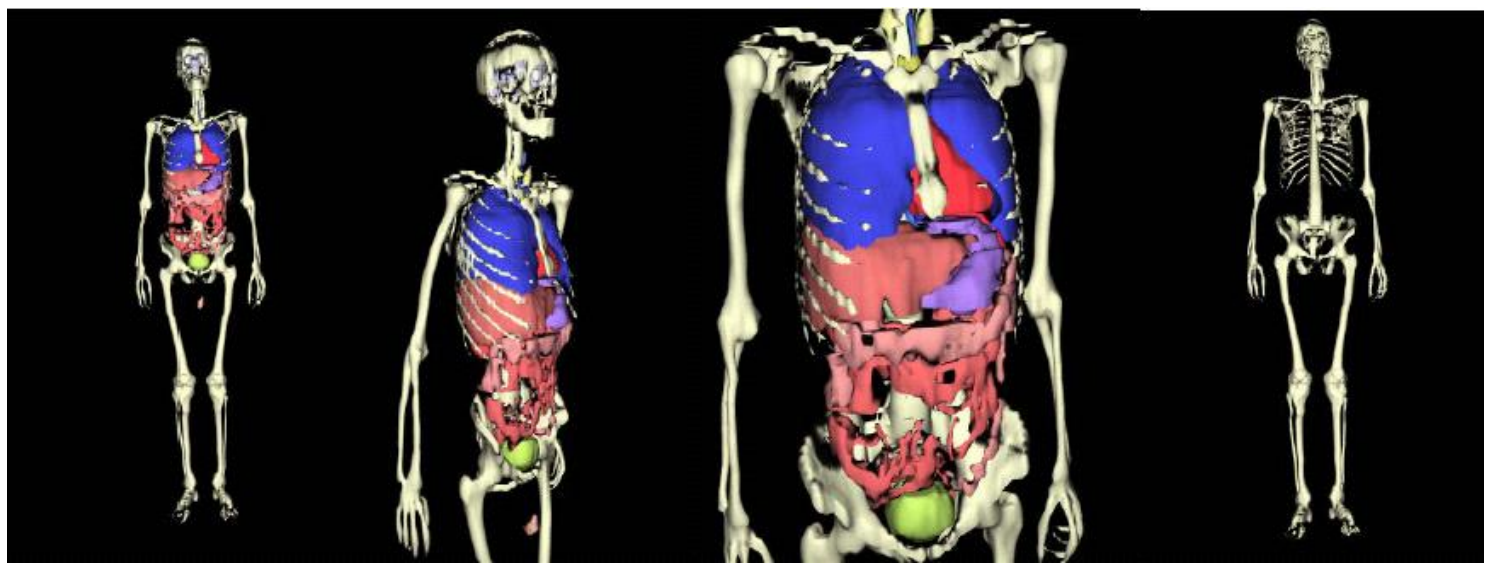

Figura 2.10: Visualizações baseadas em reconstruções 3D do voxel-phantom GOLEM [Zankl and Wittmann, 2001].

A Figura 2.11 mostra visualizações baseadas em reconstruções 3D dos voxel-phantoms femininos Helga, Donna e Irene [Gualdrini, 2005]. 


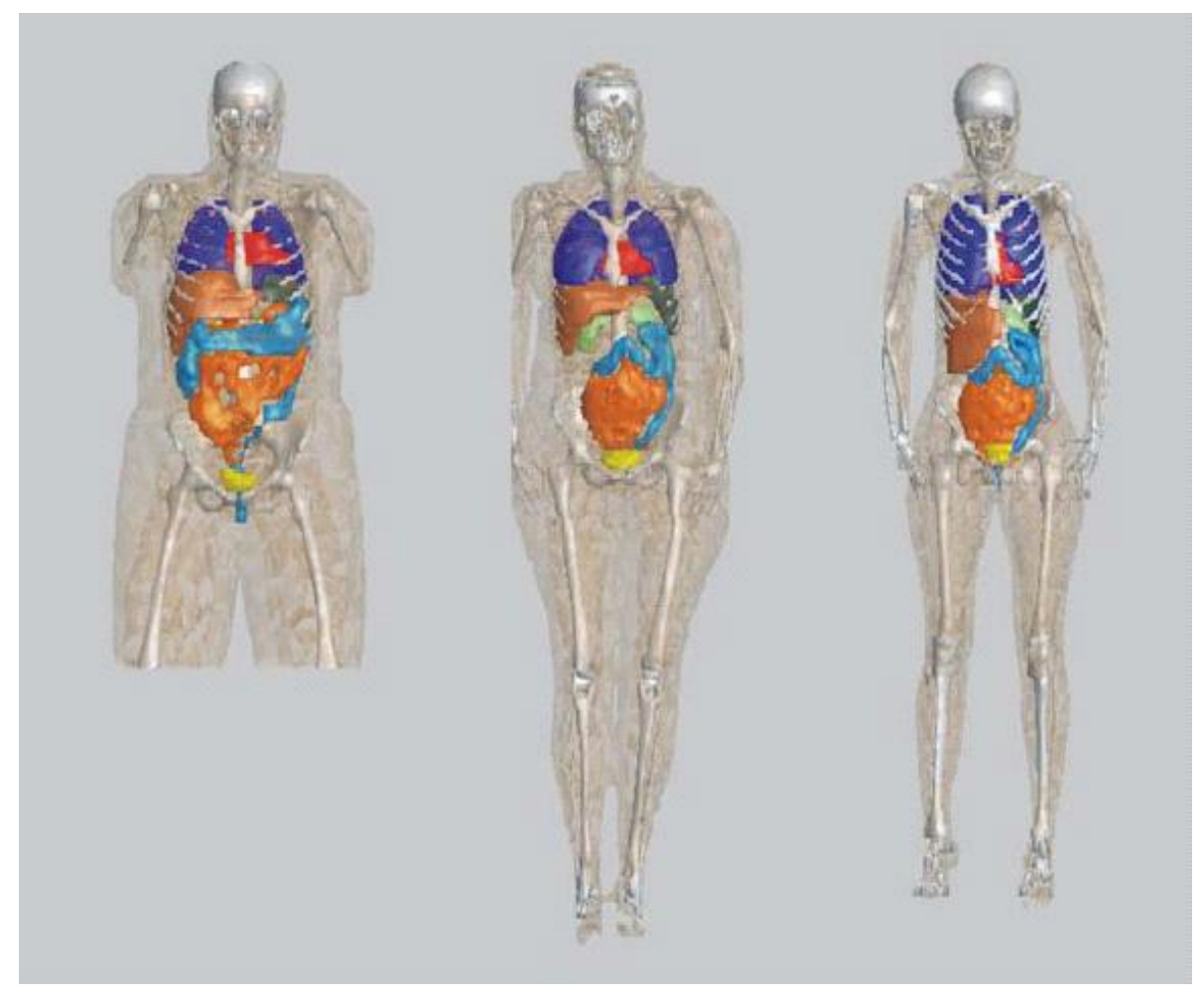

Figura 2.11: Visualizações baseadas em reconstruções 3D dos voxel-phantoms femininos Helga, Donna e Irene [Gualdrini, 2005].

A Figura 2.12 mostra visualizações bidimensionais de um voxel-phantom do joelho [Gualdrini, 2005].

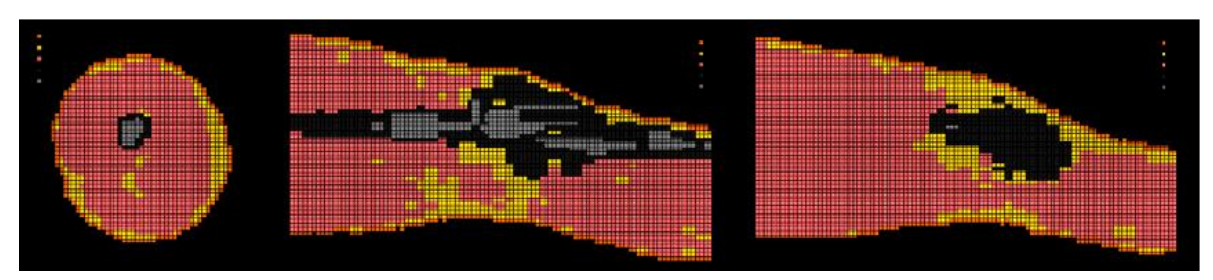

Figura 2.12: Visualizações bidimensionais de um voxel-phantom do joelho [Gualdrini, 2005].

Os fantomas baseados em voxels podem ser visualizados em três dimensões, no entanto, essa visualização é puramente ilustrativa, não permitindo nenhum tipo de interação. Não são possíveis alterações de parâmetros do fantoma (somente nas fatias $2 \mathrm{D}$, durante o processo de segmentação e colorização dos órgãos, ossos e tecidos) e tampouco a articulação deste. Também, como o modelo é gerado por reconstrução 3D a partir das imagens tomográficas, o processo de visualização tridimensional é possível somente com a utilização de toolkits de visualização, em geral, o VTK - The Visualization Tool Kit [Kitware, 2008]. Portanto, na tentativa de complementar a funcionalidade dos fantomas baseados em voxels e suprir as limitações referentes à alteração de parâmetros presentes nesse tipo de fantoma, Xu [Xu and Shi, 2005] sugeriu o desenvolvimento de um novo tipo de fantoma, denominado "modelo anatômico em 
4D”. Também segundo o autor, é possível desenvolver um modelo anatômico 4D a partir de um modelo tomográfico tridimensional já existente e possibilitar a variação das formas, tamanho e localização dos órgãos internos desse fantoma de acordo com padrões de movimento que podem ser medidos clinicamente. A abordagem para desenvolver um modelo $4 \mathrm{D}$, segundo [Xu and Shi, 2005], envolve os seguintes passos:

- Extração de características de fantomas baseados em voxels já existentes;

- Deformações dessas características em 4D utilizando equações hipotéticas;

- Associar propriedades ao modelo 4D gerado;

- Implementar as rotinas de simulação ao modelo 4D utilizando umas das variações do método de Monte Carlo.

Fantomas baseados em voxels podem ser representados graficamente em três dimensões com o auxílio de softwares de visualização 3D como o VTK - The Visualization Toolkit [Kitware, 2008]. Para tanto, os dados numéricos referentes a cada órgão que compõe o fantoma devem ser separados em arquivos individuais, passando em seguida por um processo de renderização para ser exibidos na tela do computador. No entanto, segundo o autor, o processo de extração de características nesse tipo de fantoma não é trivial, desse modo, Xu [Xu and Shi, 2005] recomenda a conversão dos arquivos que contém os dados referentes aos órgãos que compoem o fantoma em superfícies NURBS (Non-Uniform Rational B-spline). Para tanto, utiliza o software livre "vtkEditor" [vtkEditor, 2008] para que os dados do fantoma baseado em voxels possam ser lidos por um segundo software denominado Rhinoceros [Rhinoceros, 2008]. Esse software semelhante ao blender [Blender, 2008], é utilizado entre outras coisas, para a criação, edição, análise e translação de curvas NURBS, bem como de superfícies e sólidos. A conversão do fantoma inicial em superfícies NURBS é devida à facilidade em se deformar estruturas desse tipo, utilizando operações simples aplicadas a pontos de controle presentes na malha.

Também segundo, as deformações realizadas sobre as superfície NURBS que irão compor o novo modelo em 4D, poderão ser efetuadas a partir de transformações geométricas aplicadas aos pontos de controle das superfícies. A alteração de características anatômicas e a simulação dos movimentos de alguns órgãos, como o pulmão por exemplo, poderão ser realizados a partir da elaboração de equações que simulem essas características.

As últimas etapas da construção do modelo em 4D são iguais aos processos aplicados aos voxels phantoms tradicionais. Inicialmente são atribuídos coeficientes de atenuação de massa 
aos órgãos e tecidos que compoem o fantoma e em seguida, é aplicada uma das variações do método de Monte Carlo, de acordo com a fonte de radiação simulada.

O estudo preliminar realizado pelo autor, ilustra de maneira clara as limitações presentes na metodologia utilizada na construção dos voxel-phantoms e a necessidade de um método que facilite a variação de parâmetros desse tipo de fantoma. O estudo no entanto, não prevê qualquer tipo de alteração de posicionamento dos modelos, somente a alteração da dimensão das estruturas retratadas sem a necessidade da manipulação de toda uma série de imagens tomográficas.

\subsubsection{Modelos baseados em Simulações Computacionais}

Outros tipos de representação de estruturas anatômicas que não são denominadas fantomas, mas que possuem uma funcionalidade semelhante, são os modelos contruídos a partir de simulações computacionais. A maior contribuição desse tipo de abordagem, é a possibilidade de alteração de parâmetros, dessa forma, é possível que se construa uma base de dados composta por vários modelos com características anatômicas diferenciadas que são especificadas pelo usuário durante a execução dos algoritmos de simulação.

Neves [Neves, 2005], desenvolveu um modelo computacional das estruturas torácicas e pulmonares, bem como a simulação de suas imagens radiográficas. $\mathrm{O}$ algoritmo desenvolvido pelo autor foi implementado em linguagem $C$ e realiza a modelagem das estruturas torácicas e pulmonares, permitindo ainda, variações anatômicas de acordo com os dados especificados pelo usuário durante a execução do algoritmo e a simulação de algumas doenças. Também é possível que o usuário gere as imagens radiográficas correspondentes aos modelos construídos, utilizando nesse caso, uma fonte de radiação ideal, ou seja, uma fonte que possui a mesma intensidade de radiação em qualquer ponto do plano imagem. As estruturas internas do pulmão são representadas por cilindros e esferas. Os modelos são construídos utilizando uma técnica de sobreposição de camadas, que funciona de maneira semelhante a metodologia utilizada na construção dos fantomas tomográficos. No entanto, em [Neves, 2005], o delineamento das estruturas pulmonares é determinado pelo pesquisador, ao passo que, na técnica utilizada para a construção dos fantomas tomográficos, esse delineamento é estabelecido pela sequência de imagens utilizadas como referência. É possível afirmar que cada camada que compõe o modelo desenvolvido por Neves pode ser entendida como uma fatia do objeto tridimensional. A caixa torácica foi modelada utilizando-se imagens de referência, sobre as quais foram estabelecidos pontos de controle. O algoritmo simplesmente liga esses pontos de controle utilizando uma interpolação baseada na função B-Splines, que fornece o contorno arredondado das estruturas. As dimensões dos ramos aéreos e das artérias são calculadas a partir da distribuição de fluxo de 
ar dos ramos pais para os ramos filhos, parâmetros esses determinadas pelo autor, que servem como critério de parada para o crescimento dos ramos e para determinação de características anatômicas dos pacientes simulados. Um abscesso pulmonar é simulado interrompendo o crescimento dos ramos ao redor de uma região e adotando para essa área densidade radiológica específica, pois segundo o autor, nos padrões intersticiais o processo inflamatório é representado aumentando a espessura das paredes dos cilindros que simulam os bronquíolos.

Apesar desse tipo de trabalho não ser considerado como um fantoma na literatura especializada, é importante destacá-lo em função da possibilidade da alteração de parâmetros que serão aplicados ao modelo, fato que tem como consequência direta, a construção de "n" simulações diferentes com variação das características anatômicas e independência de quaisquer tipos de dados ou imagens de referência. 


\section{Materiais, Métodos e Algoritmos Desenvolvidos}

\subsection{Etapas do Trabalho}

Para construir um fantoma virtual realístico com possibilidades de variação de parâmetros anatômicos, que representa os efeitos que as diferenças anatômicas entre os indivíduos provocam nas radiografias, utilizamos a ferramenta de modelagem. Para tanto, o desenvolvimento do trabalho foi dividido em três etapas distintas:

- A primeira etapa consiste na modelagem tridimensional do sistema ósseo humano, composto por cabeça, tronco e membros;

- Na segunda etapa do trabalho, realizamos a modelagem tridimensional dos principais órgãos que compoem o corpo humano seguida da construção de modelos que representam a anatomia externa deste, com ênfase na representação das diferentes características anatômicas referentes ao aumento dos indíces de gordura corporal;

- Por fim, na terceira etapa do trabalho, realizamos o levantamento dos coeficientes de atenuação de massa referentes às estruturas anatômicas representadas associando-os em seguida, a cada um dos modelos desenvolvidos de acordo com suas características anatômicas.

\subsubsection{A Escolha do Software}

No momento em que optamos por utilizar um software de modelagem 3D, tínhamos algumas "restrições" em mente. A primeira delas é que o software utilizado, obrigatoriamente deveria possuir uma versão para o sistema operacional Linux, que é a nossa plataforma de desenvolvimento atual. Um outro fator, seria o custo de aquisição, uma vez que, os principais softwares de modelagem 3D do mercado chegam a custar alguns milhares de dólares por 
licença, custo esse que inviabilizaria a utilização da ferramenta em nosso trabalho ou mesmo por outros desenvolvedores em trabalhos futuros. Por fim, um quesito óbvio, que foi determinante na escolha do software é a qualidade final dos modelos produzidos utilizando a ferramenta.

O blender é uma ferramenta de computação gráfica completa e multi-plataforma que possibilita ao usuário realizar trabalhos de modelagem 3D, animação e renderização. Os resultados obtidos são excelentes e as possibilidades de utilização também. Com ele, o usuário pode gerar cenas estáticas de alta qualidade gráfica, filmes e animações profissionais ou até mesmo aplicações interativas utilizando um módulo específico que faz parte da ferramenta, chamado "Game Engine". Além disso, os modelos, animações e jogos desenvolvidos com o blender, podem ter a sua funcionalidade ampliada através da utilização de scripts externos desenvolvidos em Python. O Python é uma poderosa linguagem de programação com suporte à orientação a objetos, de rápido aprendizado e sintaxe simples. A linguagem tem todos os seus recursos suportados nativamente, pelo blender. Essa característica torna o uso da ferramenta ainda mais interessante, pois permite que o usuário desenvolva novas funcionalidades que poderão ser incorporadas ao modelo, ou mesmo insira algum tipo de lógica associada a uma animação, por exemplo.

\subsection{Modelagem 3D}

Nesta seção, descrevemos a metodologia utilizada no processo de modelagem tridimensional das estruturas anatômicas utilizando o software "blender", bem como a introdução de alguns conceitos necessários para o entendimento do funcionamento da ferramenta e do processo de modelagem 3D.

\subsubsection{A Interface de Trabalho do Blender}

A interface gráfica do blender é basicamente formada pela barra de menus na parte superior da tela, pela área de trabalho na região central e pelo painel inferior, dividido em várias janelas compostas por diversas ferramentas com diferentes opções de utilização. A “cena" padrão é composta por um cubo localizado no centro da área de trabalho, uma câmera e uma fonte de iluminação. Quando o blender é iniciado, a seguinte interface gráfica é exibida ao usuário (Figura 3.1):

Atualmente, existem diversas técnicas de modelagem que podem ser utilizadas. A utilização de uma ou outra técnica, depende do tipo de modelo que será desenvolvido. Em nosso trabalho, 


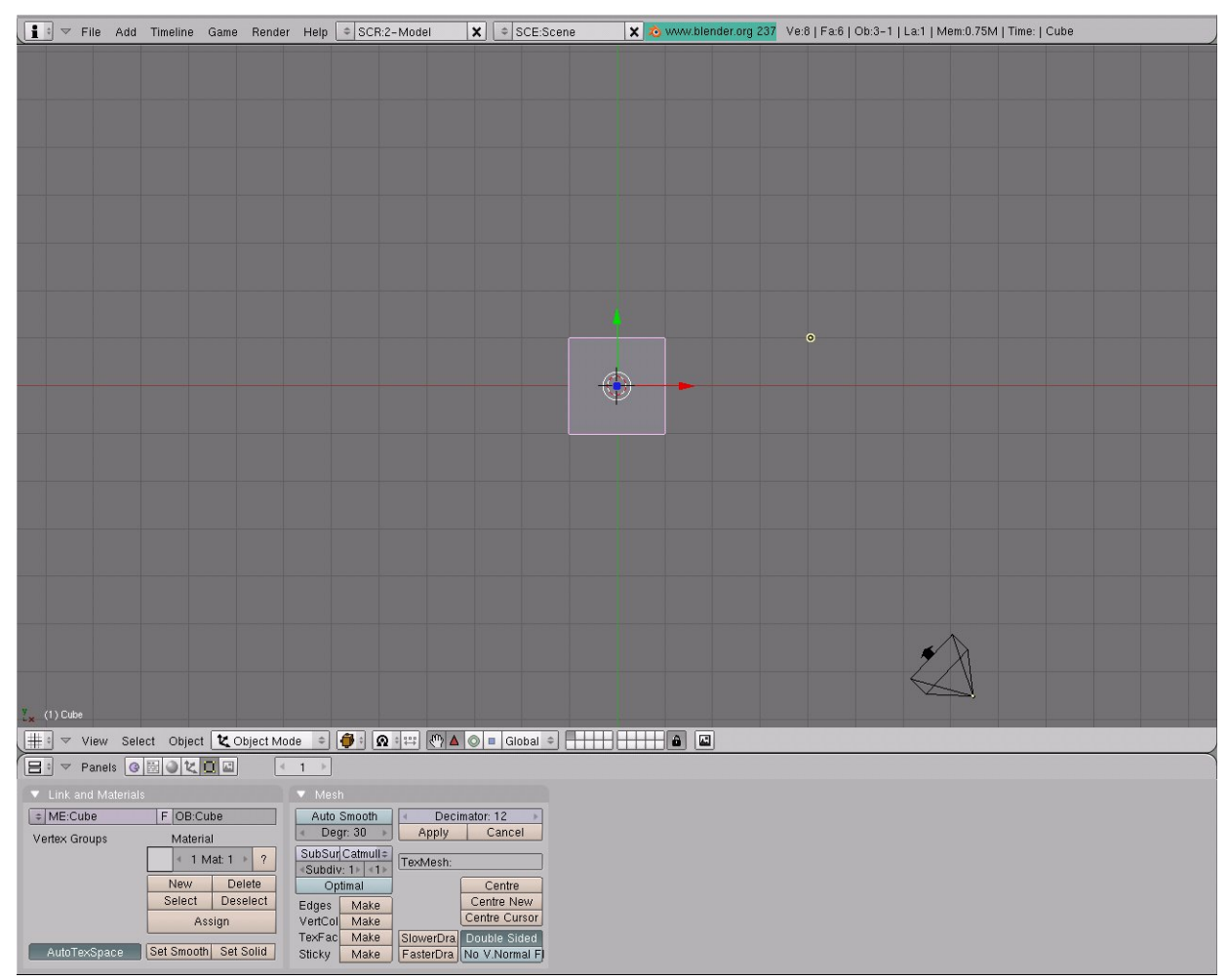

Figura 3.1: Tela principal do software de modelagem blender.

utilizamos a técnica denominada "box modeling", que consiste na deformação de uma primitiva 3D inicial, que nessa técnica em especial, é um cubo. As deformações realizadas vão desde a subdivisão dessa estrutura inicial em um número maior de pontos, vértices e faces até a extrusão e escala das mesmas, que ao decorrer do processo de modelagem vão dando forma ao modelo. Iremos a seguir, mostrar os principais recursos utilizados nesse trabalho.

Inicialmente, ativamos o recurso de visualização em múltiplas perspectivas. Essa função do software dá ao usuário a possibilidade de visualizar o que cada ação realizada sobre o modelo provoca nas outras perspectivas. Esse recurso é relevante, uma vez que, estamos trabalhando com modelos representados em três dimensões. Para tanto, dividimos a janela principal clicando na opção "Split Area", pressionando o botão direito do mouse. Em seguida, para dividir a tela em quatro quadrantes, repetimos a operação em cada uma das janelas geradas no passo anterior. Para selecionar a perspectiva desejada em cada janela, utilizamos o menu "View" e escolhemos cada uma das seguintes opções "Side, Front, Up ou Camera", que são basicamente as perspectivas lateral, frontal, superior e câmera, respectivamente.

O resultado obtido pode ser visualizado na Figura 3.2. O primeiro quadrante representa a perspectiva frontal (eixos $\mathrm{z}$ e $\mathrm{x}$ ), o segundo representa a perspectiva lateral (eixos z e y), o terceiro a perspectiva superior (eixos y e x) e o quarto representa a visão geral da cena a partir de uma câmera (eixos x,y,z). 


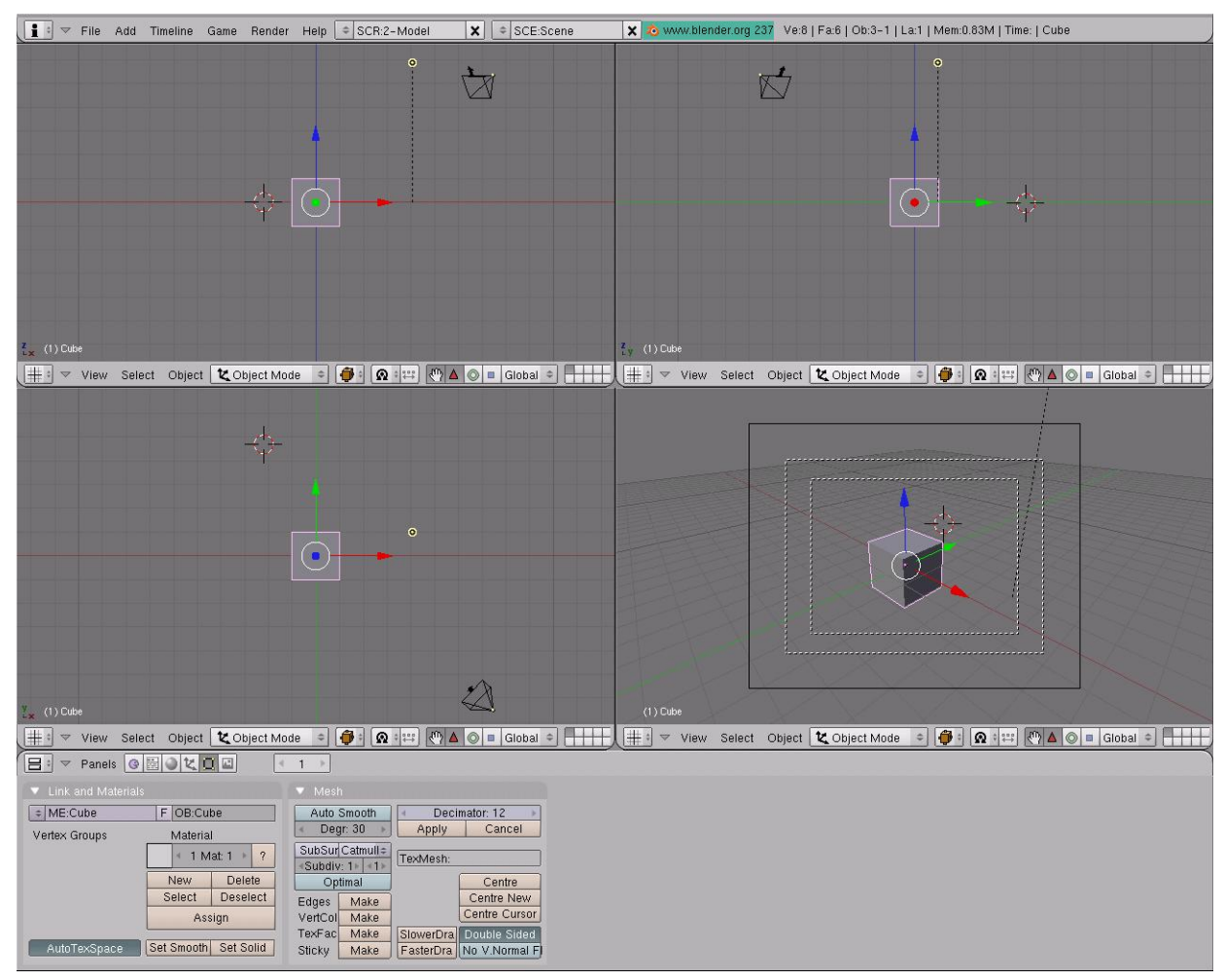

Figura 3.2: Quatro modos de visualização simultâneos.

Conforme mostra a Figura 3.1, após a inicialização do blender, é apresentada uma cena padrão composta por uma fonte de iluminação, uma câmera e uma primitiva básica, que por padrão, é um cubo. O processo de modelagem consiste justamente na deformação de uma primitiva básica que, no final do processo deverá se assemelhar visualmente com o objeto de referência a ser modelado. Desse modo, conforme podemos verificar na figura 3.3, é possível aplicarmos transformações geométricas no cubo que irão "deformar" sua forma inicial, de maneira que, a medida que a malha estiver sendo manipulada, a primitiva inicial irá, cada vez mais, se assemelhar com a estrutura modelada. Quanto maior o nível de detalhamento do modelo (representado diretamente pelo número de vértices, lados e arestas e dos processos de suavização de superfície aplicados a esses elementos), melhor será o resultado obtido.

\subsubsection{Aquisição das Imagens de Referência}

Para que o processo de modelagem possa ser iniciado e as transformações geométricas aplicadas da melhor maneira possível, são necessárias referências dos objetos que serão modelados. Artistas experientes podem utilizar referências visuais externas ao ambiente computacional, como quadros, moldes em gesso, desenhos em papel, ou fotos de referência dentro do ambiente de produção, ou seja, na tela do software de modelagem utilizado. Para utilizar essa técnica, escolhemos no blender uma perspectiva que coincide com a foto de referência e selecionamos 


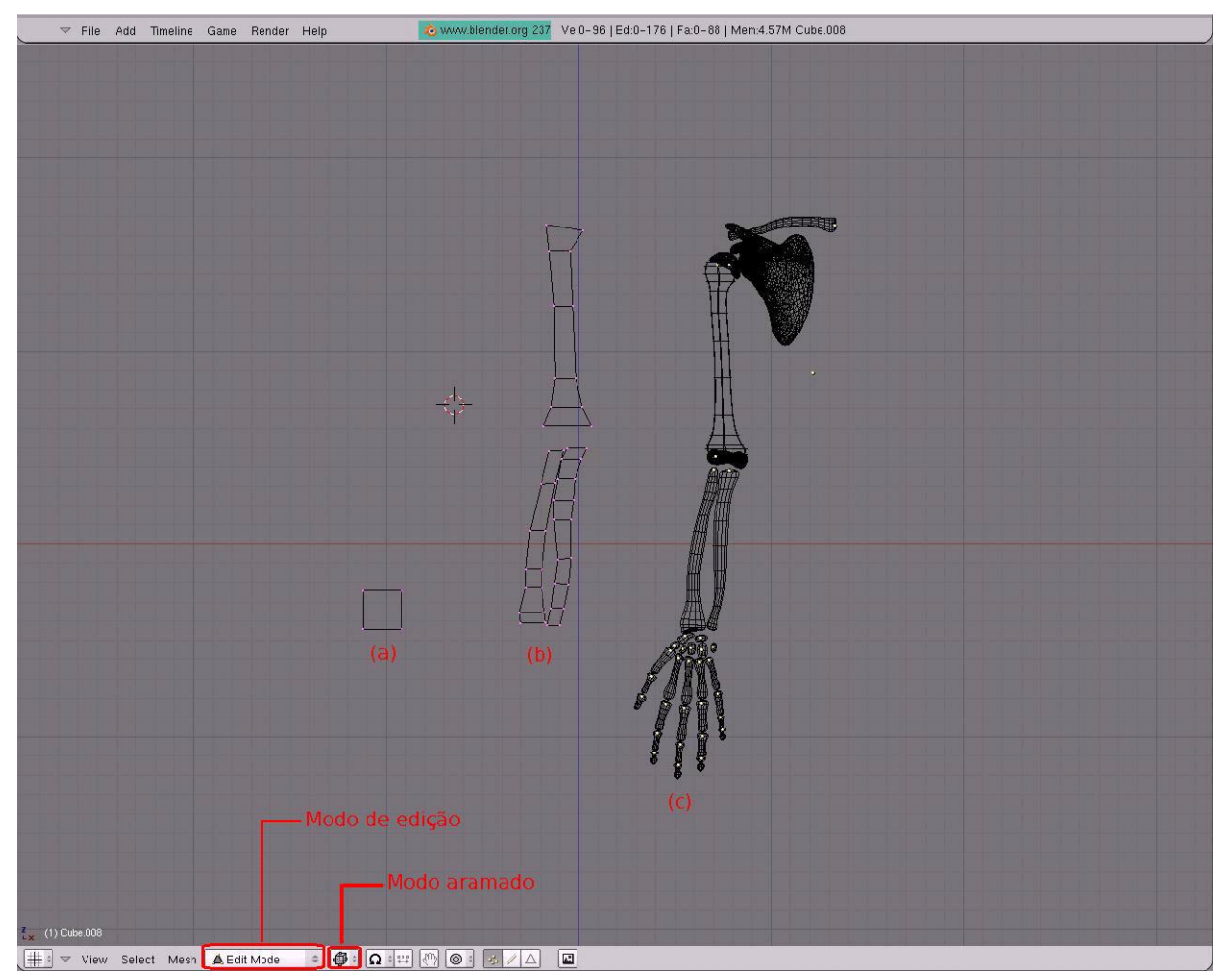

Figura 3.3: (a)Uma primitiva básica, o cubo; (b)A mesma primitiva após a realização de operações de extrusão; (c)O modelo final.

a opção "Background Image" no menu "View', conforme pode ser visto nas Figuras 3.4 e 3.5.

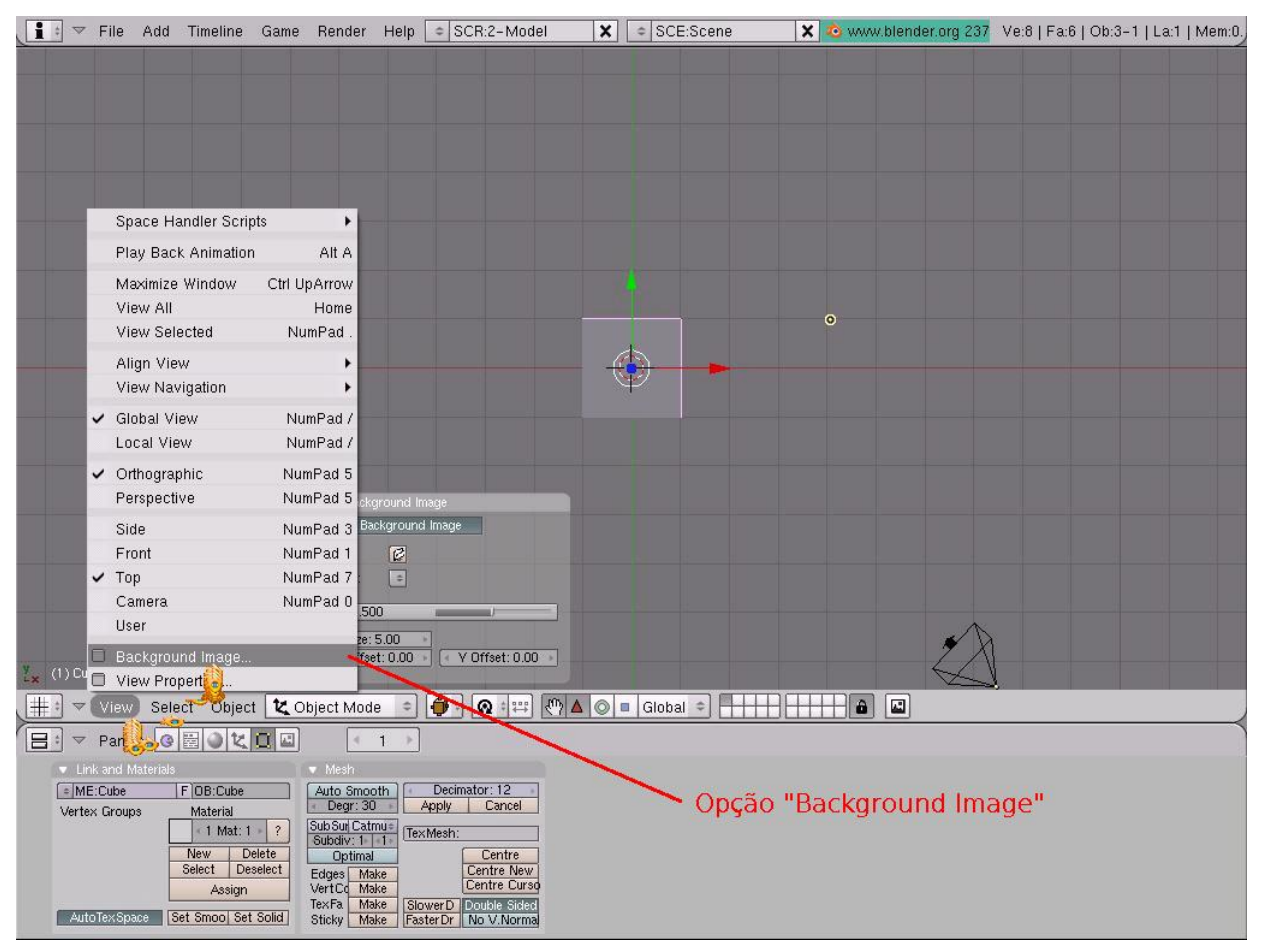

Figura 3.4: Selecionando uma imagem de referência.

O processo de aquisição das imagens de referência utilizadas durante o processo de mode- 


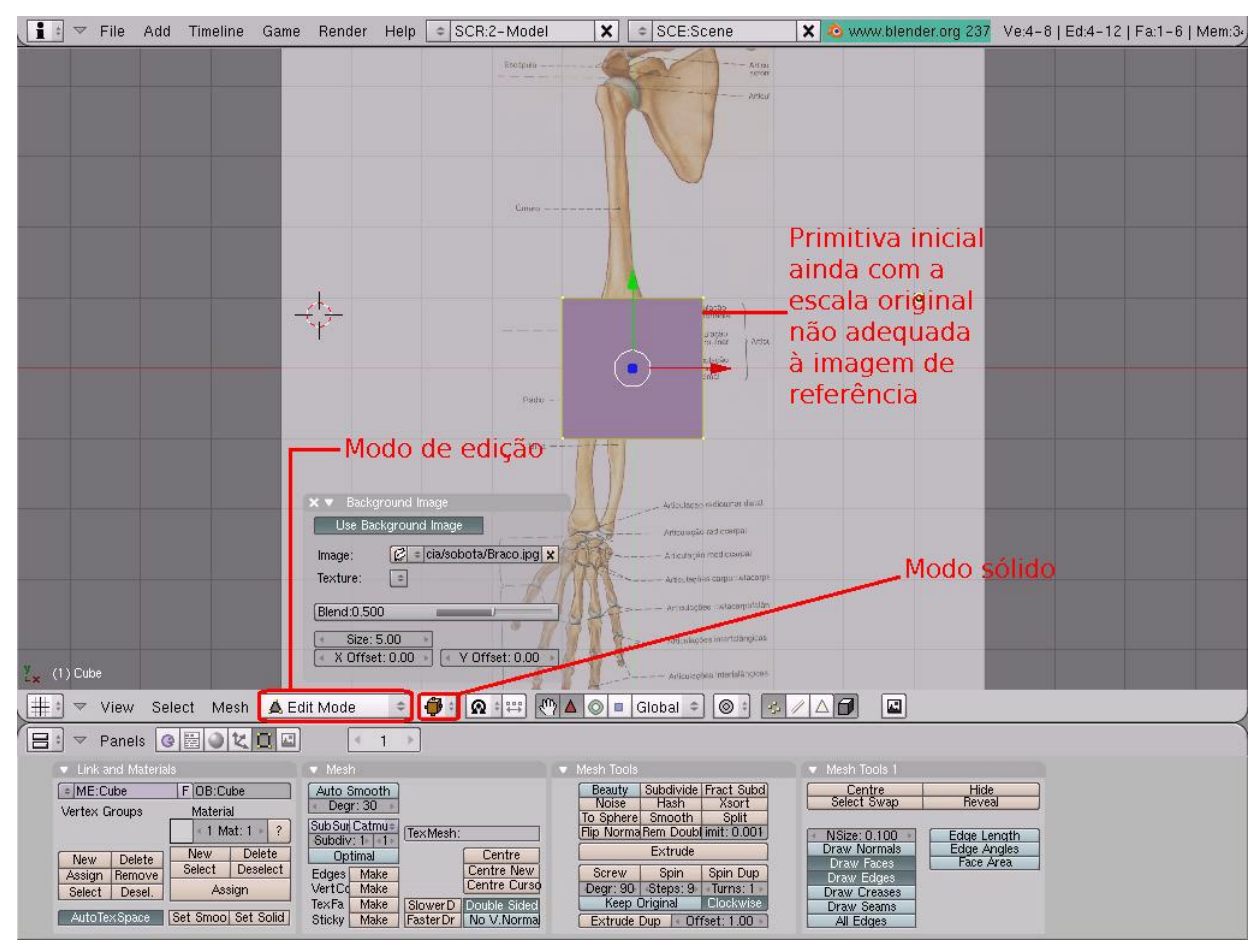

Figura 3.5: Imagem de referência selecionada.

lagem foi realizado em duas etapas distintas com a utilização de uma câmera fotográfica digital.

A primeira etapa do processo de aquisição das imagens foi realizada no hospital universitário da Universidade de Mogi das Cruzes. A referência foi um esqueleto com medidas certificadas com os ossos dos membros separados do tronco e os do tronco separados da cabeça. Fotografamos cada uma das partes separadamente, repetidas vezes e sob diferentes perspectivas.

Na segunda etapa do processo de aquisição de imagens, utilizamos um atlas de anatomia [Sobotta, 2000] e fotografamos essas imagens, em alta resolução e de excelente qualidade, uma a uma, de acordo com a região de interesse. Utilizamos esse procedimento por conta de um problema detectado nas imagens de referência durante o processo de modelagem. De fato, em função da conexão com outros componentes do esqueleto, as extremidades de alguns ossos não possuíam um grau de liberdade suficiente para que fossem posicionados de maneira que pudessem ser fotografado com boas condições a partir de uma determinada perspectiva. Desse modo, o objetivo da aquisição dessa segunda série de imagens de referência, foi detalhar melhor as estruturas modeladas a partir das fotos do esqueleto, evitando assim, a representação errônea de regiões de "difícil visualização". 


\subsubsection{Modos de Utilização}

O blender possui, entre outros, dois modos de utilização principais: o "Object Mode" e o "Edit Mode".

O Object Mode permite a inclusão de novas primitivas 3D em uma cena pré-existente. Novas primitivas criadas nesse modo de visualização serão independentes das demais existentes anteriormente. Além disso, é possível realizar três transformações geométricas básicas: escala, rotação e translação. Entretanto, no modo objeto, essas transformações podem ser realizadas somente sobre cada objeto como um todo e não sobre determinados vértices, faces ou arestas específicas, por exemplo. Isso ocorre porque o software permite somente a exibição do sólido geométrico como um todo. A Figura 3.6 mostra a área de trabalho do blender visualizada a partir do Object Mode.

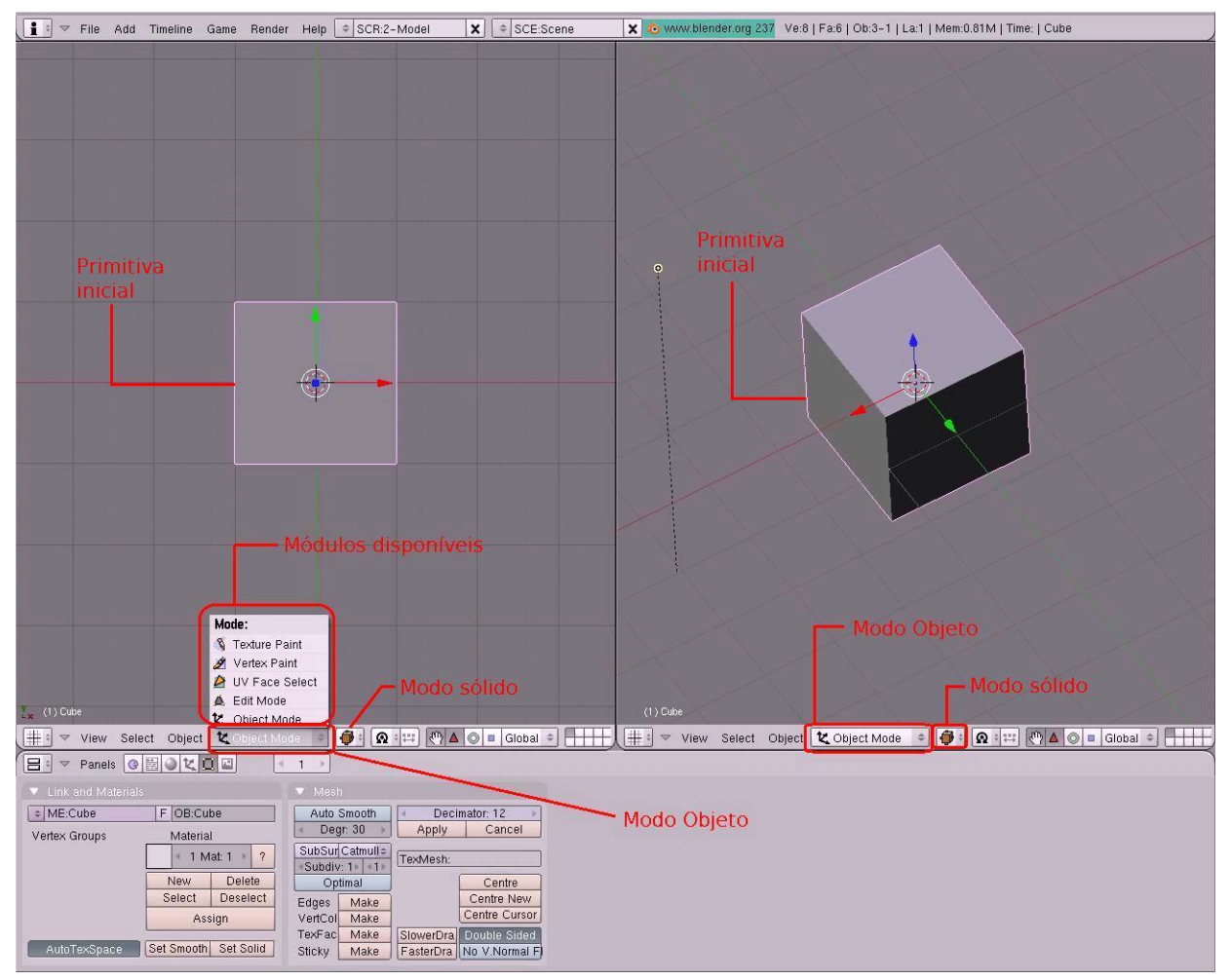

Figura 3.6: Modo objeto.

Já o Edit Mode permite a manipulação e edição das primitivas criadas a partir do Object Mode, em modo aramado. É nele que a maior parte do processo de modelagem é realizado, uma vez que a criação do modelo é baseado na aplicação de transformações geométricas básicas como escala, rotação e translação e em processos de extrusão aplicados somente aos vértices, faces ou arestas especificados pelo usuário. Esse grau de liberdade é possível nesse modo em função da representação do sólido como um conjunto de pontos ou vértices que unidos formam 
uma face, que juntas formam um sólido geométrico, como um cubo, por exemplo. Portanto, a liberdade de utilização desses pontos é total, de acordo com a necessidade do usuários e das características do modelo que será desenvolvido. A Figura 3.7 mostra a área de trabalho do blender visualizada a partir do Edit Mode.

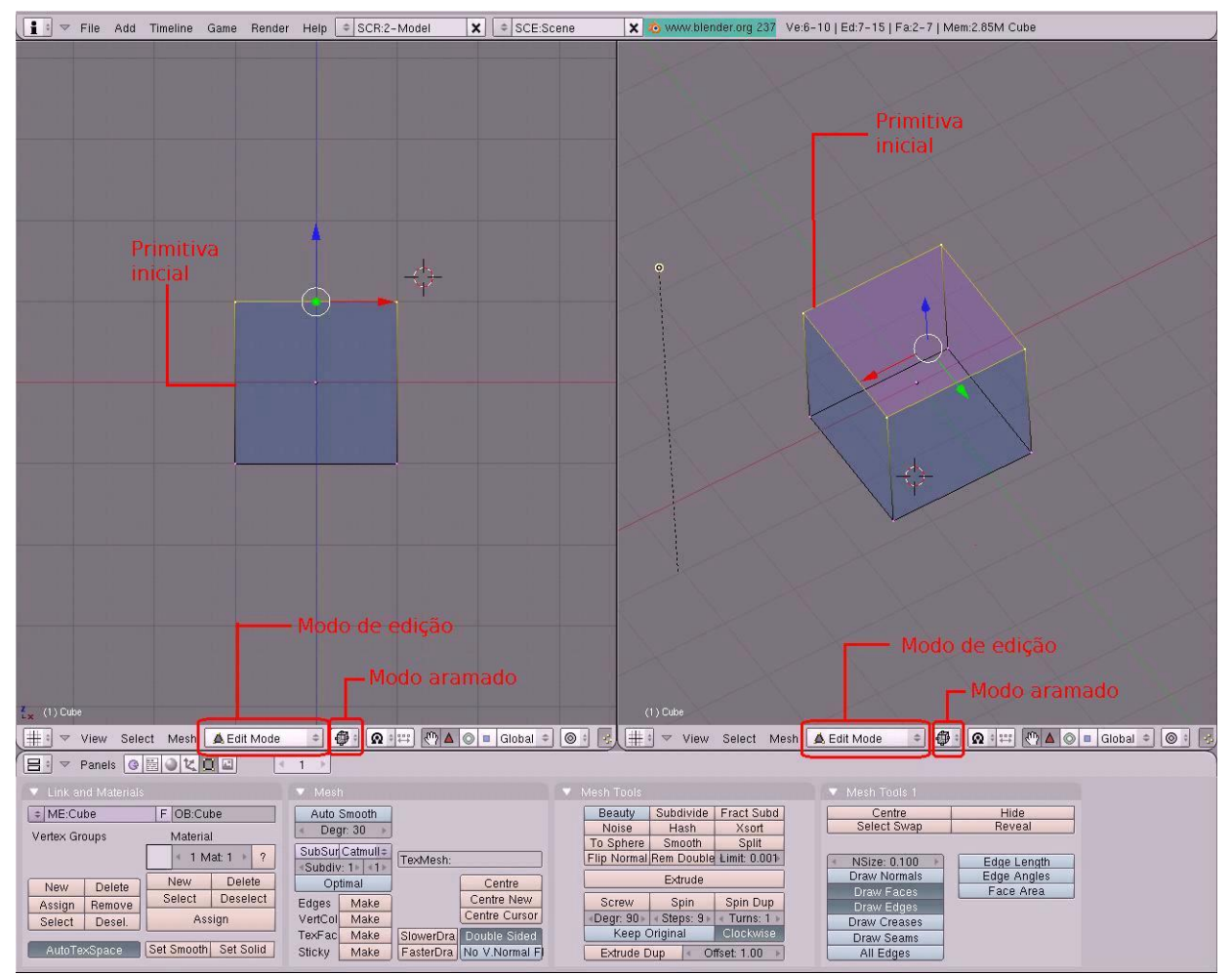

Figura 3.7: Modo de edição.

Para fins de organização, é necessário que separemos as primitivas em várias "camadas" diferentes, para tanto, basta que selecionemos o modo objeto e em seguida, com o botão direito, selecionemos o objeto a ser exportado. O próximo passo é utilizar a tecla "M" de Move e clicar na camada para a qual se deseja exportar o objeto. Quando for necessário visualizar todos os objetos em uma única cena, basta que se selecionem as camadas correspondentes no navegador de camadas (Layers) do lado direito com a tecla "SHIFT" pressionada. A Figura 3.8 demonstra o processo de seleção de camadas na interface de trabalho do blender. Portanto, podemos iniciar a modelagem de um osso a partir do cubo em uma camada e a modelagem de um outro de formato cônico em outra camada, por exemplo.

Com a figura de referência disponível e o modo de visualização adequado selecionado, basta que conheçamos algumas propriedades fundamentais do blender para iniciar as transformações geométricas que darão início ao processo de modelagem.

A primeira delas é o processo de escala, que consiste no redimensionamento de um determinado sólido ou de uma região deste. Para que o processo de escala seja realizado, basta que 


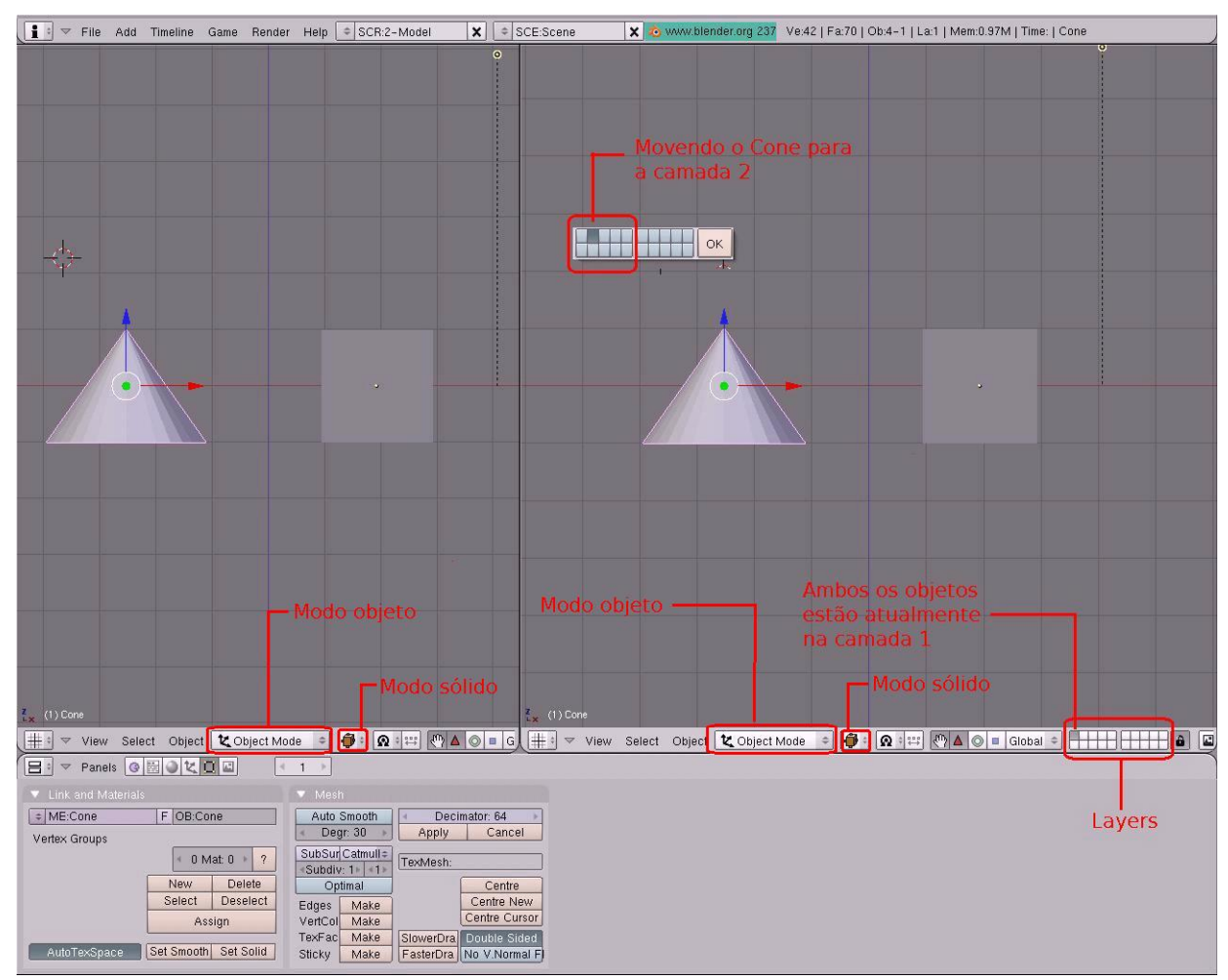

Figura 3.8: Trabalhando com múltiplas camadas.

os pontos referentes à região de interesse sejam selecionados com o mouse e em seguida, seja pressionada a tecla "S", que é uma tecla de atalho referente a escala. Se o usuário utilizar em seguida as teclas de atalho "X", "Y" ou "Z", o processo de escala será aplicado somente em relação ao eixo especificado, caso contrário, se nenhuma das teclas for pressionada, o processo será aplicado em todos os eixos. Feito isso, para que a região selecionada seja aumentada ou diminuída, basta que o usuário movimente o cursor do mouse. Em geral, movimentando-se o mouse para cima ou para a direita, os pontos selecionados terão seus segmentos aumentados, ao passo que, se o movimento for realizado para baixo ou para a esquerda, os segmentos terão seu tamanho reduzido. A Figura 3.9 demonstra a aplicação do processo de escala.

Uma outra operação fundamental no blender é a translação, um processo que consiste em transladar um ponto ou um conjunto de pontos de uma posição inicial de origem até uma nova coordenada final ou de destino. Para efetuar a translação no blender, é necessário que o usuário selecione os vértices de interesse com o mouse e em seguida, pressione a tecla "G", que é uma tecla de atalho referente ao processo de translação. Em seguida, o usuário deve movimentar o cursor do mouse para determinar a região de destino para a qual os pontos serão transladados. Os movimentos podem ser realizados em todas as direções, incluindo as diagonais, ou podem ser limitados por eixo, desde que o usuário tenha pressionado as teclas de atalho " $\mathrm{X}$ ", "Y" ou "Z”, após a tecla "G”. A Figura 3.10 demonstra a aplicação do processo de translação. 


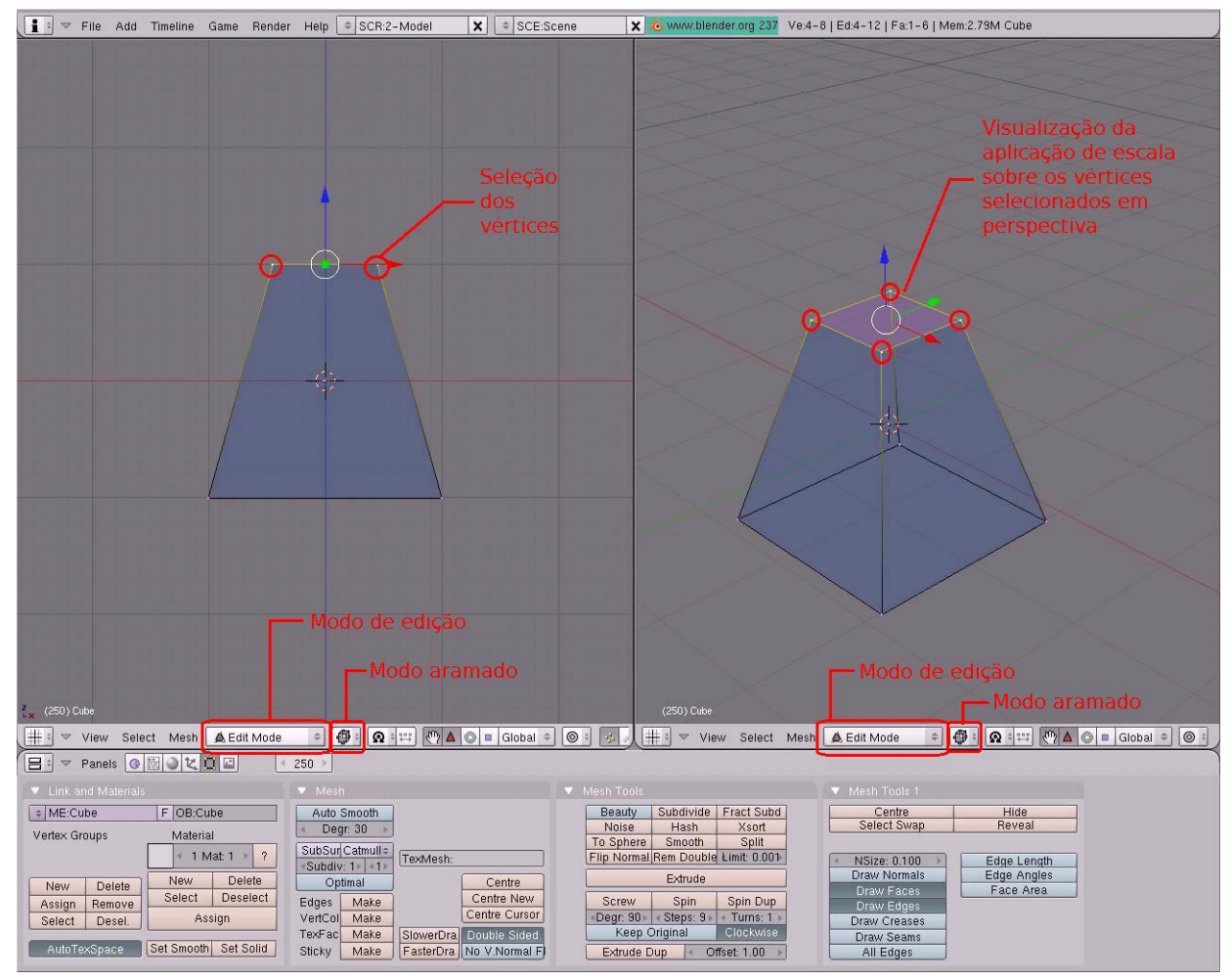

Figura 3.9: Demonstração do processo de escala.

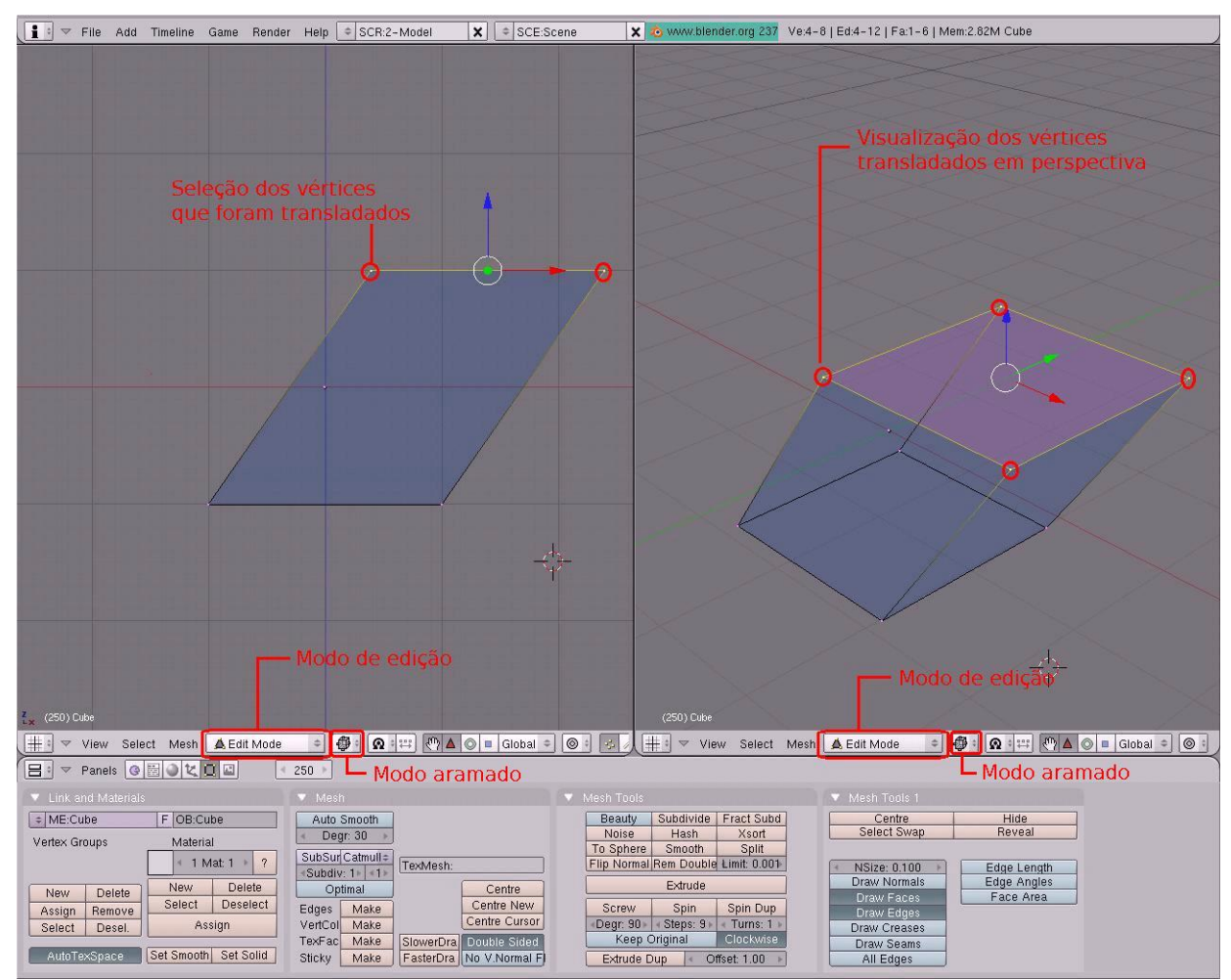

Figura 3.10: Demonstração do processo de translação. 
Uma das operações mais utilizadas no processo de modelagem é a extrusão. A extrusão é semelhante a um processo de crescimento de região, onde o usuário realiza uma operação semelhante a um alongamento, que pode ser baseado em pontos, faces ou arestas, por exemplo. Na maior parte dos casos é assim que um cubo "cresce" em uma modelagem baseada na técnica "box modeling". À medida que as extrusões ocorrem, sozinhas ou combinadas com operações de translação e/ou escala, a primitiva inicial vai sofrendo deformações e vai, cada vez mais, se aproximando do formato desejado pelo usuário. Para se realizar um processo de extrusão com o blender, basta selecionar os vértices desejados com o mouse e pressionar a tecla "E", que é uma tecla de atalho referente ao processo de extrusão. Nesse processo em especial, é altamente recomendada a utilização de uma das teclas de atalho que limitam a influência da operação sobre o eixo desejado "X", "Y" ou "Z", de modo que a extrusão não realize deslocamentos em eixos não desejados. As Figuras 3.11 e 3.12 demonstram a aplicação do processo de extrusão.

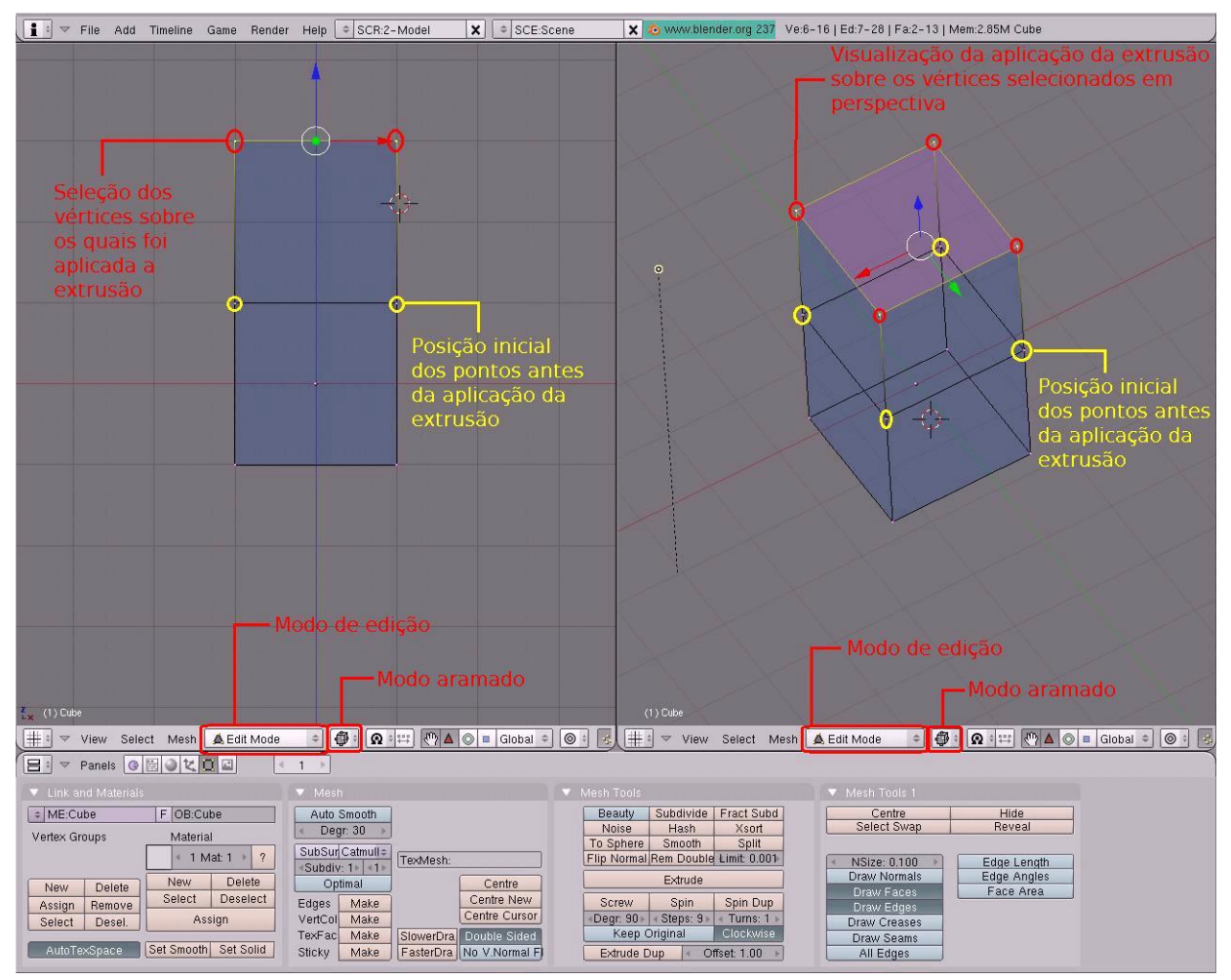

Figura 3.11: Demonstração do processo de extrusão. 


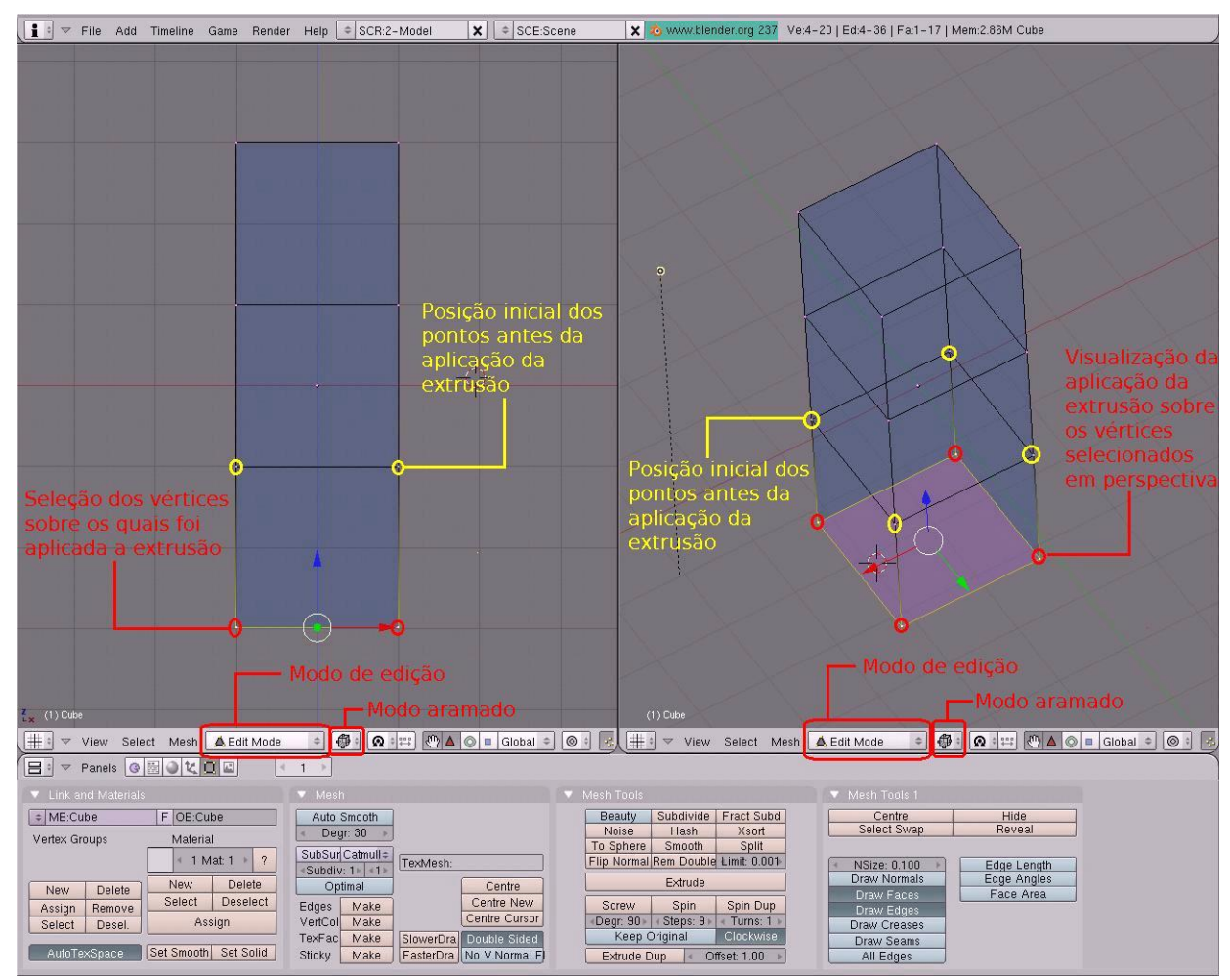

Figura 3.12: Demonstração do processo de extrusão.

\subsubsection{Iniciando o Processo de Modelagem}

Na seção anterior, foram apresentadas algumas das principais propriedades da interface de trabalho do blender. A Figura 3.13, apresenta uma imagem de referência que serviu como base para o desenvolvimento do processo de modelagem. Quando a imagem é carregada em background, nenhum componente da cena é alterado, a escala e a posição do cubo, da câmera e da luz continuam os mesmos e nesse primeiro momento, realizamos algumas operações para iniciar a modelagem.

As duas primeiras transformações geométricas que devem ser aplicadas ao cubo original apresentado na Figura 3.13, são as operações de escala e de translação. A operação de translação posiciona o cubo sobre uma região da imagem na qual o usuário inicia o processo de modelagem, ao passo que, a operação de escala redimensiona o cubo de maneira que ele passe a ter dimensões próximas a largura da região da imagem de referência sobre a qual foi posicionado, conforme mostra a Figura 3.14.

Após o posicionamento e o redimensionamento do cubo de acordo com a imagem de referência, realizamos operações de extrusão e escala de maneira que suas bordas acompanham os contornos da imagem de referência possibilitando no final do processo, a construção de um modelo semelhante à essa imagem. O resultado obtido é mostrado na Figura 3.15. 


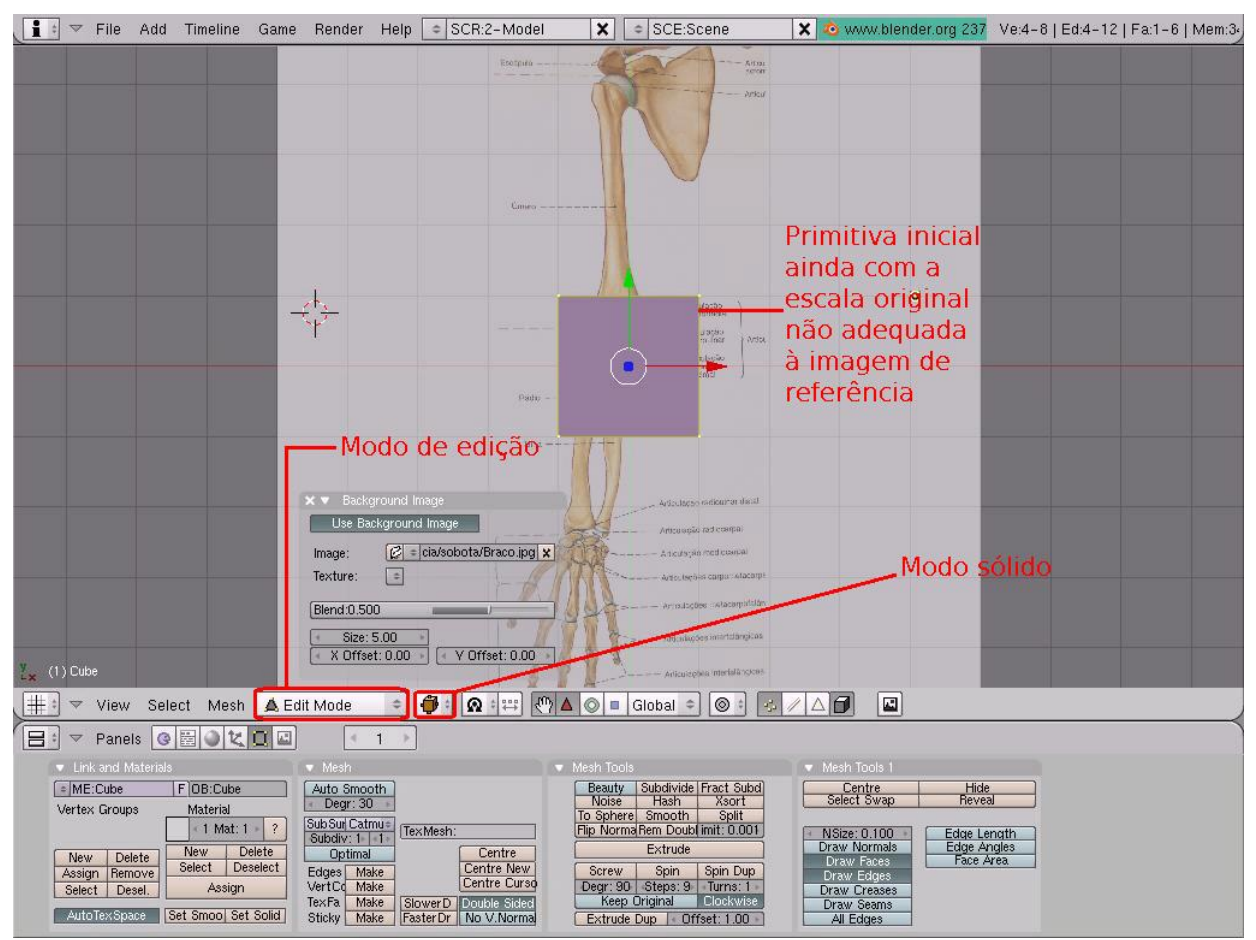

Figura 3.13: A primitiva inicial, um cubo, ainda não posicionada de maneira correta sobre a imagem de referência.

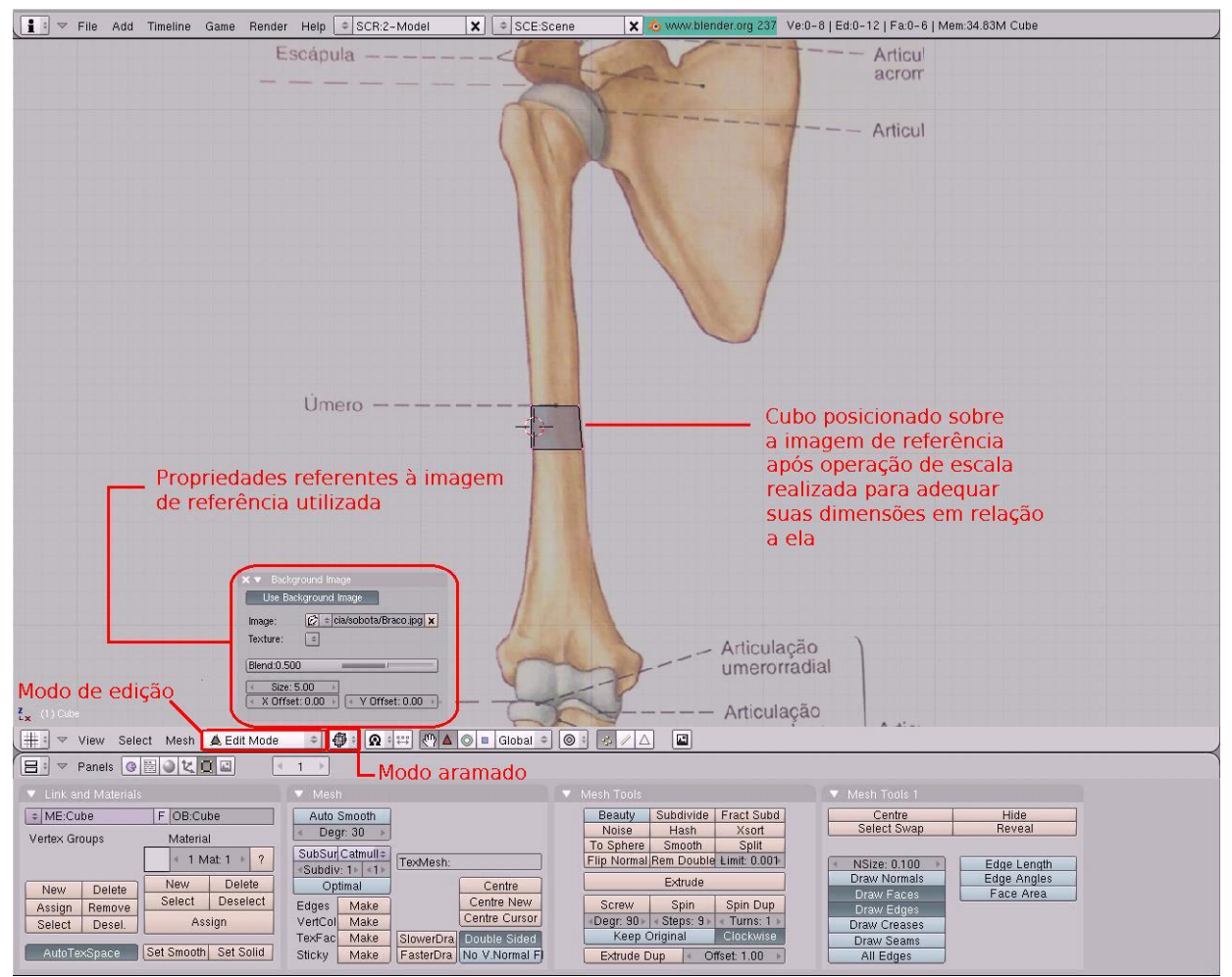

Figura 3.14: Cubo posicionado sobre a imagem de referência. 


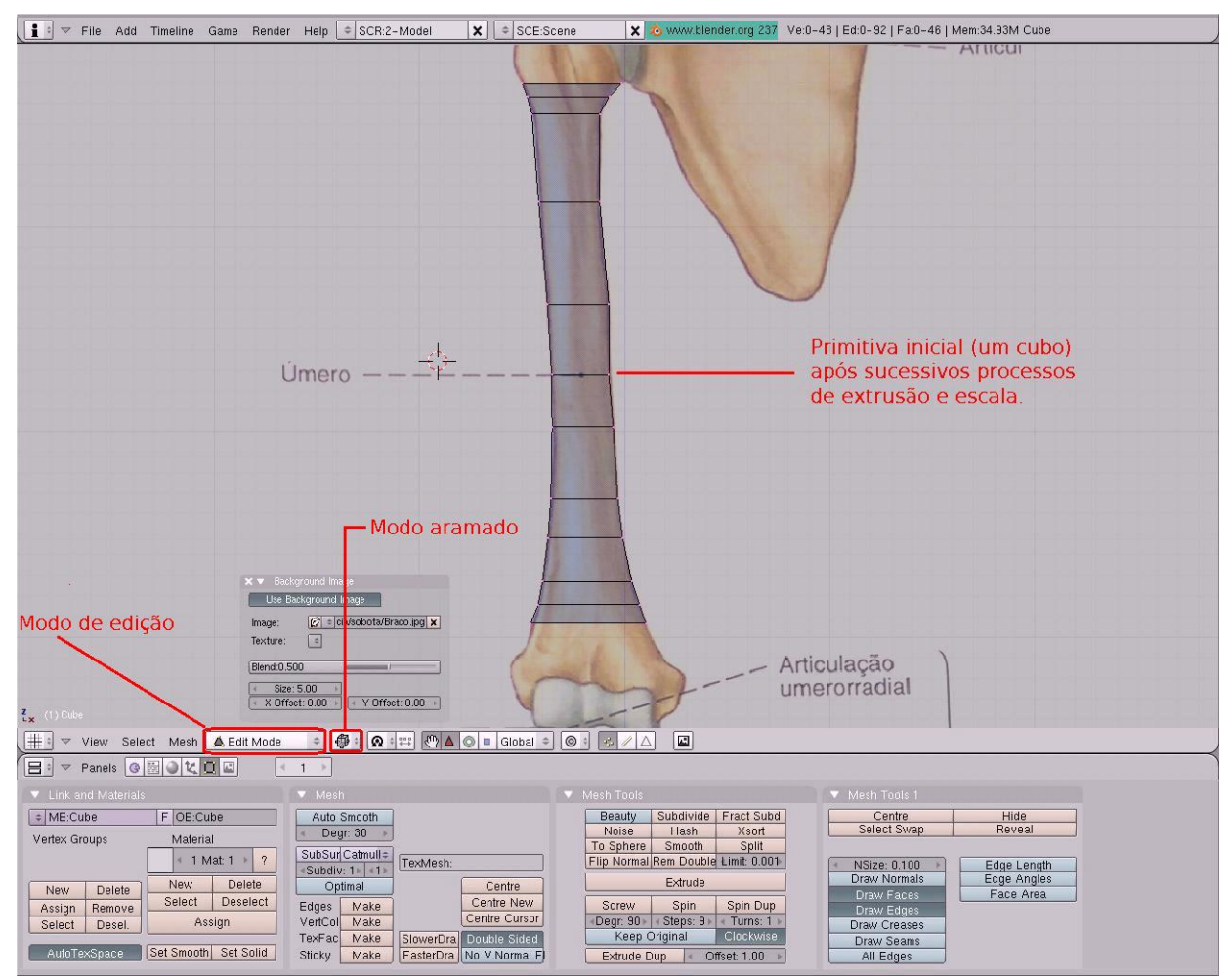

Figura 3.15: Extrusão a partir da primitiva inicial.

Analisando o modelo a partir da visão frontal, temos a impressão de que ele está representando perfeitamente a imagem de referência, uma vez que suas bordas estão acompanhando os contornos da imagem. No entanto, a partir de uma visão em perspectiva, podemos verificar que os acabamentos nas "quinas" do modelo são extremamente rudimentares, não representando as curvas de maneira suave como deveria. Isso ocorre porque a técnica de modelagem utilizada foi baseada na deformação de um cubo, que portanto, efetua a união de dois pontos adjacentes traçando um segmento de reta entre eles, operação esta que, obviamente, vai manter a aparência cúbica da primitiva inicial, especialmente nas “quinas", conforme mostra a Figura 3.16.

Para que o modelo possua contornos arredondados nas extremidades, é necessária a aplicação de um processo de suavização de superfície. Esse processo mantém o aspecto cúbico em regiões que tem realmente essa característica e dá um formato arredondado nas extremidades, ou seja, na transição entre uma face e outra em cada segmento. O resultado da aplicação de subdivisão de superfície sobre o modelo é apresentado na Figura 3.17

Seguindo esse raciocínio, no decorrer do processo de modelagem aplicamos consecutivos processos de transformação geométrica sobre a primitiva inicial e em seguida, utilizamos a técnica de suavização de superfícies sobre o modelo. Desse modo, no final do processo, temos uma malha tridimensional com representação equivalente a imagem de referência utilizada, conforme mostra a Figura 3.18 . 


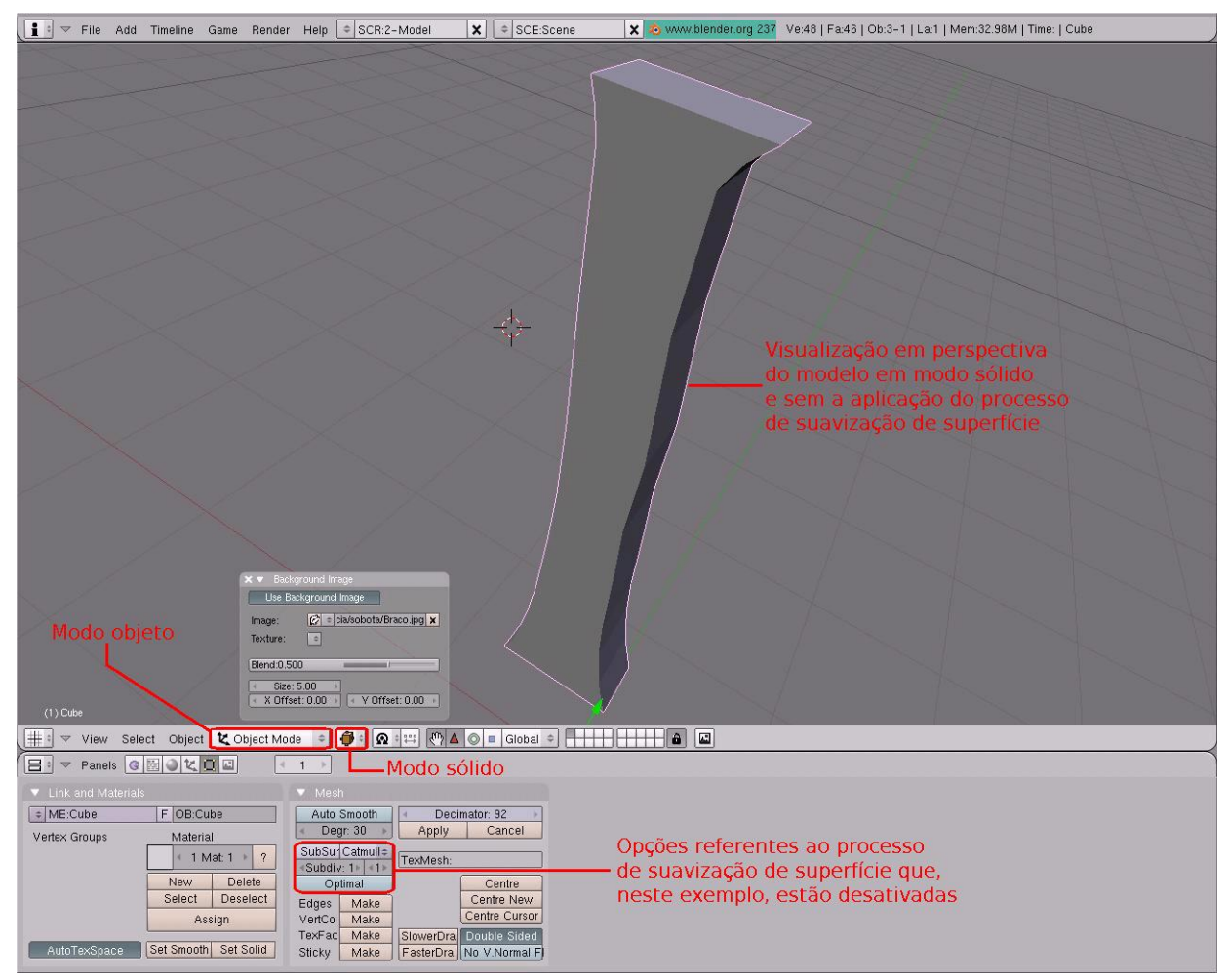

Figura 3.16: Visão tridimensional do modelo.

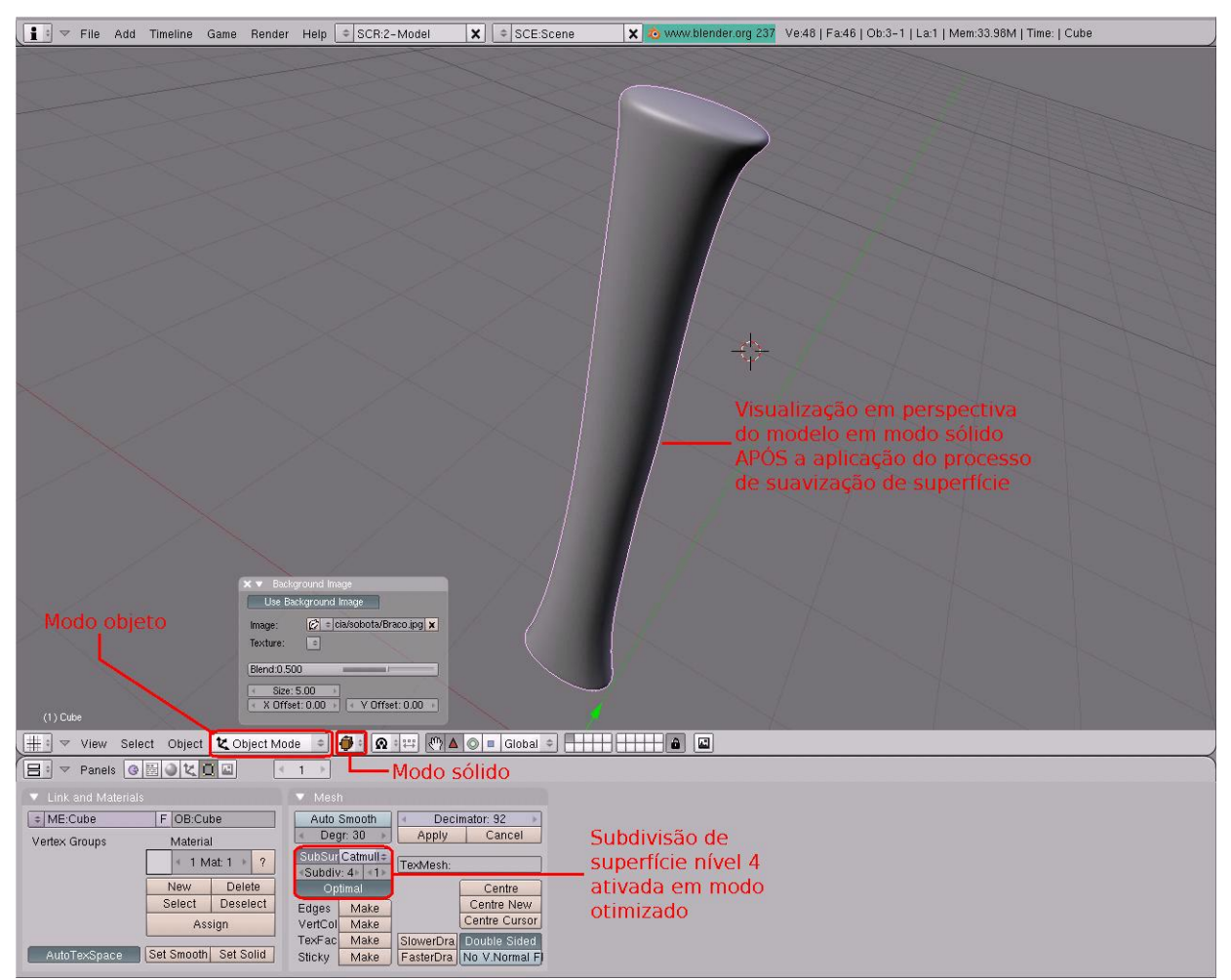

Figura 3.17: Aplicação de subdivisão de superfície. 


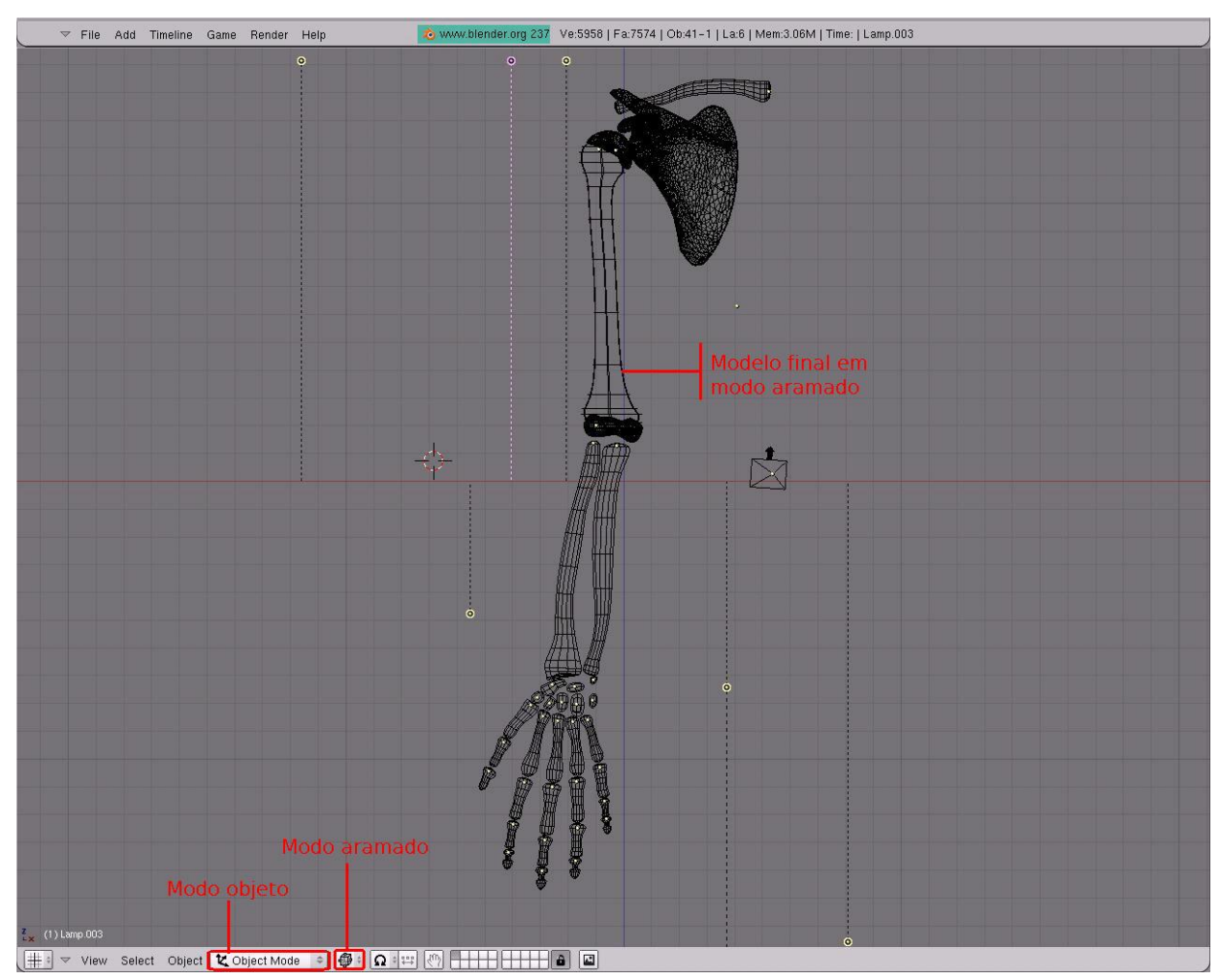

Figura 3.18: Malha do modelo em wireframe.

A Figura 3.19 mostra o modelo desenvolvido sobreposto à imagem de referência.

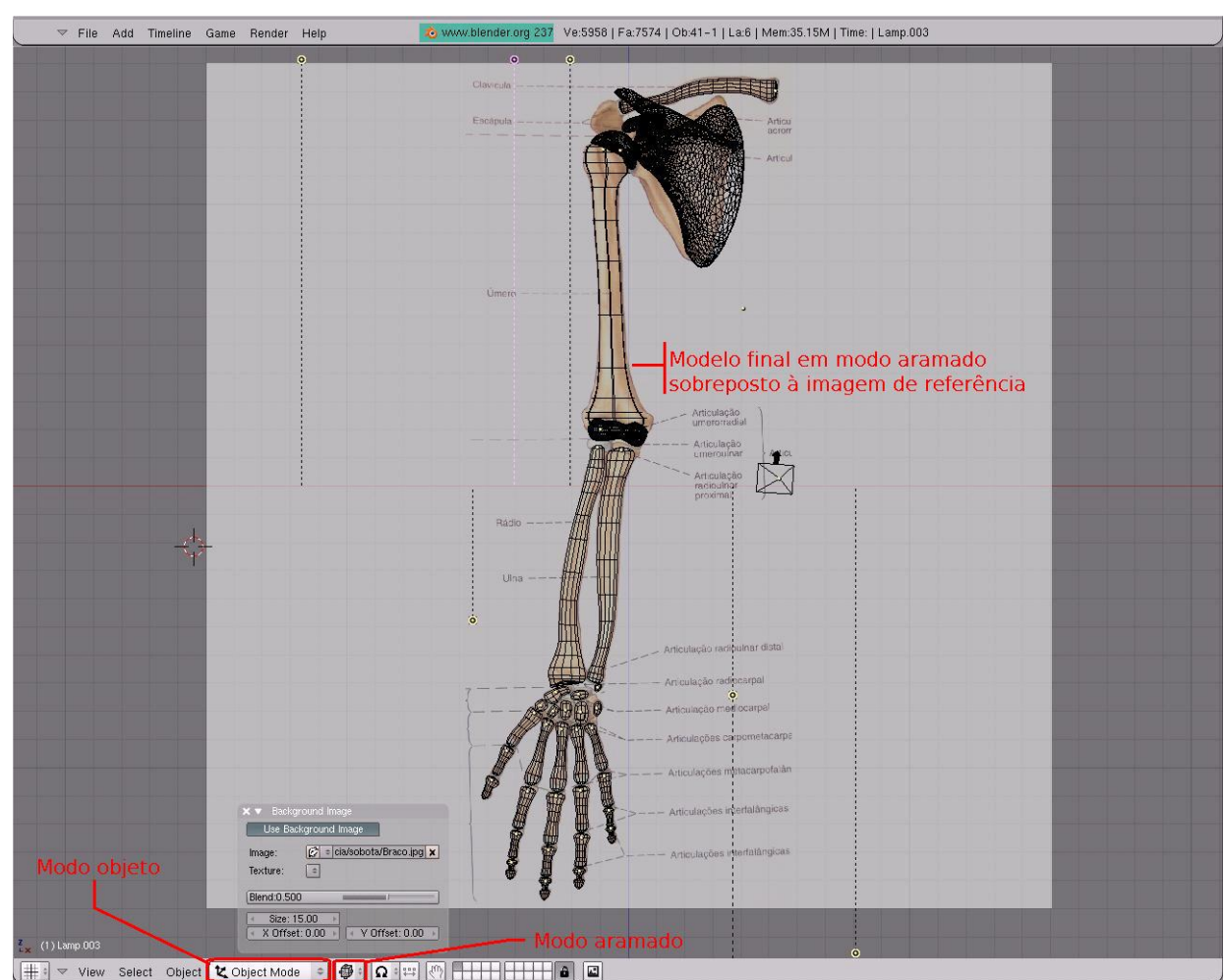

Figura 3.19: Malha do modelo em wireframe sobre a imagem de referência.

Por fim, o último passo é a aplicação de uma textura sobre o material que reveste o modelo. 
A textura utilizada pode ser extraída a partir de fragmentos de imagens ou ainda, de cores geradas a partir de combinações RGB, conforme mostra a Figura 3.20.

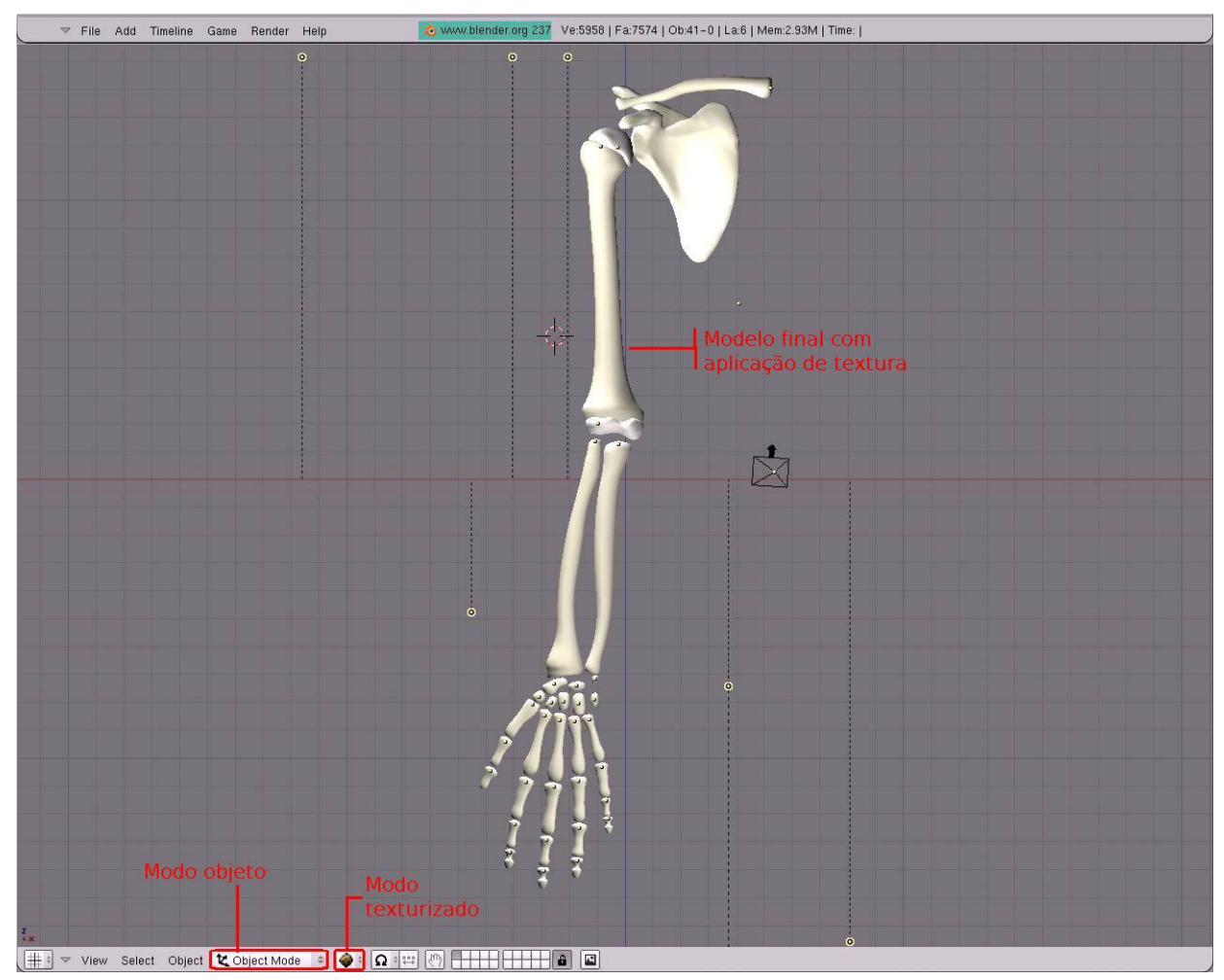

Figura 3.20: Aplicação de textura ao modelo.

\subsection{A Ferramenta}

Para gerar modelos com diferentes características anatômicas, escolhemos um script em linguagem Python denominado "Make-Human" [Make-Human, 2008]. O Make-Human pode ser utilizado em conjunto com o blender e oferece uma interface com o usuário que gera malhas 3D com o formato e a aparência de um corpo humano. Essas malhas "iniciais" podem ser modificadas livremente de acordo com as características que se queira representar, no entanto, é necessário exportá-las para o formato nativo do blender, onde são refinadas e adequadas às necessidades. 


\subsection{Determinação dos Parâmetros Necessários para Simulação das Imagens Radiológicas}

\subsubsection{Coeficientes de Atenuação de Massa}

Na terceira etapa do trabalho, submetemos os modelos desenvolvidos como pacientes virtuais, a exames radiológicos, também virtuais, realizados com a utilização de algoritmos de simulação específicos. Para tanto, inicialmente levantamos os coeficientes de atenuação de massa referentes a cada estrutura anatômica representada em nossos modelos. Esses dados podem ser obtidos no site do NIST [XCOM, 2008], em trabalhos encontrados na literatura [Chao et al., 2001], [Chao and Xu, 2004], [Jiang et al., 2005], [Kramer et al., 2003], [Xu and Chao, 2003], [Xu, 2005b], [Xu, 2005c], [Xu, 2005a], ou em relatórios do ICRU [ICRU, 1989]. No entanto, para utilizá-los, tivemos que coletar os coeficientes de atenuação de massa referentes a faixa de energia utilizada em exames radiológicos, ou seja de 0,005 a 0,150 MeV. Os dados fornecidos não são sequenciais, estão disponíveis em intervalos irregulares de pelo menos 0,010 $\mathrm{MeV}$ (intervalos esses que variam de material para material), portanto os interpolamos de modo a obter a escala completa da faixa de energia desejada para cada um dos coeficientes utilizados. Para tanto, foi utilizado o software Microcalc Origin, em ambiente Microsoft Windows.

Após o levantamento de cada um dos coeficientes e o cálculo das faixas de energia desejadas, geramos três bancos de dados para armazenamento, a saber:

- Coeficientes de atenuação de massa de materiais;

- Coeficientes de atenuação de massa de ossos;

- Coeficientes de atenuação de massa de tecidos.

Utilizamos o sistema gerenciador de banco de dados MySQL. Nomeamos as tabelas que compoem cada um dos três bancos de dados com o nome da estrutura a que se referem classificadas de acordo com sua composição: osso, tecido ou elemento da tabela periódica. Especificamos as estruturas representadas em cada um dos bancos de dados nas tabelas 3.1, 3.2, e 3.3: 
Tabela 3.1: Coeficientes de atenuação de massa de materiais.

\begin{tabular}{|l|}
\hline \multicolumn{1}{|c|}{ Material } \\
\hline Bário \\
\hline Molibdênio \\
\hline Tungstênio \\
\hline \hline
\end{tabular}

Tabela 3.2: Coeficientes de atenuação de massa de ossos e sua composição em função dos elementos básicos.

\begin{tabular}{|l|l|l|l|}
\hline Material & Densidade $\left(\mathbf{g} / \mathbf{c m}^{3}\right)$ & Composição & Percentual \\
\hline Osso & $1.45000 \mathrm{E}+00$ & Hidrogênio & 0.065471 \\
& & Carbono & 0.536945 \\
& & Nitrogênio & 0.021500 \\
& & Oxigênio & 0.032085 \\
& & Flúor & 0.167411 \\
& & Cálcio & 0.176589 \\
\hline \hline
\end{tabular}

Tabela 3.3: Coeficientes de atenuação de massa de tecidos e sua composição em função dos elementos básicos.

\begin{tabular}{|l|l|l|l|}
\hline \multicolumn{1}{|c|}{ Material } & Densidade (g/cm $\left.{ }^{3}\right)$ & Composição & Percentual \\
\hline Ar & $1.20479 \mathrm{E}-03$ & Carbono & 0.000124 \\
& & Nitrogênio & 0.755267 \\
& & Oxigênio & 0.231781 \\
& & Argônio & 0.012827 \\
\hline Músculo (ICRU-44) & $1.050 \mathrm{E}+00$ & Hidrogênio & 0.102000 \\
& & Carbono & 0.143000 \\
& & Nitrogênio & 0.034000 \\
& & Oxigênio & 0.710000 \\
\hline & & \multicolumn{3}{|c|}{ Continua na próxima página } \\
\hline
\end{tabular}


Tabela 3.3 - continuação da página anterior

\begin{tabular}{|c|c|c|c|}
\hline \multirow[t]{6}{*}{ Material } & Densidade $\left(\mathrm{g} / \mathrm{cm}^{3}\right)$ & Composição & Percentual \\
\hline & & Sódio & 0.001000 \\
\hline & & Fósforo & 0.002000 \\
\hline & & Enxofre & 0.003000 \\
\hline & & Cloro & 0.001000 \\
\hline & & Potássio & 0.004000 \\
\hline \multirow[t]{13}{*}{ Pele (ICRP) } & $1.10000 \mathrm{E}+00$ & Hidrogênio & 0.100588 \\
\hline & & Carbono & 0.228250 \\
\hline & & Nitrogênio & 0.046420 \\
\hline & & Oxigênio & 0.619002 \\
\hline & & Sódio & 0.000070 \\
\hline & & Magnésio & 0.000060 \\
\hline & & Fósforo & 0.000330 \\
\hline & & Enxofre & 0.001590 \\
\hline & & Cloro & 0.002670 \\
\hline & & Potássio & 0.000850 \\
\hline & & Cálcio & 0.000150 \\
\hline & & Ferro & 0.000010 \\
\hline & & Zinco & 0.000010 \\
\hline \multirow[t]{10}{*}{ Sangue (ICRU-44) } & $1.060 \mathrm{E}+00$ & Hidrogênio & 0.102000 \\
\hline & & Carbono & 0.110000 \\
\hline & & Nitrogênio & 0.033000 \\
\hline & & Oxigênio & 0.745000 \\
\hline & & Sódio & 0.001000 \\
\hline & & Fósforo & 0.001000 \\
\hline & & Enxofre & 0.002000 \\
\hline & & Cloro & 0.003000 \\
\hline & & Potássio & 0.002000 \\
\hline & & Ferro & 0.001000 \\
\hline \multirow[t]{4}{*}{ Tecido Adiposo (ICRU-44) } & $9.500 \mathrm{E}-01$ & Hidrogênio & 0.114000 \\
\hline & & Carbono & 0.598000 \\
\hline & & Nitrogênio & 0.007000 \\
\hline & & Oxigênio & 0.278000 \\
\hline & & Continua na pro & xima página \\
\hline
\end{tabular}


Tabela 3.3 - continuação da página anterior

\begin{tabular}{|l|l|l|l|}
\hline Material & Densidade $\mathbf{( g / \mathbf { c m } ^ { 3 } )}$ & Composição & Percentual \\
\hline & & Sódio & 0.001000 \\
& & Enxofre & 0.001000 \\
Tecidos Moles (ICRU-44) & $1.060 \mathrm{E}+00$ & Hidrogênio & 0.102000 \\
& & Carbono & 0.143000 \\
& & Nitrogênio & 0.034000 \\
& & Oxigênio & 0.708000 \\
& & Sódio & 0.002000 \\
& & Fósforo & 0.003000 \\
& & Enxofre & 0.003000 \\
& & Cloro & 0.002000 \\
& & Potássio & 0.003000 \\
\hline \hline
\end{tabular}

De acordo com a literatura [Kramer et al., 2004], órgãos como o estômago, intestinos, pâncreas, fígado, baço, rins, coração e bexiga, utilizam coeficientes de atenuação "genéricos" sendo classificados simplesmente como tecidos moles e, por esse motivo, não possuem coeficientes de atenuação de massa específicos. Portanto, para simular as imagens radiológicas da região abdominal, consideramos uma mistura composta por $50 \%$ de bário e $50 \%$ de ar, para os pixels referentes ao intestino grosso, de modo a representar a influência do contraste normalmente ingerido pelo paciente, em exames realizados nessa região. 


\subsubsection{Características Físicas}

Utilizamos como características físicas dos modelos aquelas recomendadas pelo "Homem de Referência" do ICRP [ICRP, 2003], conforme mostra a tabela 3.4.

Tabela 3.4: Valores de massa para órgãos e tecidos segundo o "Homem de Referência" do ICRP.

\begin{tabular}{|l|l|}
\hline \multicolumn{1}{|c|}{ Órgão/Tecido } & \multicolumn{1}{|c|}{ Massa (g) } \\
\hline Baço & 150 \\
\hline Bexiga Urinária & 50 \\
\hline Esôfago & 40 \\
\hline Espinha Dorsal & 3510 \\
\hline Esqueleto & 10500 \\
\hline Estômago & 400 \\
\hline Fígado & 1800 \\
\hline Intestino Delgado & 1000 \\
\hline Intestino Grosso & 670 \\
\hline Músculos & 29000 \\
\hline Pâncreas & 140 \\
\hline Pele & 3300 \\
\hline Pulmões & 1200 \\
\hline Rins & 310 \\
\hline Tecido Adiposo & 14600 \\
\hline Corpo Completo & 73000 \\
\hline Altura & $176 \mathrm{~cm}$ \\
\hline \hline
\end{tabular}

O volume do modelo denominado "proporcional" é de 28,47 B.U. (Blender Units). Já o volume do modelo denominado "desproporcional", é de 41,56 B.U, sendo um acréscimo de $45,97 \%$ de tecido adiposo do primeiro modelo. O volume dos modelos foi determinado através da utilização de um script desenvolvido em linguagem Python. Vale lembrar que o esqueleto e os órgãos utilizados para compor o modelo denominado "desproporcional", são os mesmos utilizados no modelo "proporcional", a diferença entre ambos portanto, se dá somente na malha referente ao tecido adiposo. 


\subsubsection{Seccionamento dos Modelos}

A tridimensionalidade dos modelos desenvolvidos permite sua visualização em diferentes perspectivas. No entanto, para que o algoritmo de simulação das imagens radiológicas os utilize como dado de entrada, foi necessário seccioná-los, de modo a criar uma espécie de vetor de "fatias", semelhante às fatias produzidas em exames tomográficos. A união desse conjunto de fatias, representa o modelo completo. Essa abordagem é necessária para que o delineamento das estruturas seja corretamente representado pelo algoritmo e também para que as espessuras dos ossos, tecidos e órgãos de cada estrutura seja definida corretamente. Para seccionar os modelos, utilizamos o script "Knife", desenvolvido por [Hoydonck and Stefano, 2008]. O script funciona dentro do blender e requer que um plano seja posicionado perpendicularmente ao eixo em que se deseja realizar os cortes. O plano é então deslocado ao longo do eixo escolhido, de modo que a sua intersecção com o modelo determina a região em que o corte é realizado, bastando para tanto, um clique no botão "Cut", presente na interface do script. A operação de seccionamento do modelo ocorre em sua totalidade com o deslocamento do plano entre dois pontos localizados nas extremidades do modelo. A localização desses pontos, denominados (a) e (b), é ilustrada na Figura 3.21. A Figura 3.22 mostra um exemplo de aplicação do método de seccionamento sobre o modelo proporcional, utilizando para melhor visualização, uma espessura cinco vezes maior do que a espessura usada na simulação.

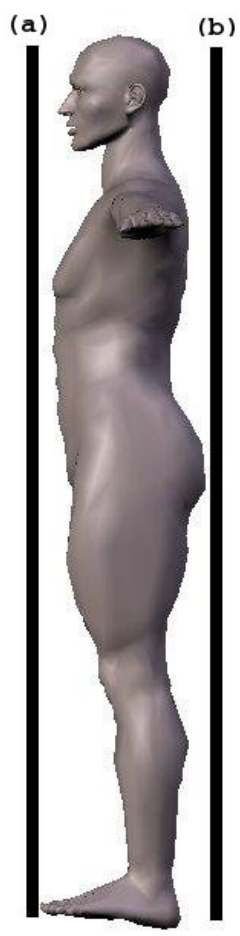

Figura 3.21: Localização dos pontos (a) e (b) em relação ao modelo proporcional para posterior realização da operação de seccionamento. 


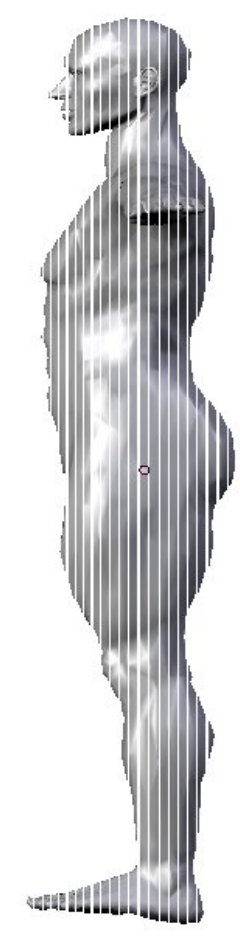

Figura 3.22: Seccionamento do modelo proporcional em vinte e três fatias, utilizando uma espessura de corte cinco vezes maior do que a espessura usada na simulação.

O seccionamento foi realizado separadamente nas malhas referentes a pele, ao esqueleto e aos órgãos internos, gerando dessa forma, três conjuntos de fatias distintos, à saber:

- Modelo da pele, indivíduo com peso e altura proporcionais: 127 fatias;

- Modelo da pele, indivíduo obeso, com acréscimo de 45,97\% de tecido adiposo: 174 fatias;

- Modelo do esqueleto: 103 fatias;

- Modelo dos órgãos internos: 75 fatias.

Armazenamos as fatias seccionadas em bancos de dados organizados da seguinte maneira:

- Modelo com peso e altura proporcionais:

Nome do Banco de dados: proporcional;

Tabelas criadas: pele, ossos e órgãos;

Campos que compoem as tabelas: índice e imagem.

- Modelo com peso e altura desproporcionais:

Nome do Banco de dados: obeso; 
Tabelas criadas: pele, ossos e órgãos;

Campos que compoem as tabelas: índice e imagem.

\subsubsection{Algoritmo de Simulação das Imagens Radiológicas}

As imagens radiográficas da região abdominal são normalmente realizadas utilizando-se tensões na faixa de 100 a $125 \mathrm{kVp}$. Para a simulação destas imagens utilizamos espectros de alta tensão referentes a um tubo com alvo de tungstênio e corrente de 10 mAs [Boone and Seibert, 1997].

A intensidade dos raios $\mathrm{X}$ que chegam em cada ponto da imagem é dada pela equação 3.1 [Wolbarst, 1993]. A equação determina, pixel a pixel, a quantidade de fótons resultantes, representados por $I_{\text {total }}$, em cada ponto da imagem, desde o momento da emissão do espectro inicial, passando em seguida pela filtração inerente ocorrida na janela do tubo, e considerando por fim, a atenuação sofrida ao atravessar as estruturas retratadas.

A intensidade final em cada ponto da imagem é dada pela somatória da intensidade em cada intervalo de energia, representado por $I o_{i}$, onde i varia de zero até a energia escolhida. consideramos todas as estruturas retradadas e calculamos os coeficientes de atenuação de massa de cada material, $\mu_{i j}$, multiplicando a densidade da estrutura pelos coeficientes de absorção de massa para cada energia de cada material que compõe o órgão ou tecido. A equação é genérica e permite incluir os materiais necessários para filtrar o espectro.

$$
I_{\text {total }}=\sum_{i=0}^{k v p} I_{i} e^{-\sum_{j=t e c i d o} \mu_{j, i} X_{j}}
$$

onde, $I_{\text {total }}$ é o espectro total atenuado que chega num ponto do plano imagem; $I_{0 i}$ é a intensidade gerada para cada faixa do espectro primário; j - representa cada tecido envolvido; $\mu_{i, j}$ é o coeficiente de absorção linear para cada energia do espectro; $X_{j}$ é a espessura de cada tecido.

A fonte simulada é ideal e a intensidade final em cada pixel da imagem produz um nível de cinza numa escala de 256 níveis.

A figura 3.23 mostra o fluxograma do algoritmo de simulação de imagens radiológicas, onde os três conjuntos de fatias referentes à pele, esqueleto e órgãos, são lidos simultaneamente no terceiro passo. Como há uma diferença na quantidade de fatias existentes em cada um desses conjuntos, geramos indíces vazios que representam fatias sem nenhum dado, fazendo com que todos os vetores de imagens passassem a ter a mesma dimensão, nesse caso, 174 posições ou 
fatias, que é o número de fatias referente ao modelo mais extenso, o modelo obeso. Como os órgãos são internos à estrutura do esqueleto e este é interno à estrutura da pele, a leitura de um modelo completo, que contempla pele, ossos e órgãos, é realizada simultaneamente nos três vetores de imagens, pixel a pixel, através da realização de uma operação "AND” que executa o cálculo dos coeficientes de atenuação de massa no pixel corrente de acordo com a estrutura retratada nessa posição em cada uma das imagens. No modelo proporcional completo original, por exemplo, são lidas 25 fatias da pele até que a primeira fatia que inicia a representação do esqueleto seja alcançada, Desse modo, essas primeiras 25 posições na tabela de fatias do esqueleto, são preenchidas com fatias vazias, de modo a compatibilizar o tamanho de ambas, facilitando dessa forma a leitura e a utilização da base de dados. As demais fatias vazias, são inseridas após a representação do último osso. O procedimento é análogo em relação à tabela que representa os órgãos internos. 

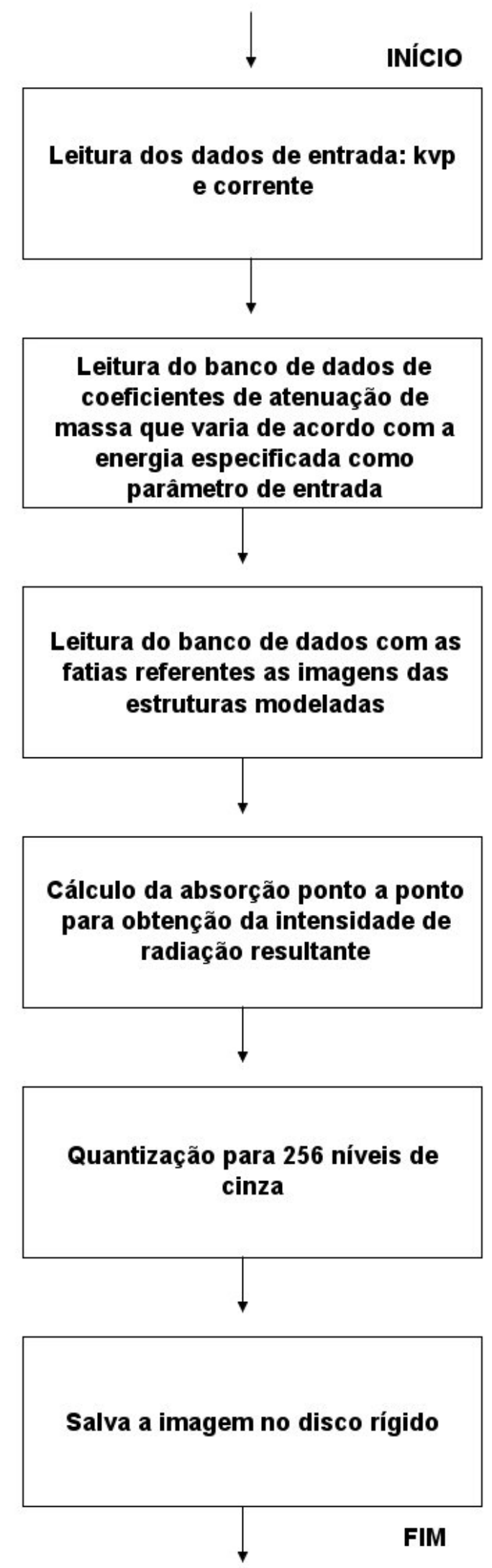

Figura 3.23: Fluxograma do algoritmo de simulação de imagens radiológicas. 


\subsection{Validação dos Modelos Desenvolvidos}

\subsubsection{Validação por Subtração de Imagens}

Para validar as estruturas modeladas, utilizamos um método quantitativo baseado no número de pixels. Comparamos as estruturas modeladas com imagens de referência obtidas num atlas de anatomia humana [Sobotta, 2000] sobrepondo as imagens do atlas anatômico digitalizadas sobre as imagens dos modelos desenvolvidos.

Contamos todos os pixels não coincidentes e calculamos a porcentagem destes em relação ao número total de pixels da imagem modelada.

\subsubsection{Validação por Comparação Visual dos Modelos}

Subtemos os modelos desenvolvidos a três especialistas, um da área de enfermagem e dois patologistas, que responderam ao questionário apresentado à seguir, analisando a semelhança com estruturas anatômicas.

\section{Questionário Utilizado para Avaliação dos Modelos}

Questão 01 - Avaliação da modelagem do esqueleto.

1.1) A representação dos arcos costais e das clavículas nas imagens apresentadas está:
Ótima [ ]
Boa [ ]
Satisfatória [ ]
Ruim []

1.2) A representação das escápulas nas imagens apresentadas está:
Ótima [ ]
Boa [ ]
Satisfatória [ ]
Ruim [ ]

1.3) A representação da coluna vertebral nas imagens apresentadas está:
Ótima [ ]
Boa [ ]
Satisfatória [ ]
Ruim [ ]

1.4) A representação da caixa torácica nas imagens apresentadas está:

Ótima [ ] Boa [ ] Satisfatória [ ] Ruim [ ]

1.5) A representação dos membros superiores nas imagens apresentadas está:

Ótima [ ] Boa [ ] $\quad$ Satisfatória [ ] Ruim [ ]

1.6) A representação dos membros inferiores nas imagens apresentadas está:

Ótima [ ] Boa [ ] $\quad$ Satisfatória [ ] Ruim [ ]

1.7) A representação da região pélvica nas imagens apresentadas está:
Ótima [ ]
Boa [ ]
Satisfatória [ ]
Ruim [ ]

Caso tenha alguma observação relevante, utilize este espaço: 
Questão 02 - Avaliação da modelagem dos órgãos.

2.1) A representação dos pulmões nas imagens apresentadas está:
Ótima [ ]
Boa [ ]
Satisfatória [ ]
Ruim [ ]

2.2) A representação do fígado nas imagens apresentadas está:
Ótima [ ]
Boa [ ]
Satisfatória [ ]
Ruim [ ]

2.3) A representação do estômago nas imagens apresentadas está:
Ótima [ ]
Boa [ ]
Satisfatória [ ]
Ruim [ ]

2.4) A representação do pâncreas nas imagens apresentadas está:
Ótima [ ]
Boa [ ]
Satisfatória [ ]
Ruim [ ]

2.5) A representação dos rins nas imagens apresentadas está:
Ótima [ ]
Boa [ ]
Satisfatória [ ]
Ruim [ ]

2.6) A representação do intestino grosso nas imagens apresentadas está:
Ótima [ ]
Boa [ ]
Satisfatória [ ]
Ruim [ ]

2.7) A representação do intestino delgado nas imagens apresentadas está:
Ótima [ ]
Boa [ ]
Satisfatória [ ]
Ruim [ ]

Caso tenha alguma observação relevante, utilize este espaço:

Questão 03 - Avaliação da modelagem da anatomia externa (pele).

3.1) A representação das características externas do corpo humano referentes a um indivíduo com peso e altura proporcionais nas imagens 4.29 e 4.31 está:
Ótima [ ]
Boa [ ]
Satisfatória [ ]
Ruim [ ]

3.2) A representação das características externas do corpo humano referentes a um indivíduo com peso e altura desproporcionais em função da quantidade de tecido adiposo nas imagens 4.33 e 4.35 está:
Ótima [ ]
Boa [ ]
Satisfatória [ ]
Ruim [ ]

Caso tenha alguma observação relevante, utilize este espaço:

Questão 04 - Avaliação do modelo completo.

4.1) A disposição do esqueleto em função da pele nas imagens apresentadas está:
Ótima [ ]
Boa [ ]
Satisfatória [ ]
Ruim [ ]

4.2) A disposição dos órgãos em função do esqueleto, da pele e aos demais órgãos nas imagens apresentadas está:
Ótima [ ]
Boa [ ]
Satisfatória [ ]
Ruim [ ]

4.3) As dimensões e proporções do esqueleto em nas imagens apresentadas está:
Ótima [ ]
Boa [ ]
Satisfatória [ ]
Ruim [ ]

4.4) As dimensões e proporções dos órgãos nas imagens apresentadas está:
Ótima [ ]
Boa []
Satisfatória [ ]
Ruim [ ] 
Caso tenha alguma observação relevante, utilize este espaço:

Questão 05 - No geral, você considera a qualidade dos modelos:
Ótima [ ]
Boa [ ]
Satisfatória [ ]
Ruim [ ]

Caso tenha alguma observação relevante, utilize este espaço:

\subsubsection{Cálculo da Média dos Níveis de Cinza}

Simulamos as imagens radiográficas utilizando os modelos desenvolvidos como pacientes virtuais. Como o algoritmo de simulação considera a composição de cada estrutura homogênea, comparamos a média dos níveis de cinza de cada região das imagens reais e simuladas.

\subsubsection{Validação por Comparação Visual das Imagens Radiográficas}

A validação foi realizada por três radiologistas utilizando o questionário à seguir.

\section{Questionário Utilizado para Avaliação das Imagens Radiográficas}

Questão 01 - Avaliação da imagem 4.36 - modelo com peso e altura proporcionais.

1.1) Qual a semelhança da imagem simulada com a radiografia real?
Ótima [ ]
Boa [ ]
Satisfatória [ ]
Ruim [ ]

1.2) A representação dos ossos na imagem apresentada está:
Ótima [ ]
Boa []
Satisfatória [ ]
Ruim [ ]

1.3) A representação do intestino grosso na imagem apresentada está:

Ótima [ ] Boa [ ] Satisfatória [ ] Ruim [ ]

1.4) A representação do intestino delgado na imagem apresentada está:
Ótima [ ]
Boa [ ]
Satisfatória [ ]
Ruim [ ]

1.5) A representação da sobreposição de estruturas na imagem apresentada está:

Caso tenha alguma observação relevante, utilize este espaço:

Questão 02 - Avaliação da imagem 4.37 - modelo com peso e altura desproporcionais.

2.1) Qual a semelhança da imagem simulada com a radiografia real?
Ótima [ ]
Boa []
Satisfatória [ ]
Ruim [ ]

2.2) A representação dos ossos na imagem apresentada está:
Ótima [ ]
Boa [ ]
Satisfatória [ ]
Ruim [ ]

2.3) A representação do intestino grosso na imagem apresentada está:
Ótima [ ]
Boa [ ]
Satisfatória [ ]
Ruim [ ] 
2.4) A representação do intestino delgado na imagem apresentada está:
Ótima [ ]
Boa [ ]
Satisfatória [ ]
Ruim [ ]

2.5) A representação da sobreposição de estruturas na imagem apresentada está:

Caso tenha alguma observação relevante, utilize este espaço:

Questão 03 - Avaliação da modelagem da anatomia externa (pele).

3.1) A representação das características externas do corpo humano referentes a um indivíduo com peso e altura proporcionais na imagem 4.36 está:
Ótima [ ]
Boa [ ]
Satisfatória [ ]
Ruim [ ]

3.2) A representação das características externas do corpo humano referentes a um indivíduo com peso e altura desproporcionais em função da quantidade de tecido adiposo na imagem 4.37 está:

Ótima [ ] Boa [ ] Satisfatória [ ] Ruim [ ]

Caso tenha alguma observação relevante, utilize este espaço:

Questão 04 - Avaliação do modelo completo.

4.1) A disposição do esqueleto em função da pele nas imagens apresentadas está:
Ótima [ ]
Boa [ ]
Satisfatória [ ]
Ruim [ ]

4.2) A disposição dos órgãos em função do esqueleto, da pele e aos demais órgãos nas imagens apresentadas está:

Ótima [ ] Boa [ ] Satisfatória [ ] Ruim [ ]

4.3) As dimensões e proporções do esqueleto em nas imagens apresentadas está:

Ótima [ ] Boa [ ] Satisfatória [ ] Ruim [ ]

4.4) As dimensões e proporções dos órgãos nas imagens apresentadas está:

Ótima [ ] Boa [ ] $\quad$ Satisfatória [ ] Ruim [ ]

Caso tenha alguma observação relevante, utilize este espaço:

Questão 05 - No geral, você considera a qualidade dos modelos:
Ótima [ ]
Boa []
Satisfatória [ ]
Ruim [ ]

Caso tenha alguma observação relevante, utilize este espaço: 


\section{Resultados}

\subsection{Modelo Tridimensional do Sistema Ósseo Humano}

O modelo do sistema ósseo humano é exibido ao usuário em diferentes perspectivas e diferentes modos de visualização. Inicialmente, o modelo é apresentado parcialmente, divido por regiões para facilitar a visualização, sendo em seguida, apresentado integralmente, sendo: Caixa torácica: Visualização anterior, posterior e lateral, Figura 4.1; Espinha dorsal: Visualização anterior, posterior e lateral, Figura 4.4; Membros superiores: Visualização anterior e posterior, Figura 4.2; Membros inferiores: Visualização anterior e posterior, Figura 4.3; Modelo completo do esqueleto: Visualização anterior, posterior e lateral, Figura 4.5.

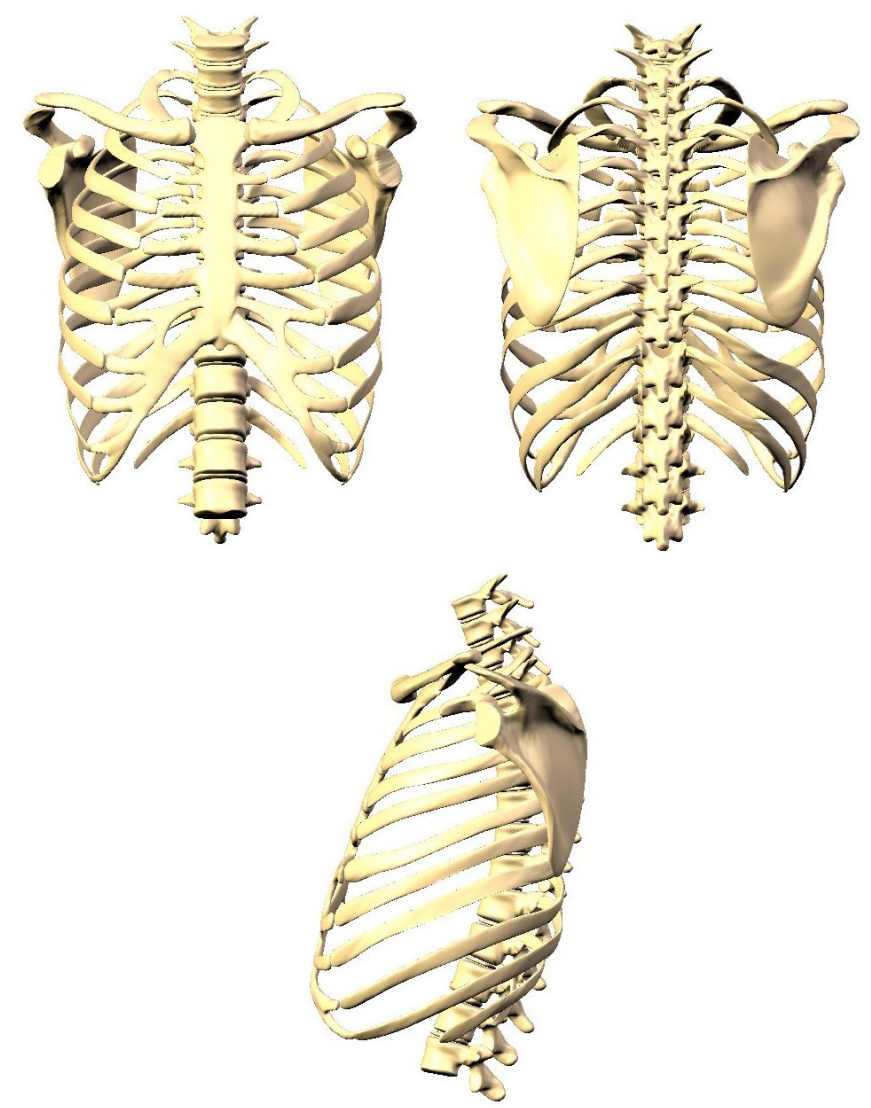

Figura 4.1: Visualização anterior, posterior e lateral do modelo tridimensional da caixa torácica 

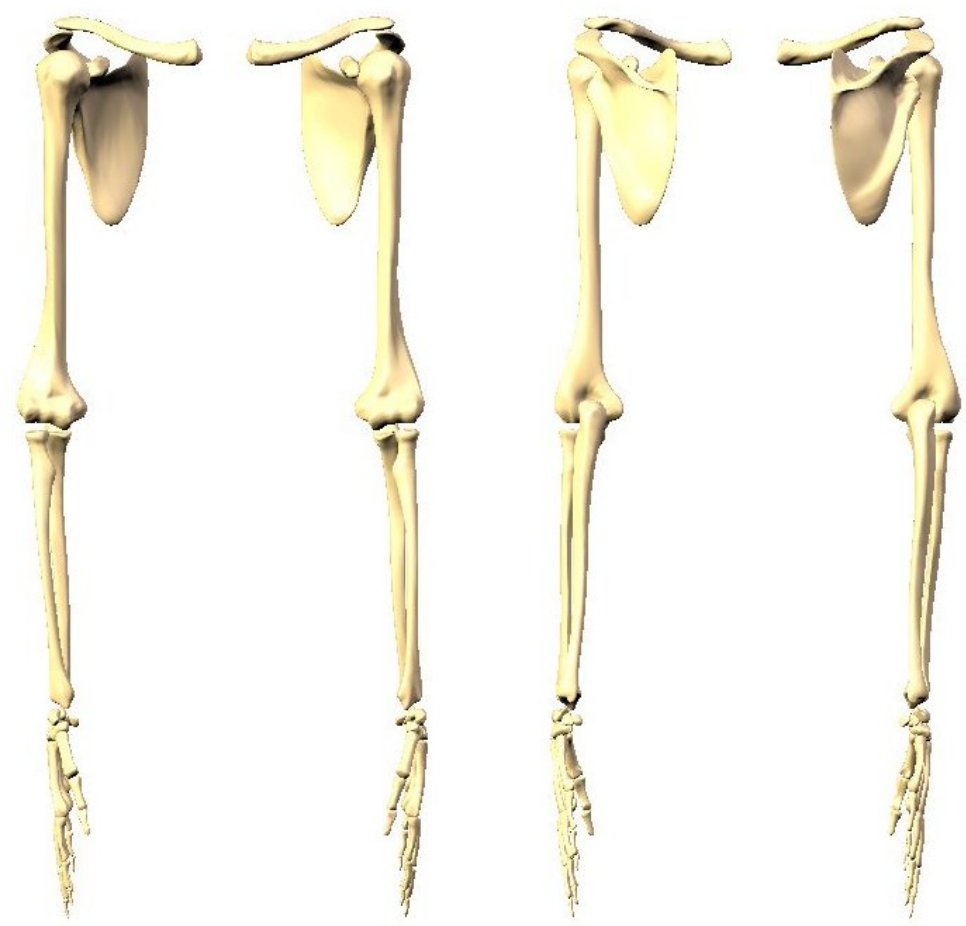

Figura 4.2: Visualização anterior e posterior do modelo tridimensional dos membros superiores.

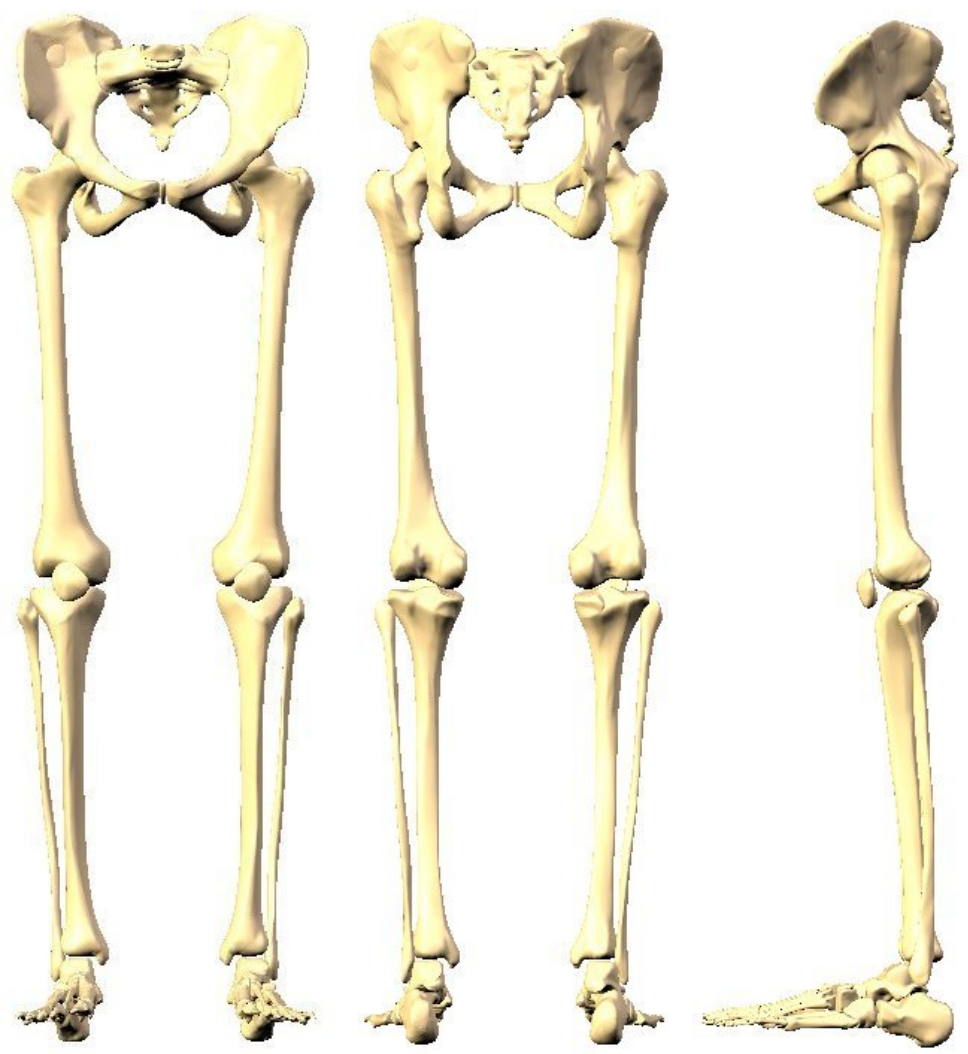

Figura 4.3: Visualização anterior, posterior e lateral do modelo tridimensional dos membros inferiores. 


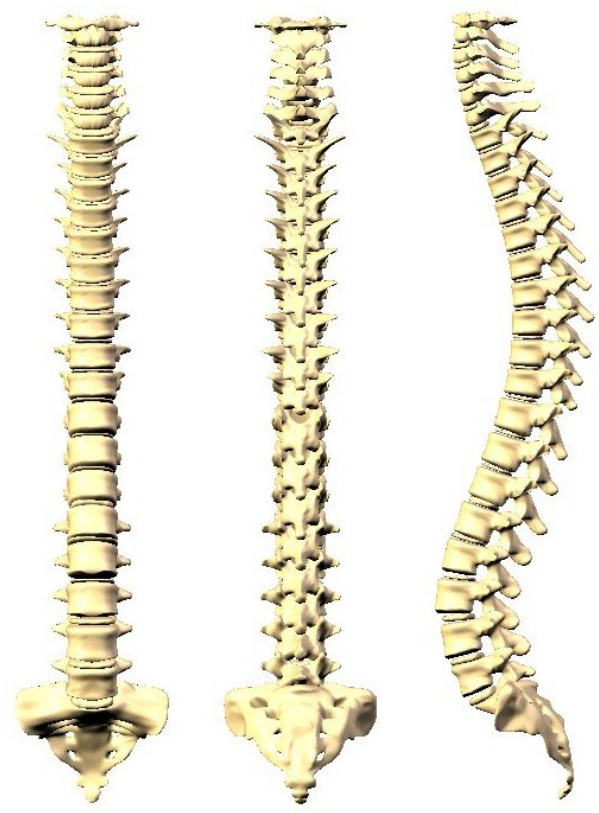

Figura 4.4: Visualização anterior, posterior e lateral do modelo tridimensional da espinha dorsal.
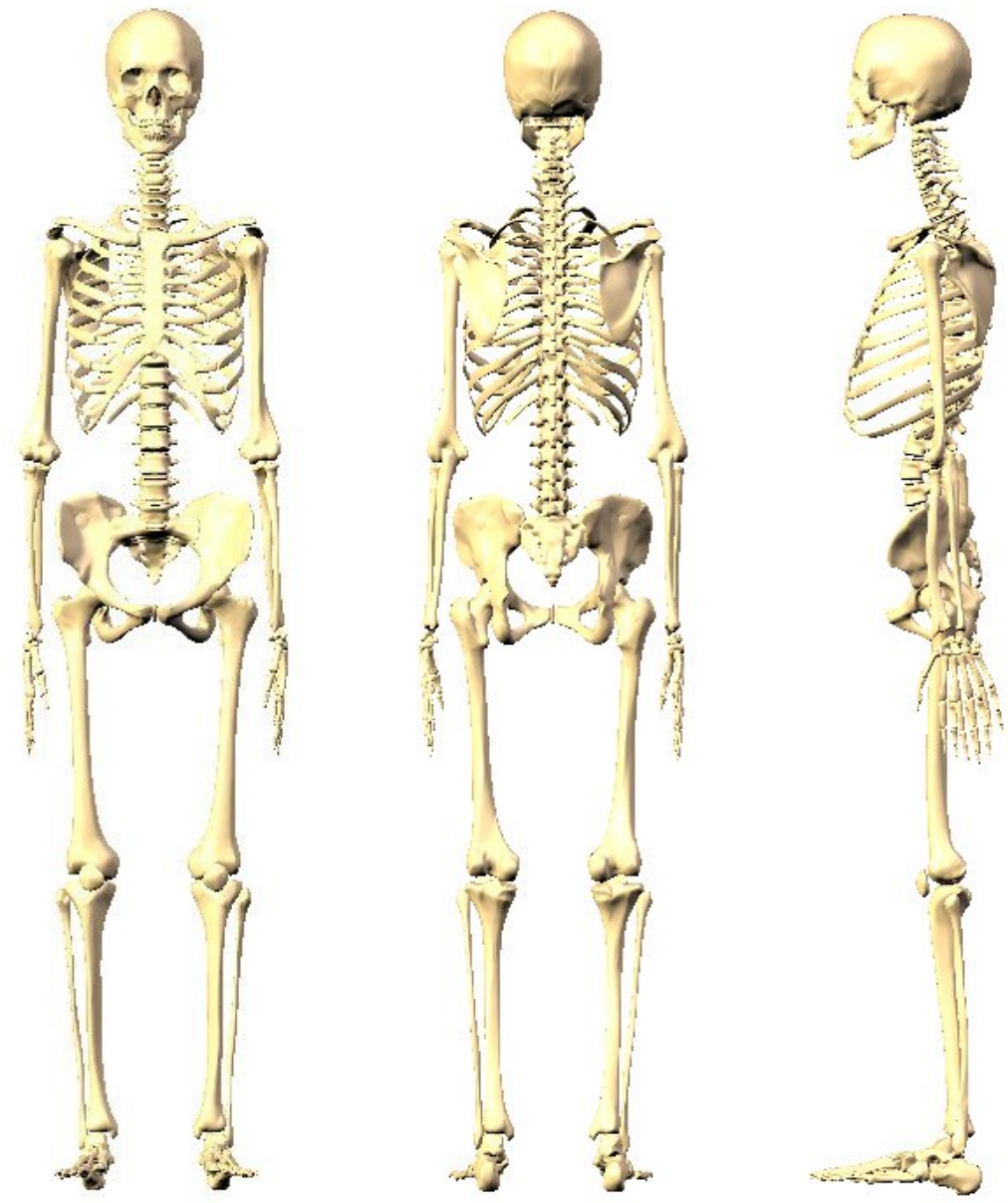

Figura 4.5: Visualização anterior, posterior e lateral do modelo tridimensional completo do esqueleto. 


\subsection{Modelo Tridimensional da Pele}

Foi modelada a anatomia externa do corpo humano, atuando como uma espécie de "pele". A Figura 4.6 mostra a visualização anterior, posterior e lateral do modelo tridimensional da pele que representa um indivíduo com altura e peso proporcionais e a Figura 4.7 mostra as mesmas projeções para um indivíduo com altura e peso desproporcionais devido a maior quantidade de tecido adiposo.

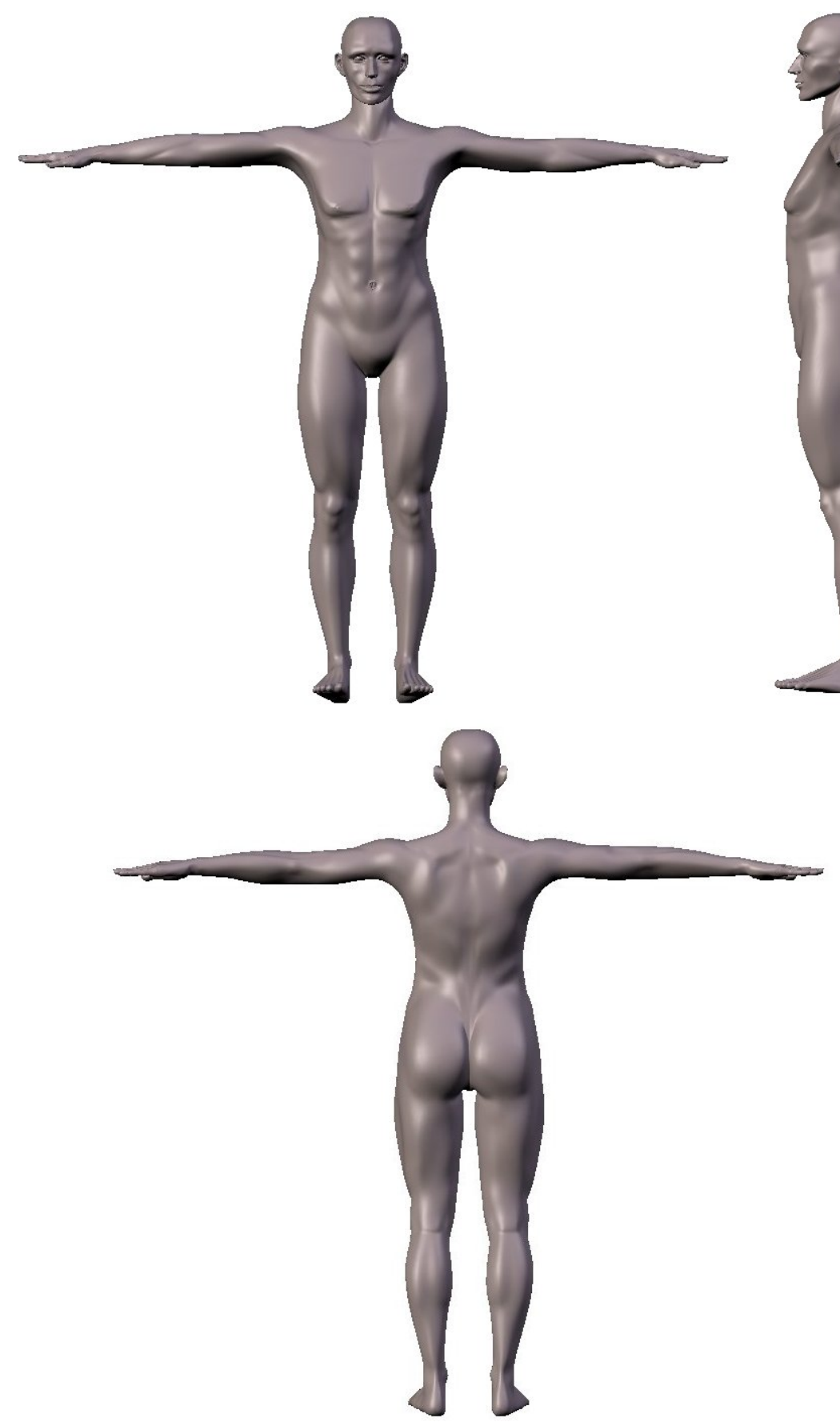

Figura 4.6: Visualização anterior, posterior e lateral do modelo tridimensional da pele de um indivíduo com altura e peso proporcionais. 


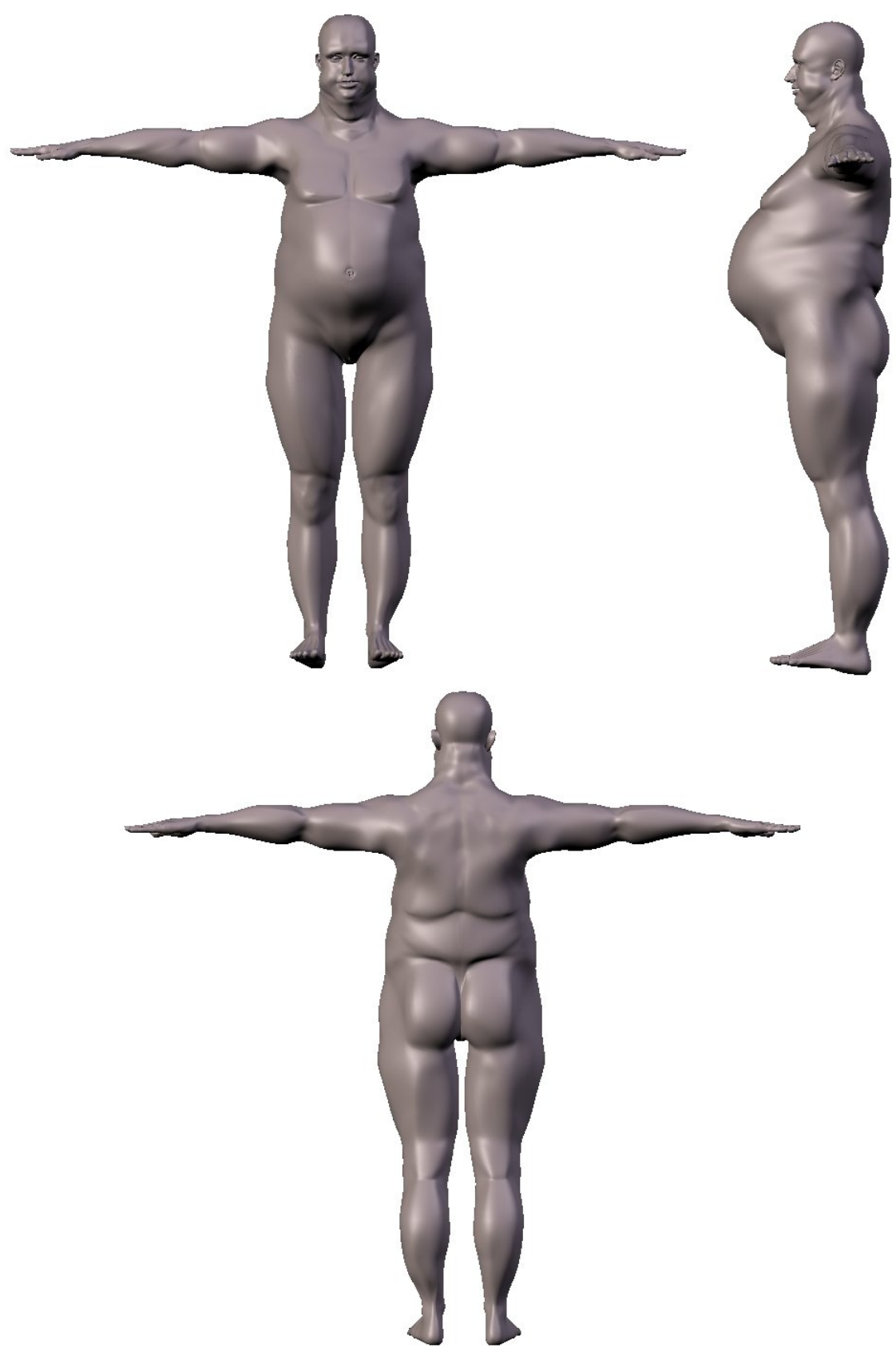

Figura 4.7: Visualização anterior, posterior e lateral do modelo tridimensional da pele de um indivíduo com altura e peso desproporcionais em função da quantidade de tecido adiposo.

\subsection{Modelos Tridimensionais dos Órgãos}

A Figura 4.8 mostra a visualização anterior, posterior e lateral do modelo tridimensional do pulmão.

A Figura 4.9 mostra a visualização anterior, posterior e lateral do modelo tridimensional do sistema gastro-intestinal. 


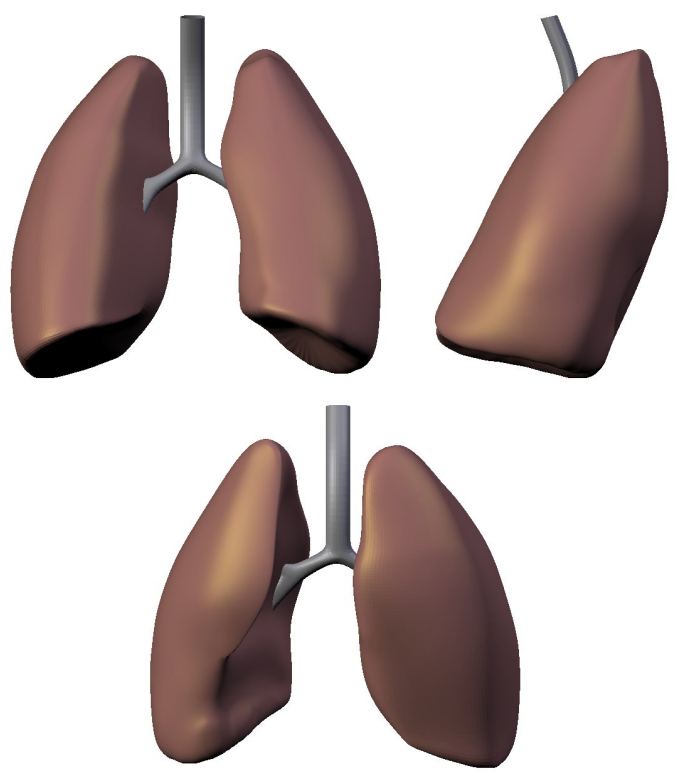

Figura 4.8: Visualização anterior, posterior e lateral do modelo tridimensional do pulmão.
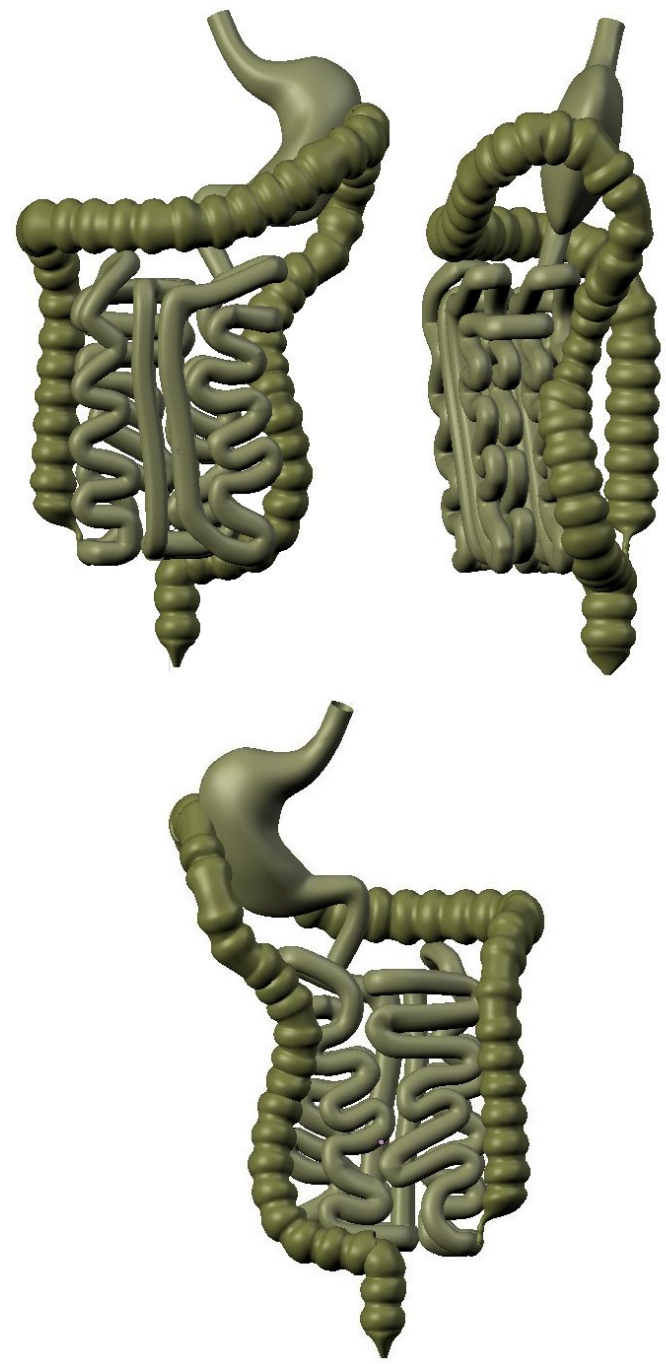

Figura 4.9: Visualização anterior, posterior e lateral do modelo tridimensional do sistema gastro-intestinal. 


\subsubsection{Pulmões, Coração, Fígado, Estômago, Pâncreas, Rins, Intestino Grosso, Intestino Delgado e Bexiga}

A Figura 4.10 mostra a visualização anterior, posterior e lateral dos modelos tridimensionais dos pulmões, coração, fígado, estômago, pâncreas, rins, intestino grosso, intestino delgado e bexiga.

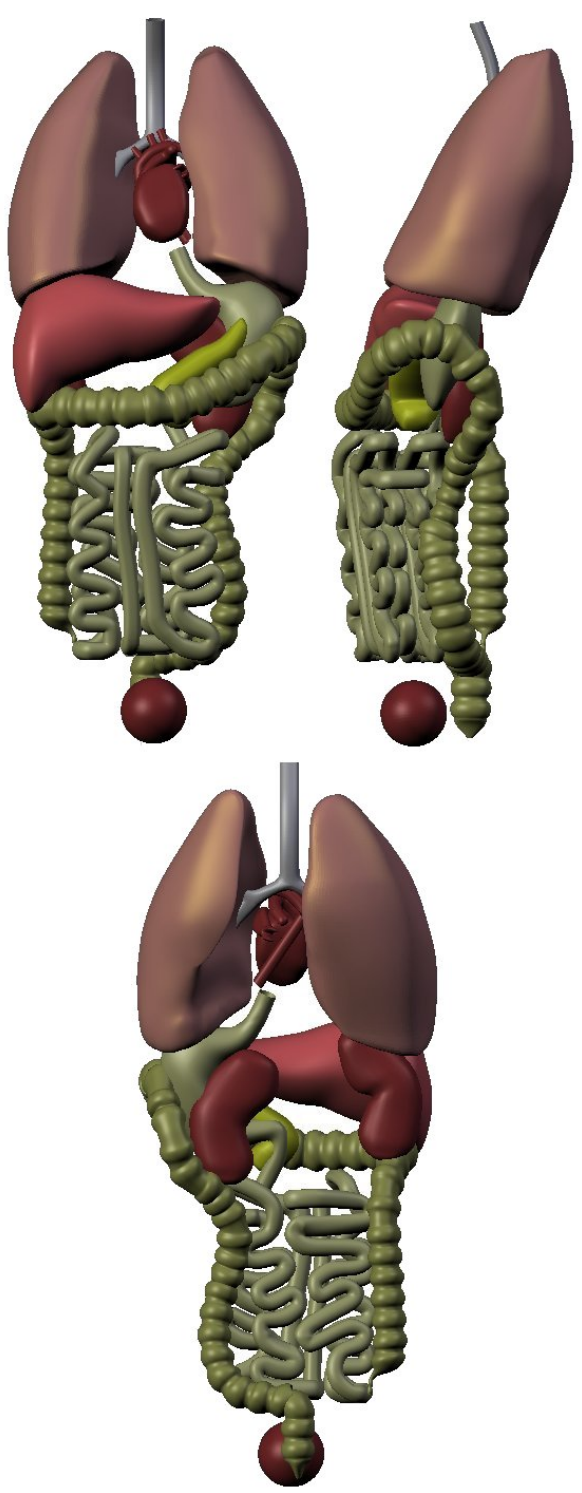

Figura 4.10: Visualização anterior, posterior e lateral dos modelos tridimensionais dos órgãos presentes no corpo humano.

\subsection{Variações Anatômicas}

Para evidenciar claramente os efeitos que as diferenças anatômicas entre os indivíduos provocam nas imagens radiológicas, em especial, a região do intestino, foram simuladas as 
variações mais comuns do seu formato.

Para demonstrar a versatilidade da metodologia empregada no desenvolvimento das estruturas retratadas, o modelo do intestino grosso classificado como "normal" na literatura, Figura 4.11(a) foi modificado de modo a representar: Forma de serpente, Figura 4.11(b); Forma de "u”, Figura 4.11(c); Forma de “v”, Figura 4.11(d).
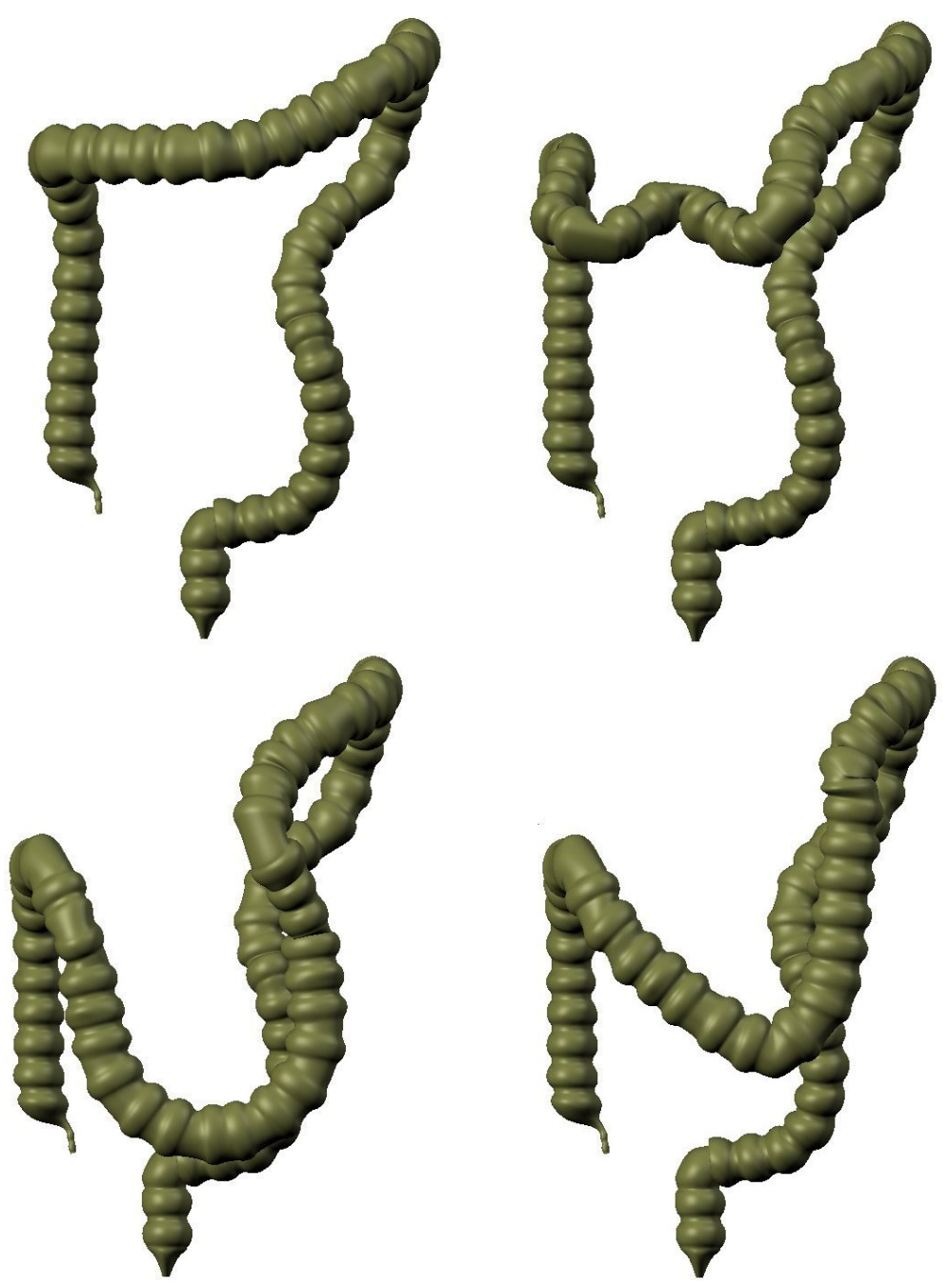

Figura 4.11: Visualização frontal do modelo do intestino em formato "normal".

\subsection{Modelos Completos}

"Modelos completos", que contemplam todas as estruturas apresentadas nas seções anteriores foram desenvolvidos. O primeiro, com peso e altura proporcionais e o segundo, com peso e altura desproporcionais em função da quantidade de tecido adiposo. Para cada um desse modelos, foram gerados mais três novos modelos completos, que diferem-se entre si em função da representação da variação de formato do intestino grosso. 
65
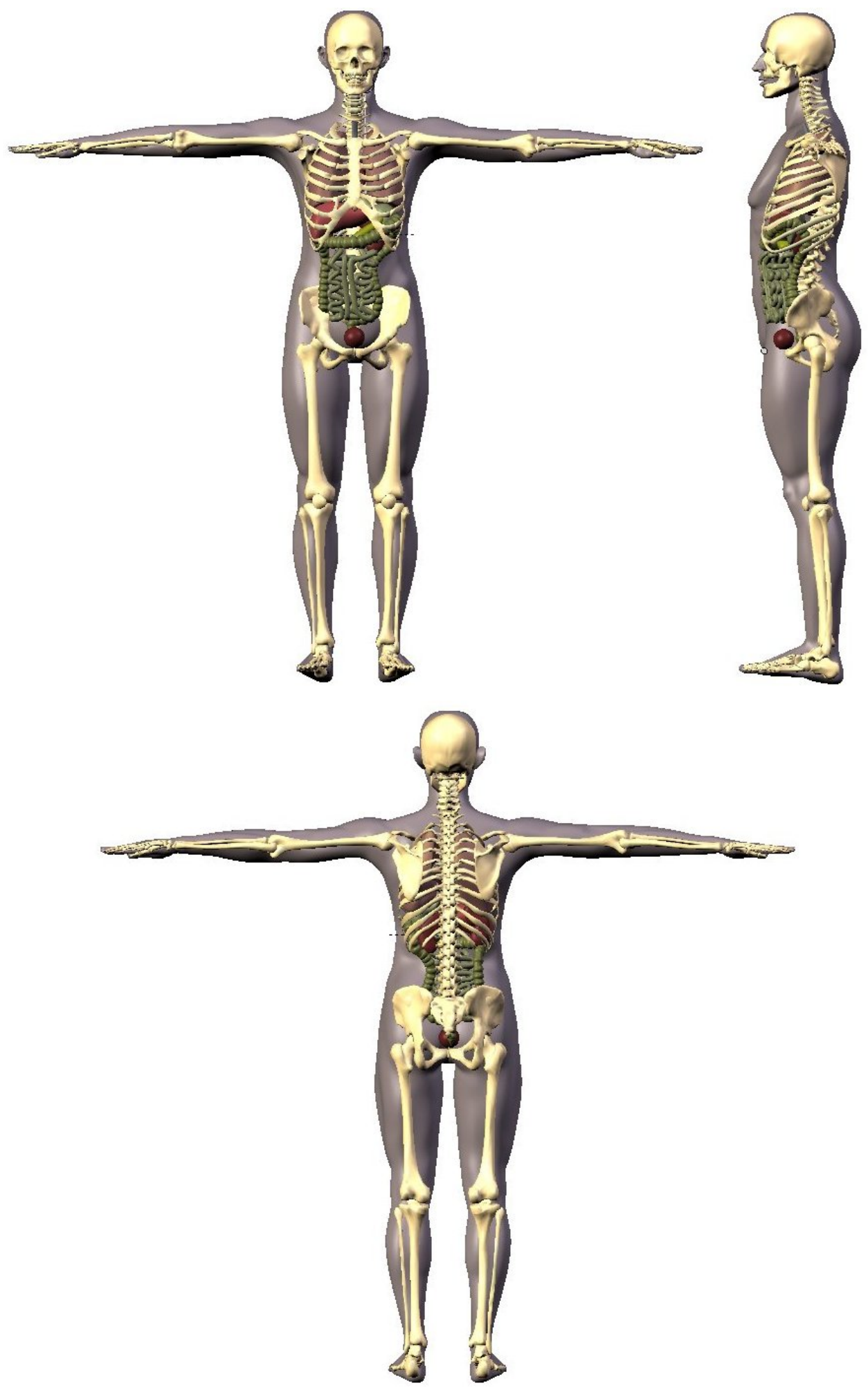

Figura 4.12: Visualização frontal, lateral e posterior do modelo tridimensional completo do corpo humano com peso e altura proporcionais. 

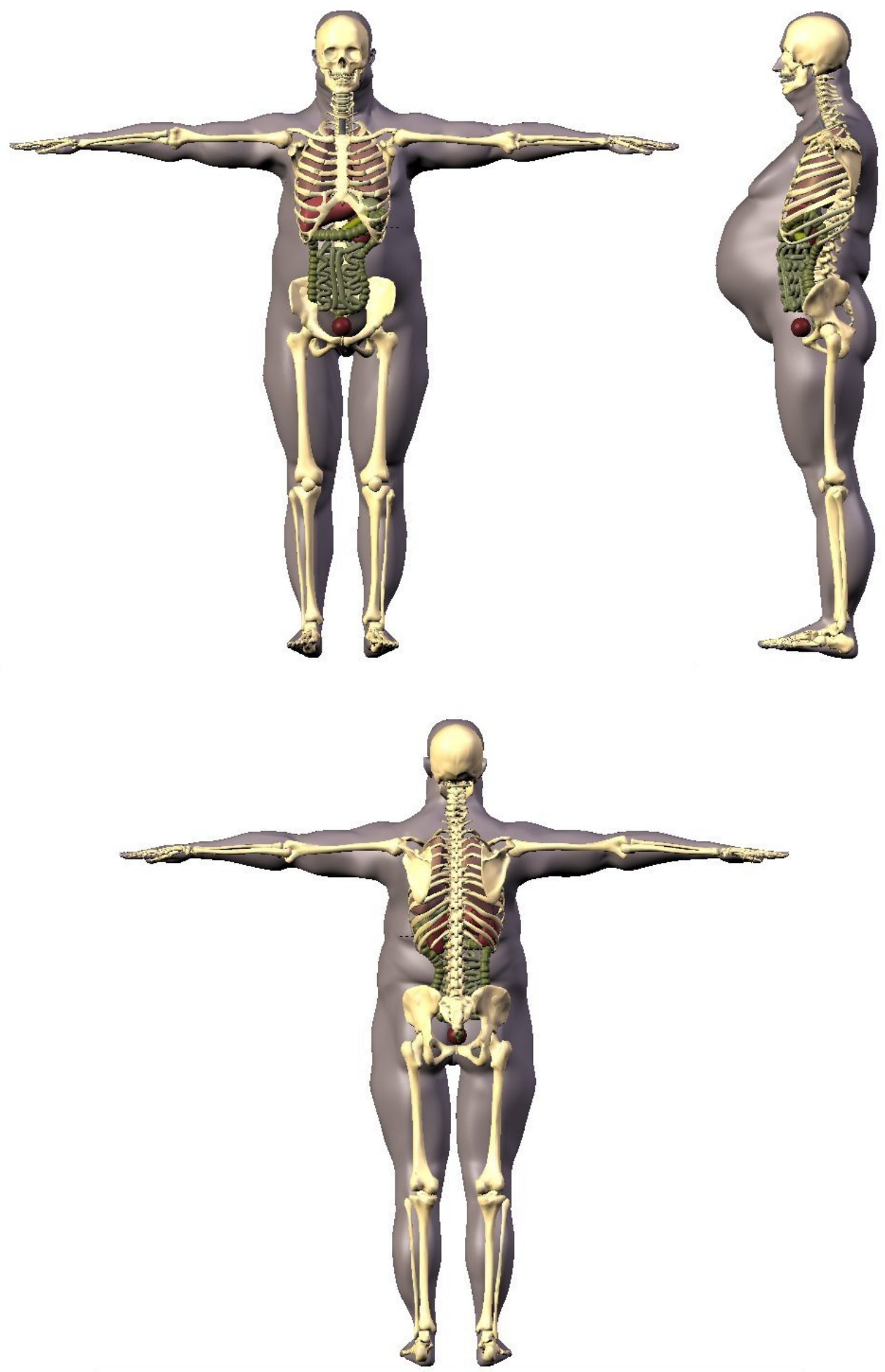

Figura 4.13: Visualização frontal, lateral e posterior do modelo tridimensional completo do corpo humano com peso e altura desproporcionais em função da quantidade de tecido adiposo. 


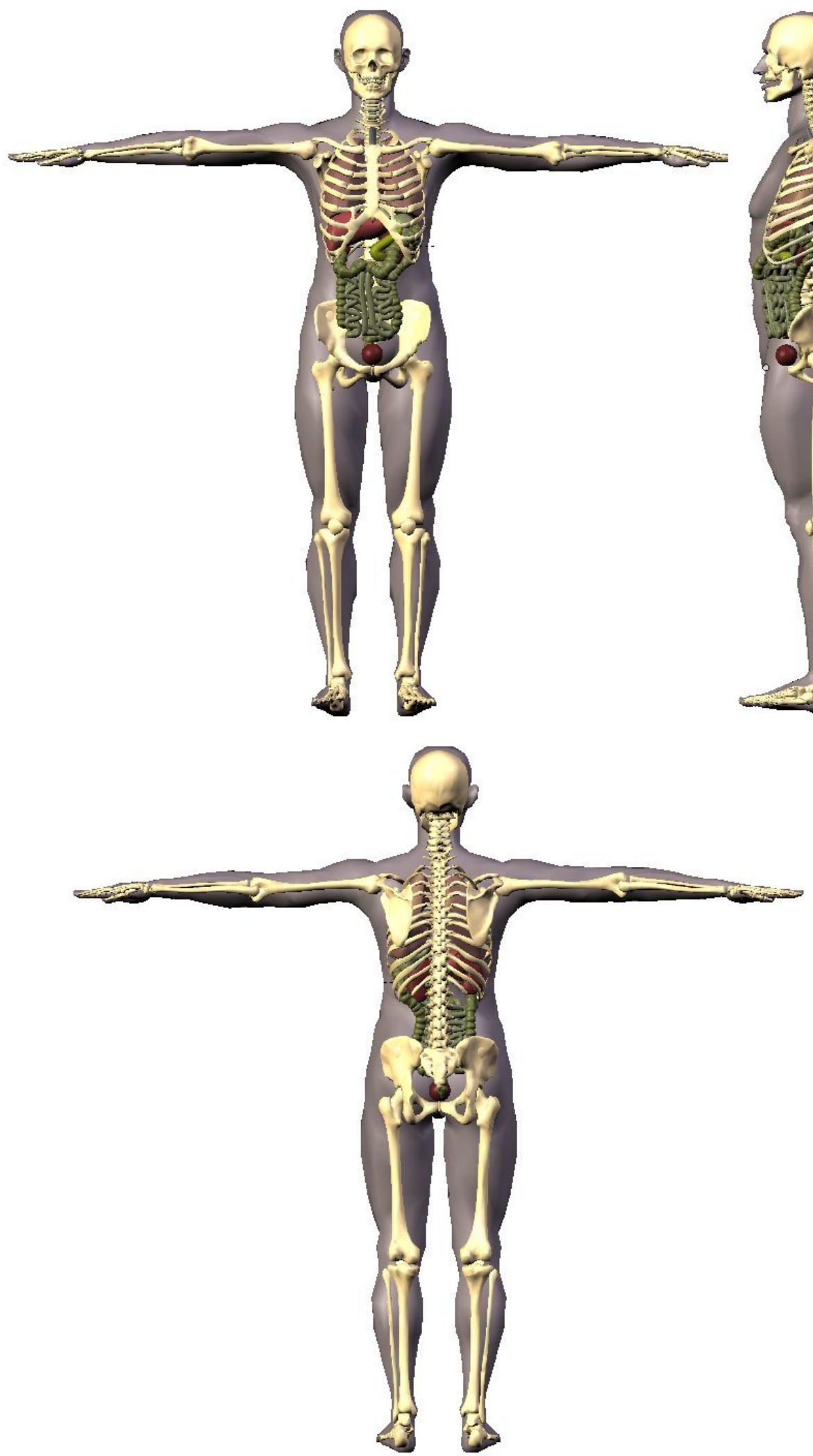

Figura 4.14: Visualização frontal do modelo tridimensional completo do corpo humano com peso e altura proporcionais e intestino em formato de serpente. 


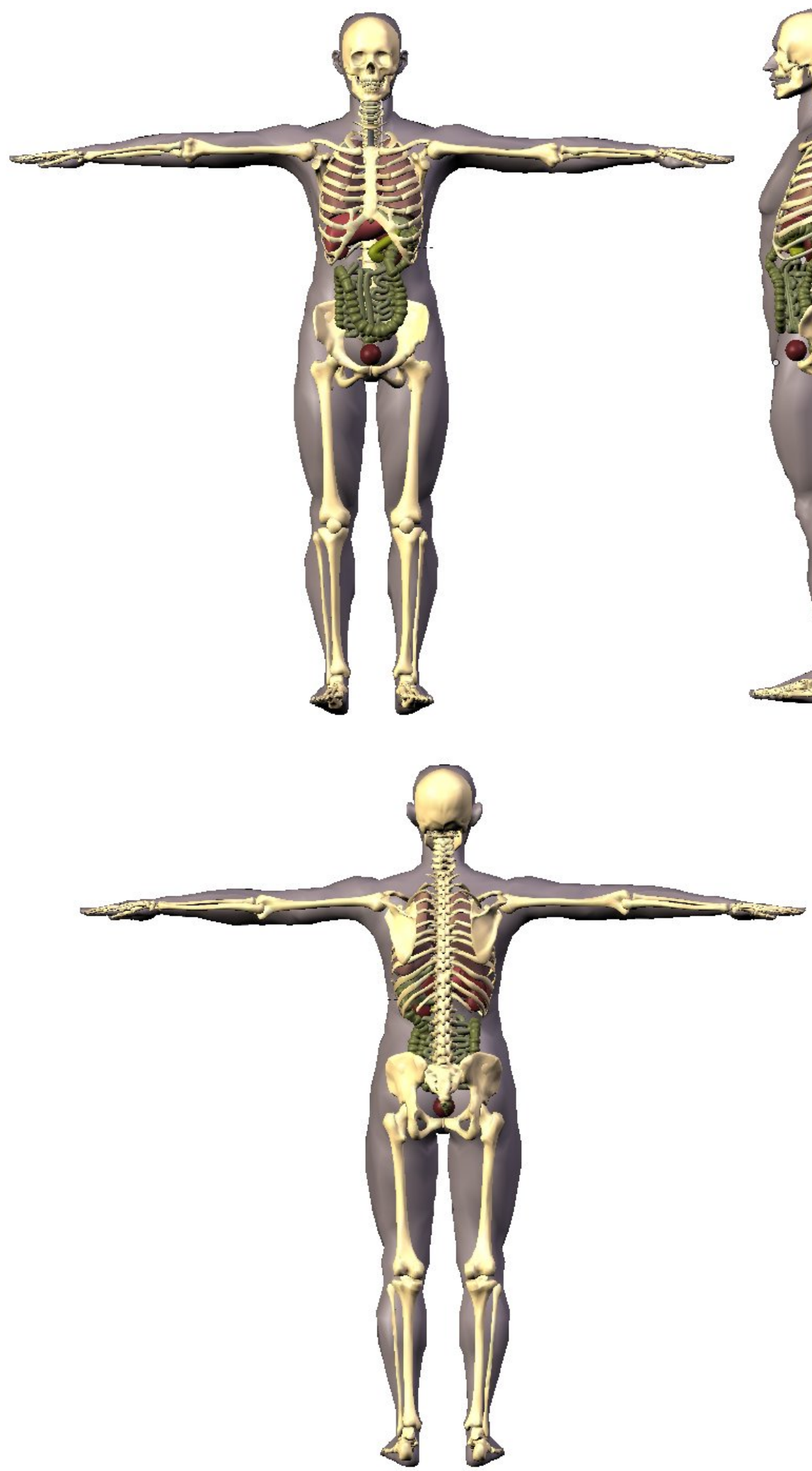

Figura 4.15: Visualização frontal do modelo tridimensional completo do corpo humano com peso e altura proporcionais e intestino em formato de "U". 

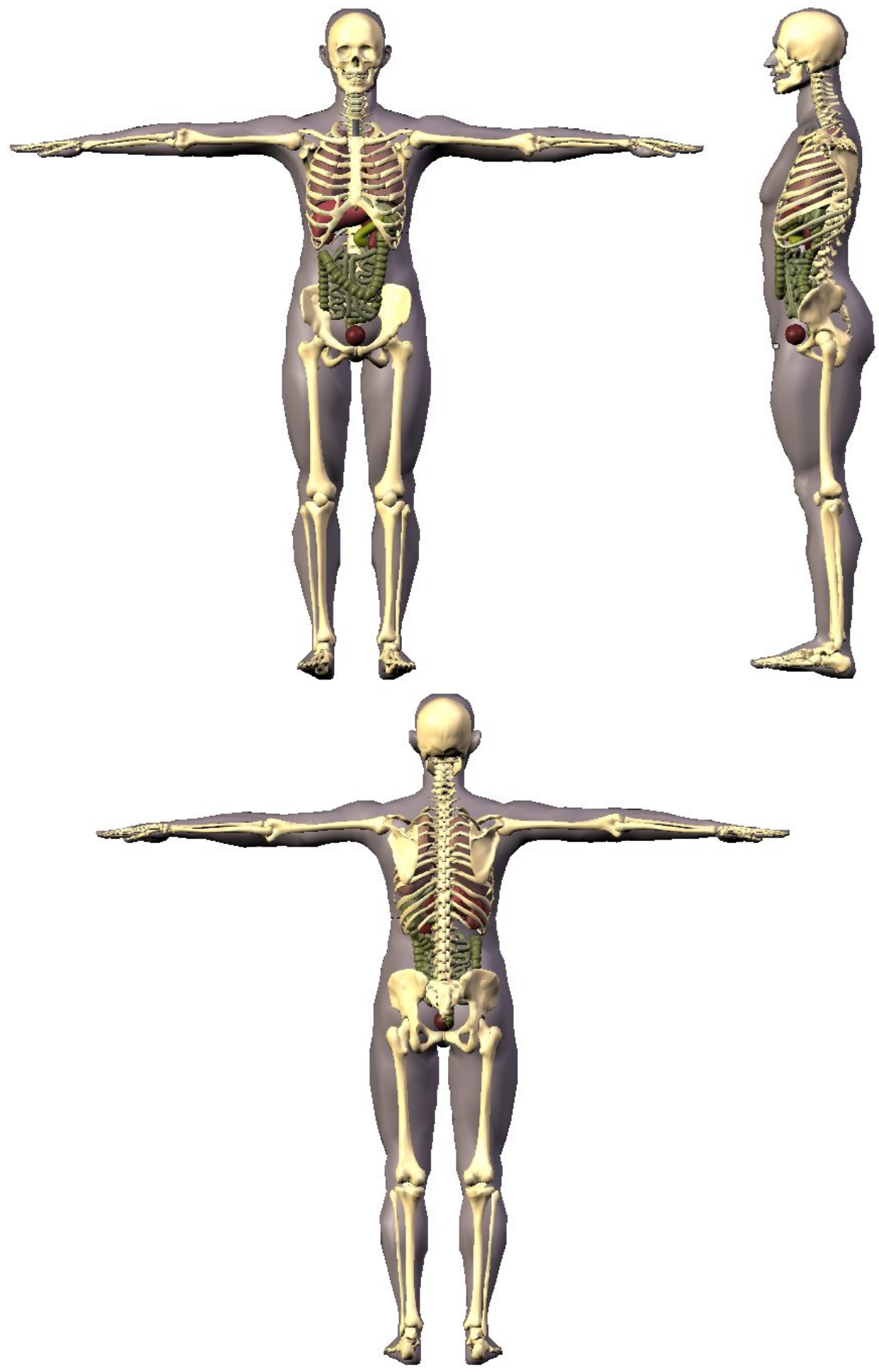

Figura 4.16: Visualização frontal/s do modelo tridimensional completo do corpo humano com peso e altura proporcionais e intestino em formato de "V". 
70
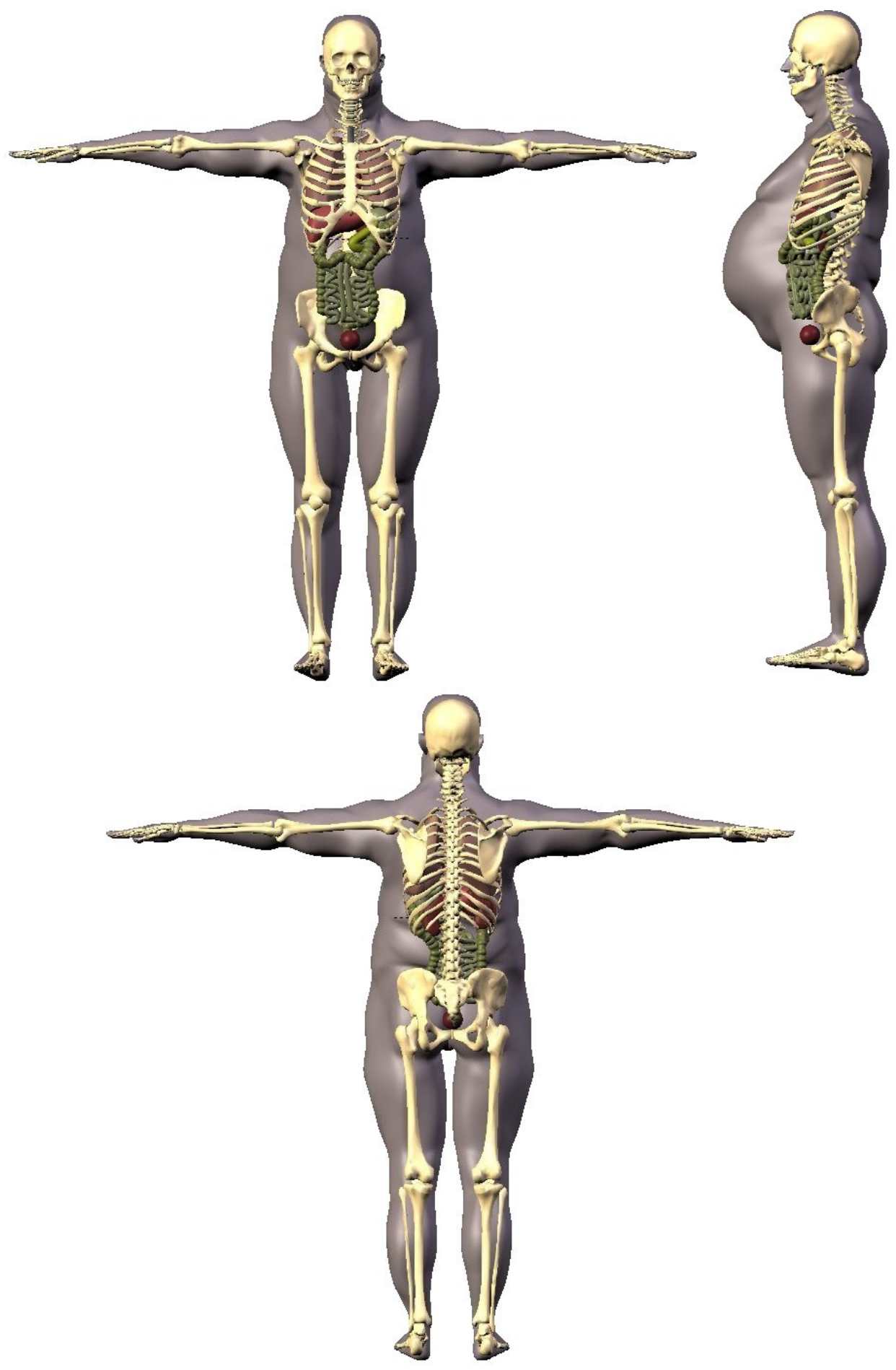

Figura 4.17: Visualização frontal do modelo tridimensional completo do corpo humano com peso e altura desproporcionais em função da quantidade de tecido adiposo e intestino em formato de serpente. 


$$
\frac{\pi}{\pi}
$$




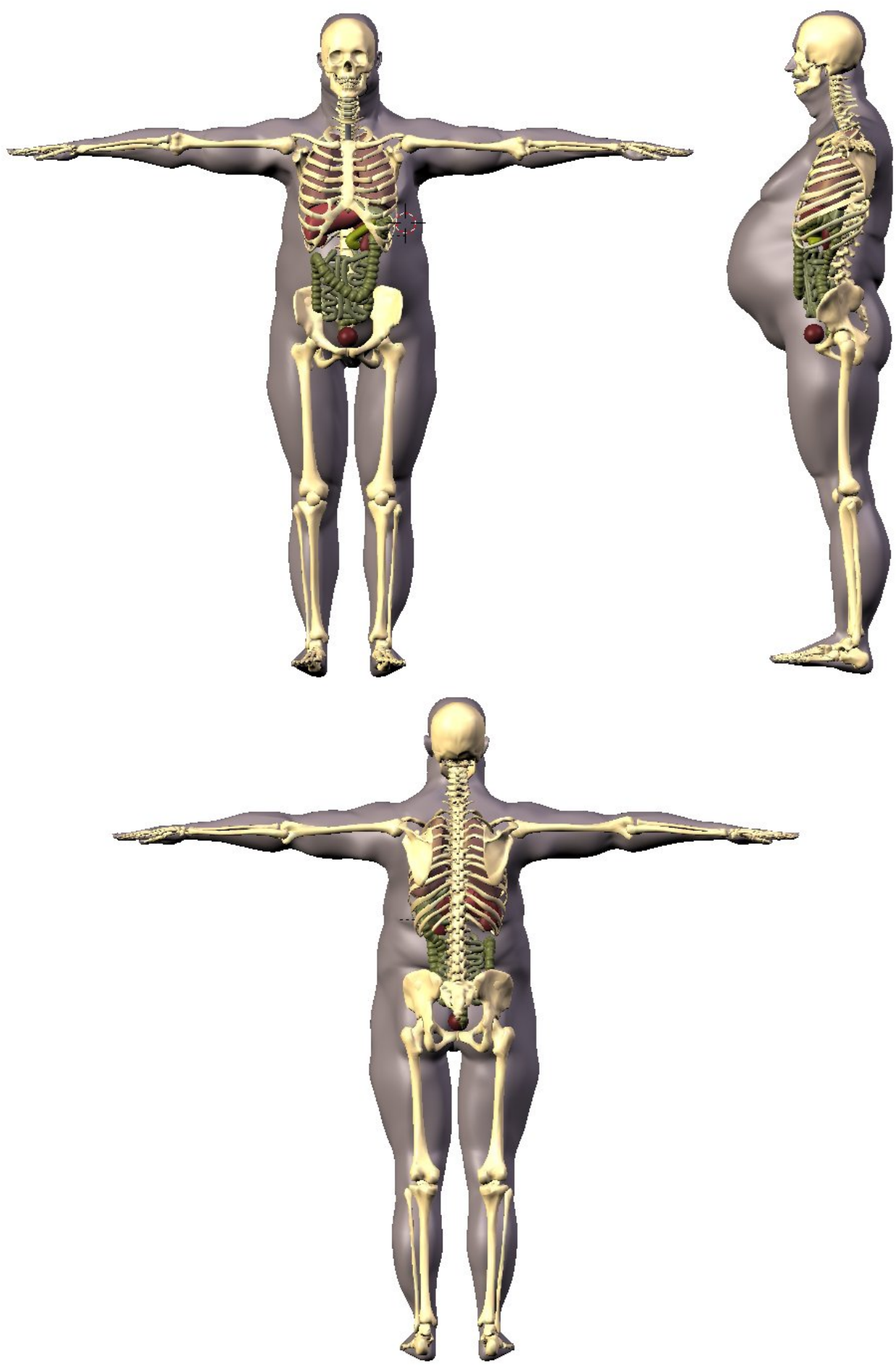

Figura 4.19: Visualização frontal do modelo tridimensional completo do corpo humano com peso e altura desproporcionais em função da quantidade de tecido adiposo e intestino em formato de "V". 


\subsection{Validação dos Modelos por Subtração de Imagens}

Para facilitar a visualização, binarizamos as imagens geradas a partir dos modelos tridimensionais e mantivemos os modelos digitalizados com as cores originais.
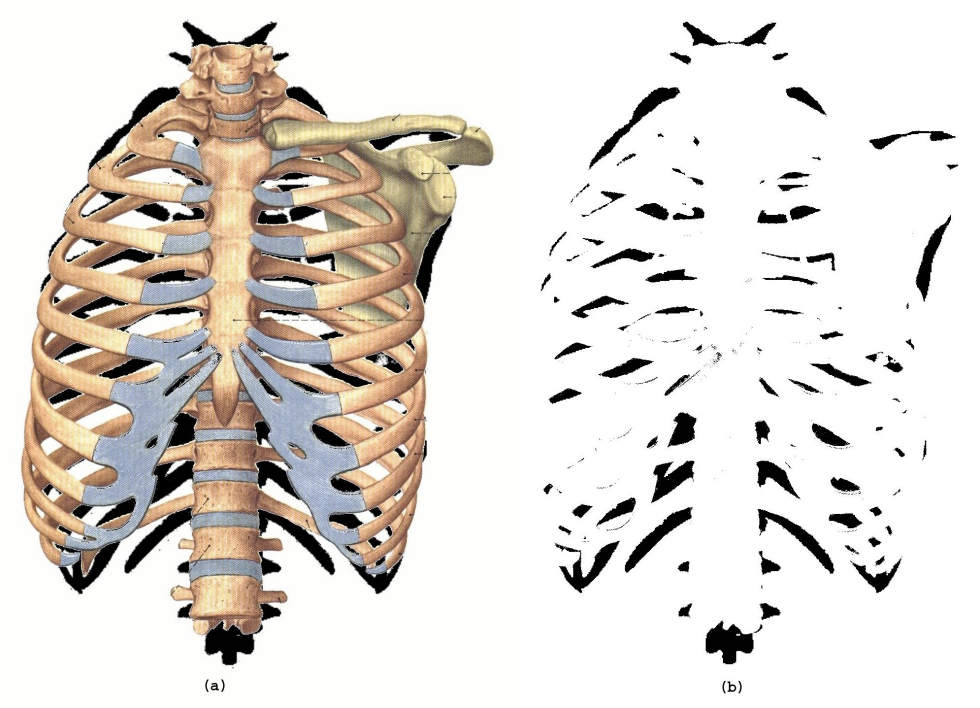

Figura 4.20: (a) Imagem frontal da caixa torácica obtida em um atlas anatômico sobreposta à malha que a representa em nosso modelo. (b) Operação de subtração entre a imagem obtida em um atlas anatômico e a imagem da malha de nosso modelo.

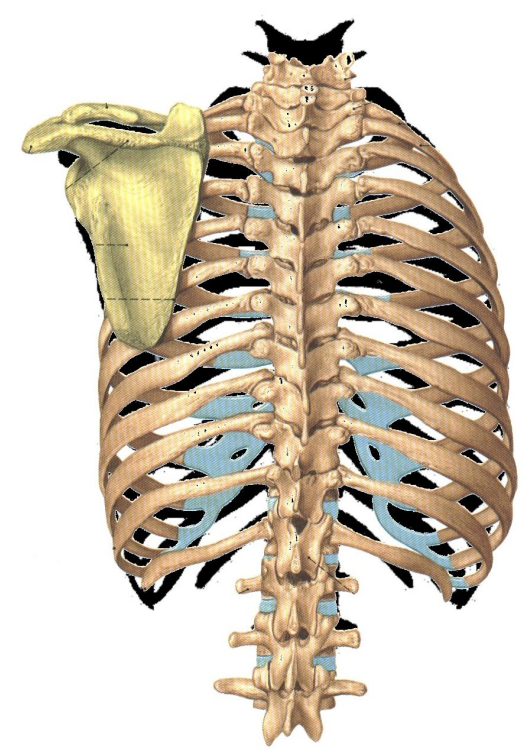

(a)

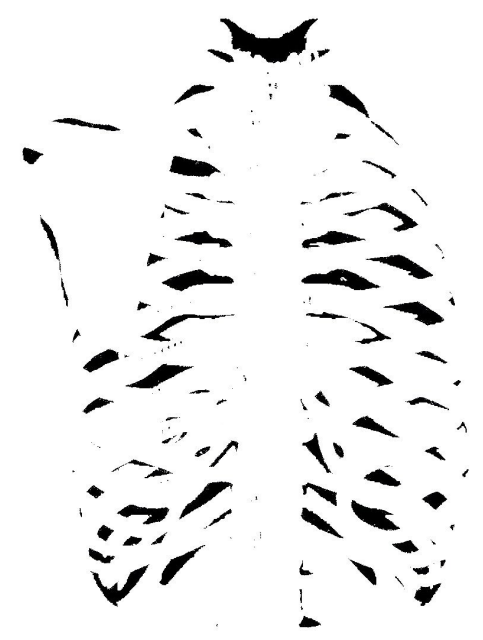

(b)

Figura 4.21: (a) Imagem posterior da caixa torácica obtida em um atlas anatômico sobreposta à malha que a representa em nosso modelo. (b) Operação de subtração entre a imagem obtida em um atlas anatômico e a imagem da malha de nosso modelo. 

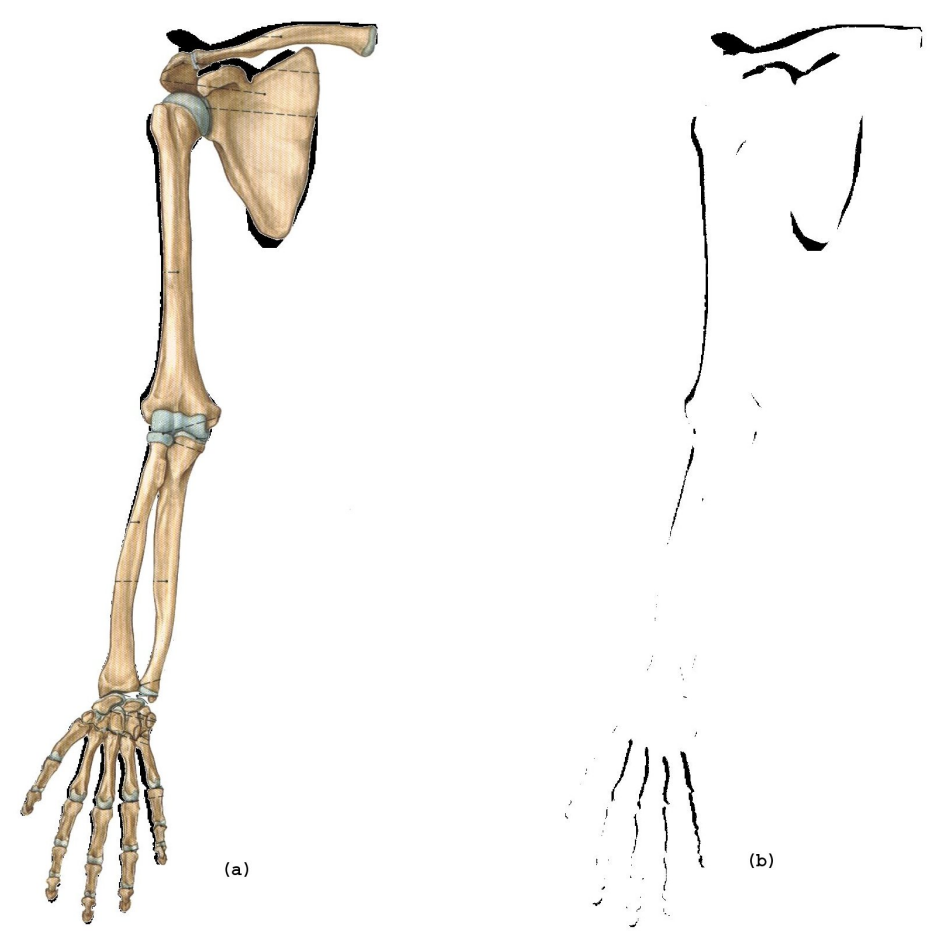

Figura 4.22: (a) Imagem frontal dos membros superiores obtida em um atlas anatômico sobreposta à malha que a representa em nosso modelo. (b) Operação de subtração entre a imagem obtida em um atlas anatômico e a imagem da malha de nosso modelo.
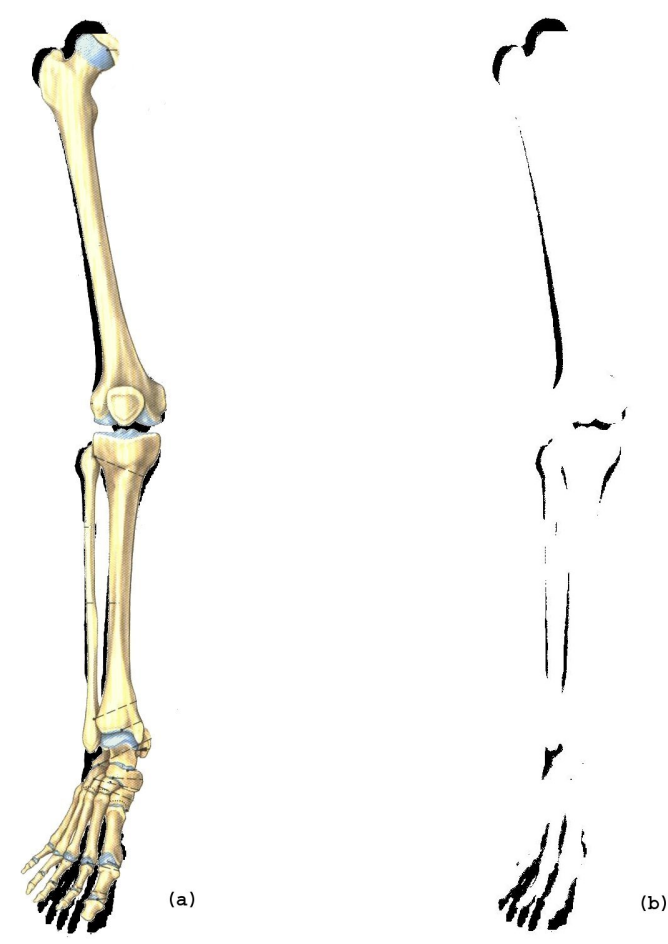

Figura 4.23: (a) Imagem frontal dos membros inferiores obtida em um atlas anatômico sobreposta à malha que a representa em nosso modelo. (b) Operação de subtração entre a imagem obtida em um atlas anatômico e a imagem da malha de nosso modelo. 
A tabela 4.1 apresenta os dados referentes à análise da concordância obtida pela sobreposição dos modelos com as imagens de atlas, sendo que a quantidade total de pixels é referente à estrutura de referência (os pixels que representam o fundo da imagem são desconsiderados) e a quantidade de pixels não correspondentes entre a imagem obtida no atlas anatômico e a imagem da malha da estrura equivalente é obtido por subtração entre as duas imagens;

Tabela 4.1: Dados referentes à análise quantitativa baseada em contagem de pixels realizada em nossos modelos.

\begin{tabular}{|l|l|l|l|}
\hline \multicolumn{1}{|c|}{ Estrutura retratada } & Qt. total de pixels & Qt. de pixels não correspondentes & Percentual \\
\hline Caixa torácica frontal & 737603 & 80303 & $10,88 \%$ \\
Caixa torácica posterior & 581940 & 57594 & $9,89 \%$ \\
Membros Superiores & 192136 & 15378 & $8 \%$ \\
Membros Inferiores & 117690 & 14299 & $12,14 \%$ \\
\hline \hline
\end{tabular}




\subsection{Validação dos Modelos por Comparação com Atlas Anatômico}

Inicialmente, comparamos os modelos gerados (4.25 e 4.27) com imagens do torso (4.24 e 4.26) obtidas em um atlas anatômico [Sobotta, 2000].

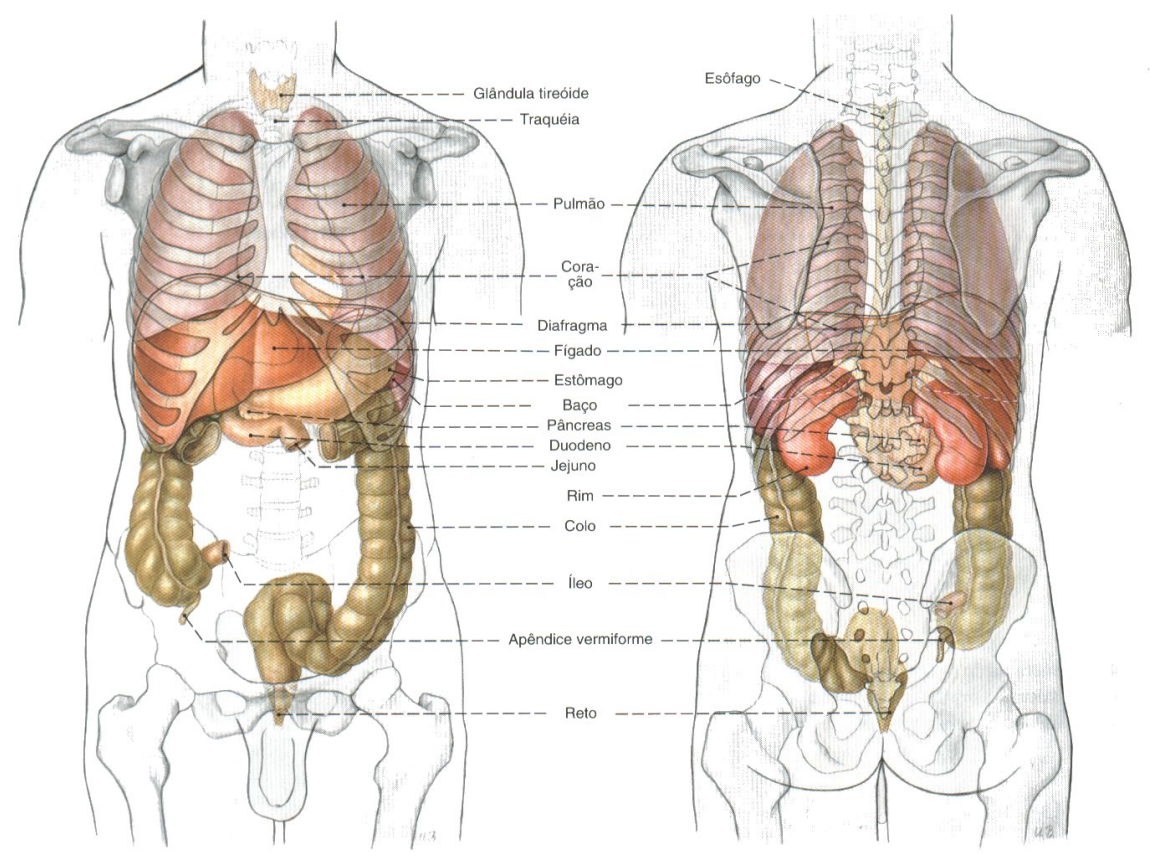

Figura 4.24: Imagem frontal e posterior do torso obtida em um atlas anatômico [Sobotta, 2000].
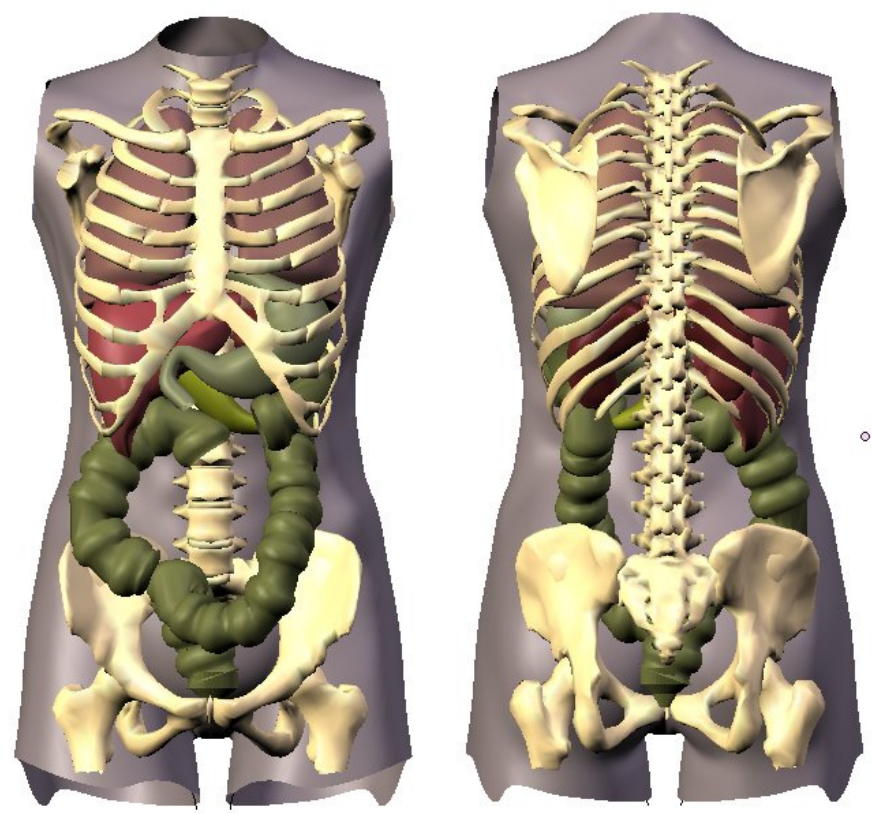

Figura 4.25: Imagem frontal e posterior da malha que representa o torso obtida em nosso modelo. 


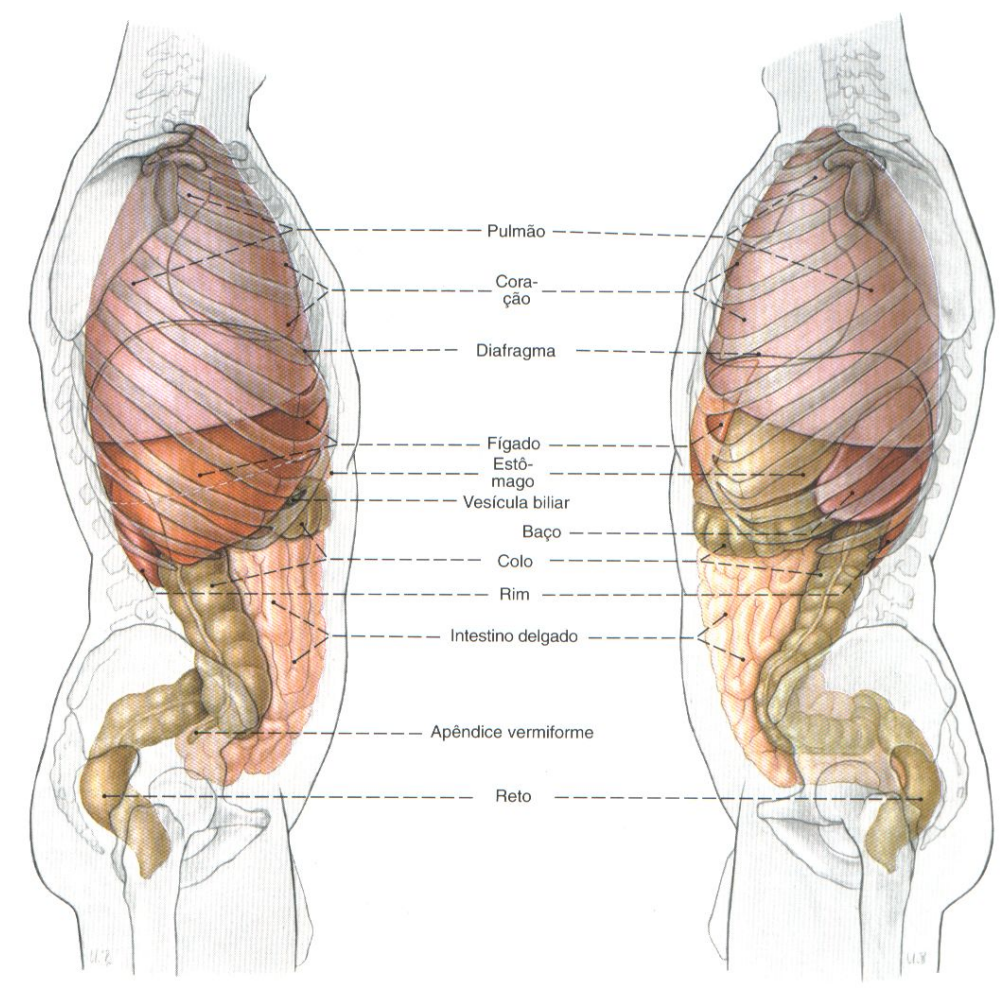

Figura 4.26: Imagem lateral do torso obtida em um atlas anatômico [Sobotta, 2000].
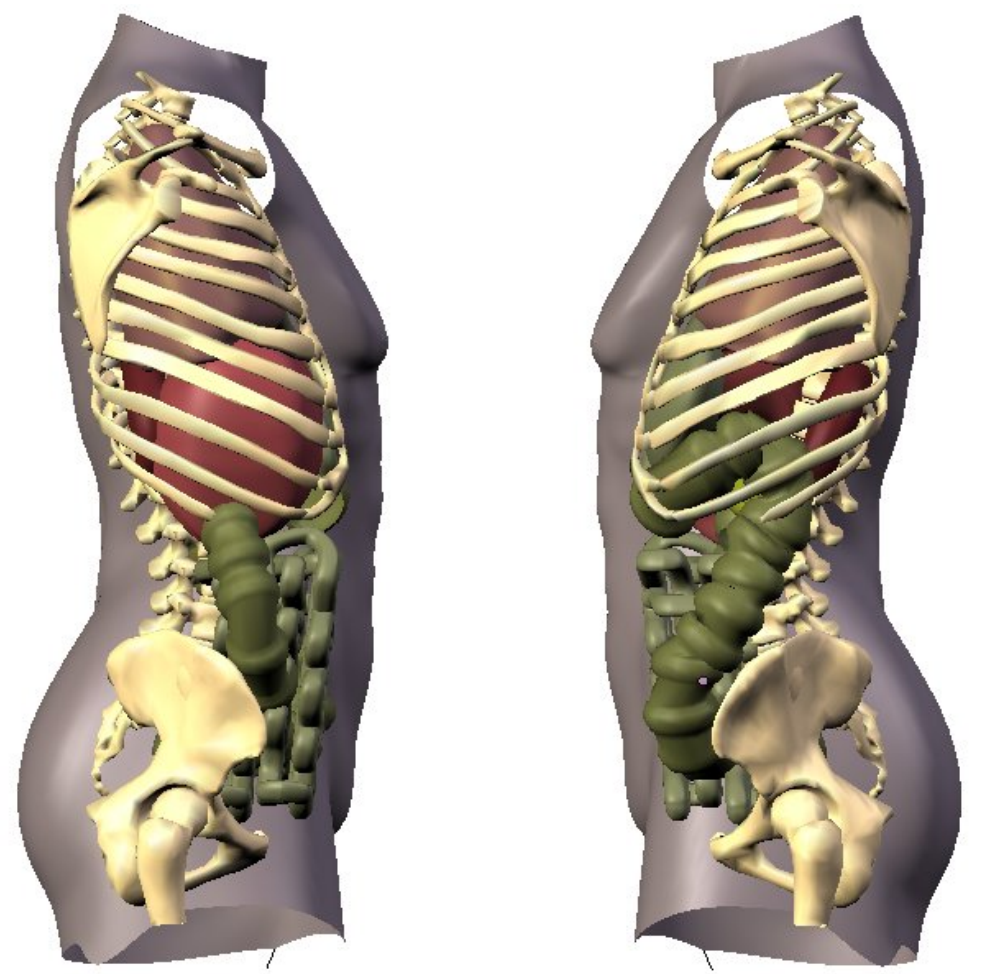

Figura 4.27: Imagem lateral da malha que representa o torso obtida em nosso modelo. 
Em seguida, comparamos as malhas referentes a modelos obesos (4.29 e 4.31) com imagens do torso de indivíduos normais, (4.28 e 4.30) obtidas em um atlas anatômico [Sobotta, 2000].

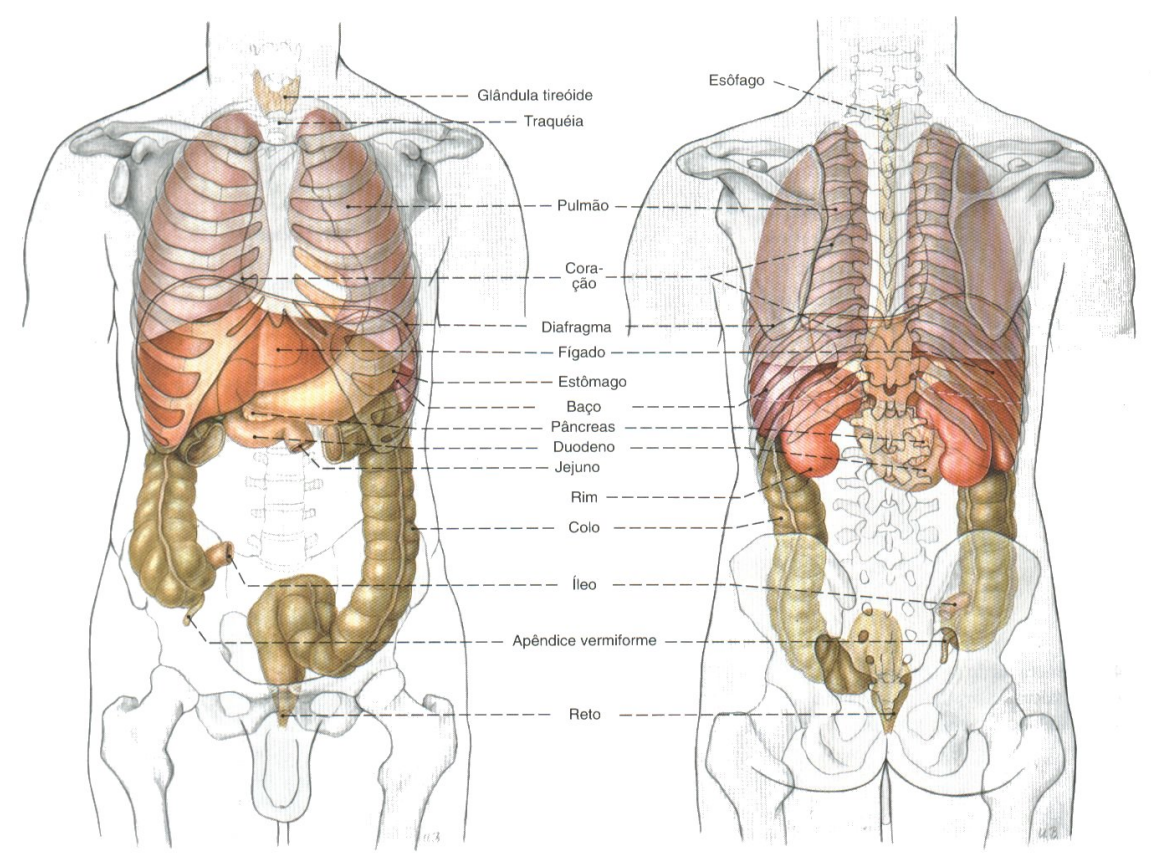

Figura 4.28: Imagem frontal e posterior do torso obtida em um atlas anatômico [Sobotta, 2000].
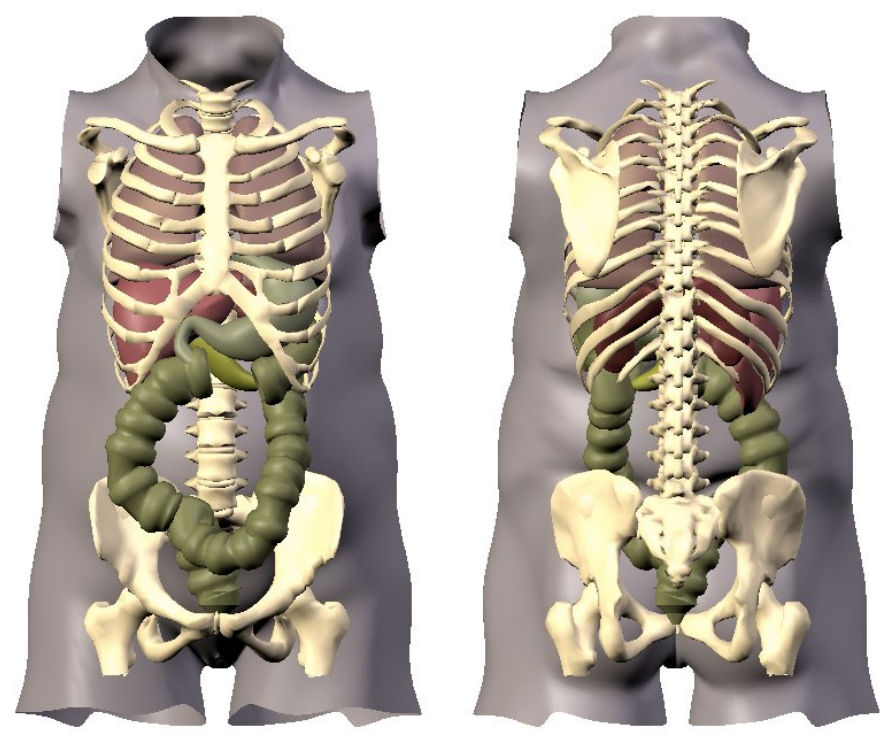

Figura 4.29: Imagem frontal e posterior da malha que representa o torso obtida em nosso modelo obeso. 


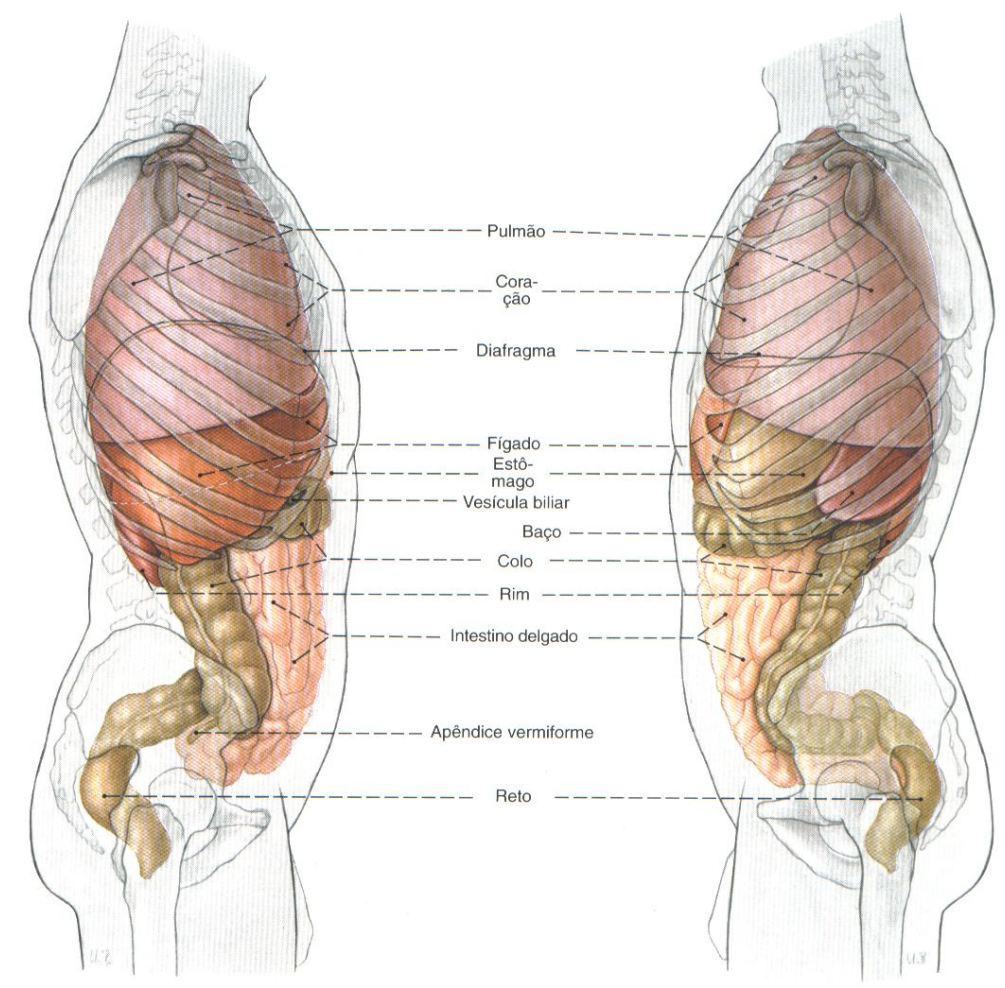

Figura 4.30: Imagem lateral do torso obtida em um atlas anatômico [Sobotta, 2000].
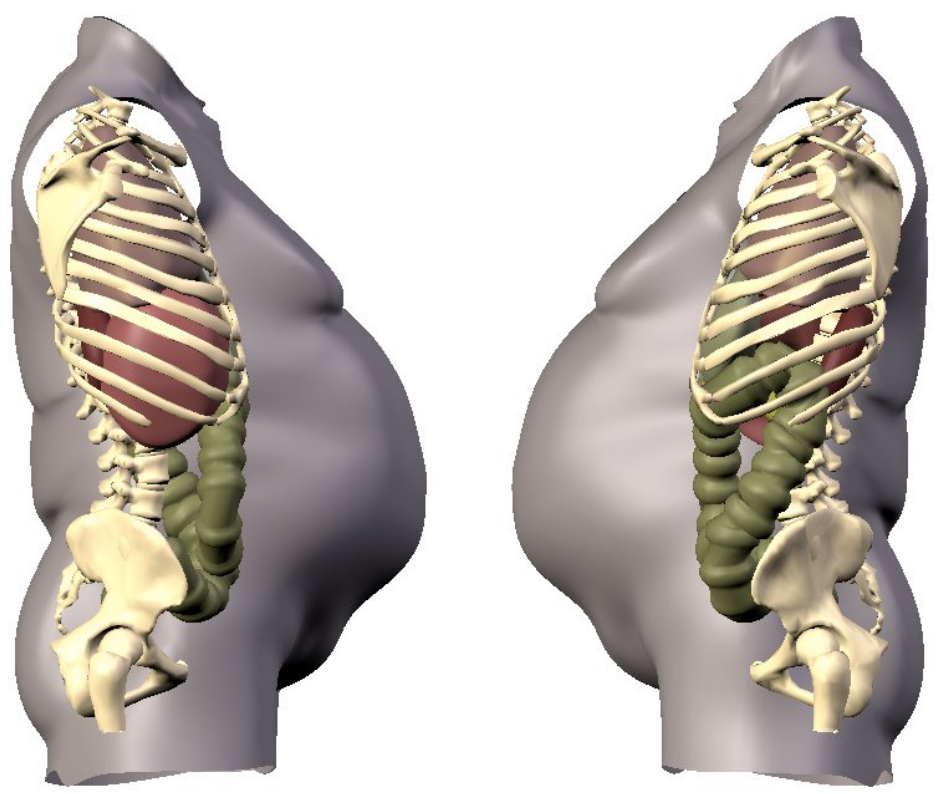

Figura 4.31: Imagem lateral da malha que representa o torso obtida em nosso modelo obeso. 


\subsubsection{Avaliação dos Modelos por Especialistas}

Os especialistas consideraram que $75 \%$ das representações estão boas e $25 \%$ satisfatórias.

\subsection{Validação das Imagens Simuladas por comparação com Imagens Radiográficas}

Geramos as imagens das Figuras 4.32 e 4.33 (imagens à esquerda) utilizando o algoritmo de simulação da fonte de raios-x e os modelos que representam um indíviduo com peso e altura proporcionais e o outro, com peso e altura desproporcionais em função da quantidade de tecido adiposo. Não consideramos as composições heterogêneas das estruturas radiografadas e o contraste radiográfico. Utilizamos um sistema de registro digital, sem considerar o conjunto écran-filme. Comparamos as imagens simuladas com imagens radiográficas de um indivíduo magro Figuras 4.32 e um obeso 4.33 (imagens à direita). Selecionamos regiões dessas imagens correspondentes às estruturas do intestino grosso $(\mathrm{A})$, delgado $(\mathrm{C})$, das regiões de sobreposição do primeiro sobre o segundo (D) e do osso (B). Calculamos a média de intensidade de níveis de cinza para cada uma dessas regiões. A tabela 1 apresenta a comparação dos níveis de cinza das estruturas representadas nos modelos proporcional e não proporcional e nos indivíduos gordo e magro.
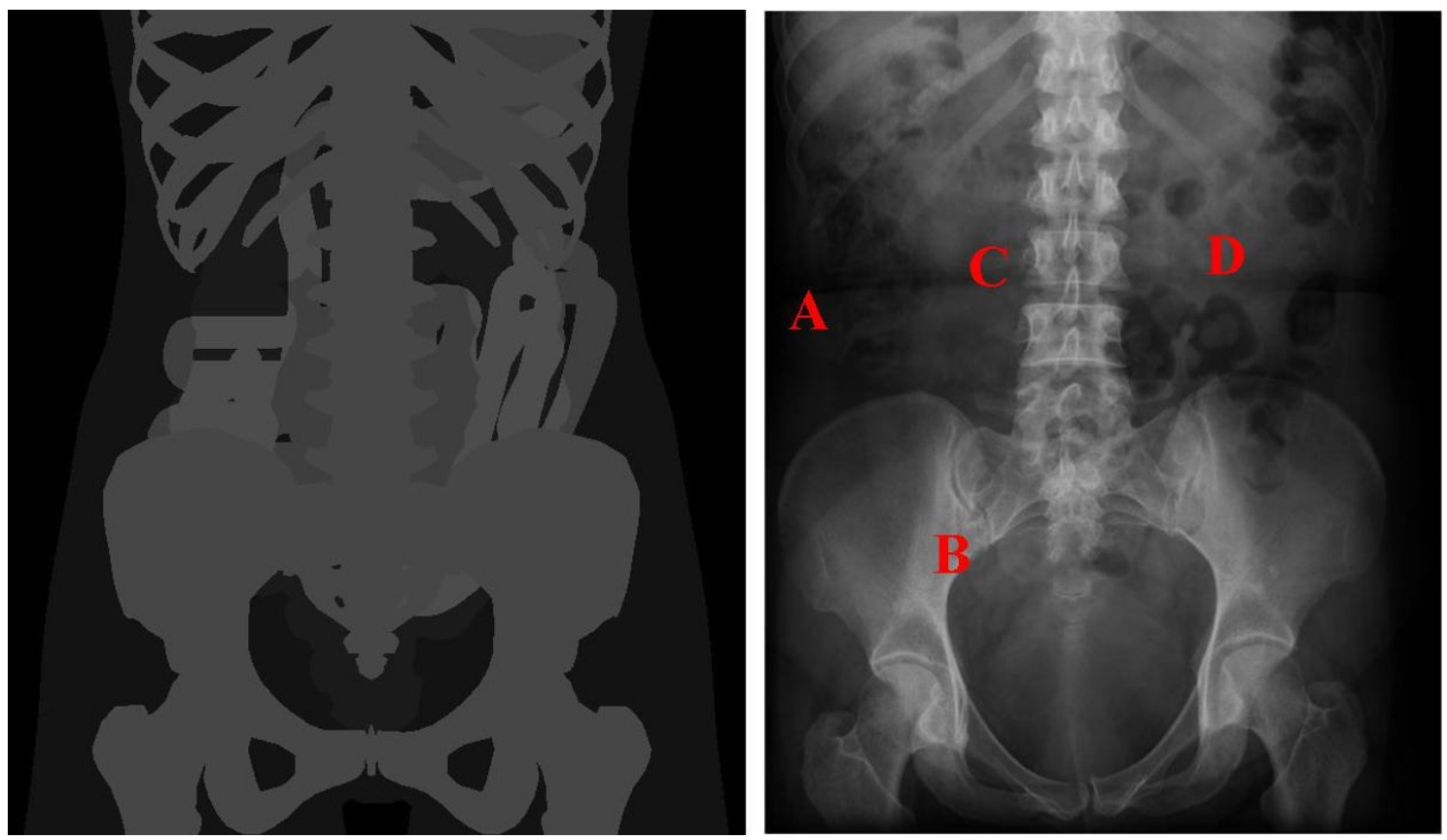

Figura 4.32: Imagem radiográfica simulada de um indivíduo com peso e altura proporcionais e imagem radiográfica real de um indivíduo com características semelhantes. 

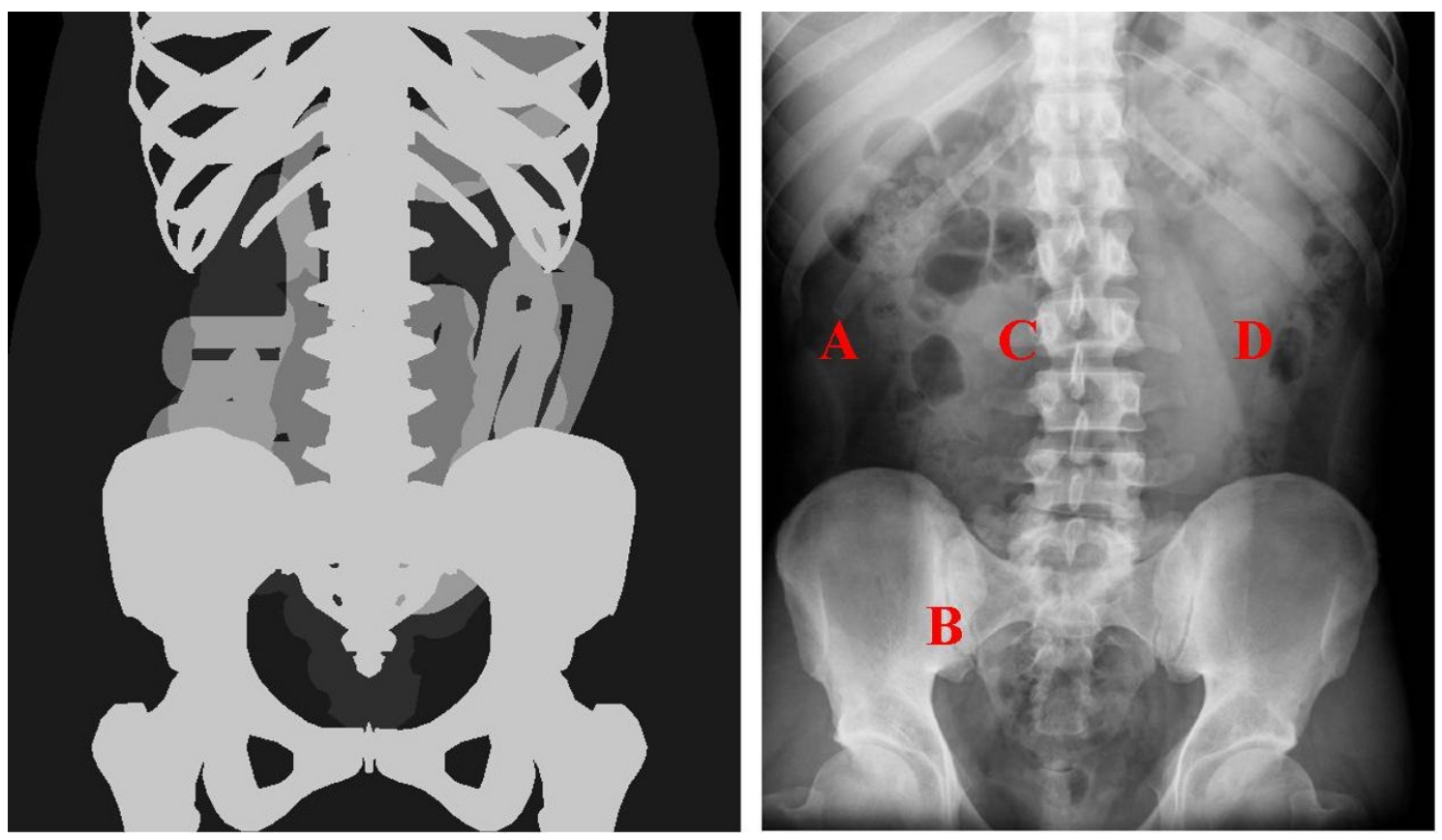

Figura 4.33: Imagem radiográfica simulada de um indivíduo com peso e altura desproporcionais e imagem radiográfica real de um indivíduo com características semelhantes.

Tabela 4.2 - Comparação dos níveis de cinza em função das estruturas representadas nos modelos com peso e altura proporcionais, com peso e altura desproporcionais e as imagens radiológicas de indivíduos com essas mesmas características.

\begin{tabular}{|l|c|c|c|c|}
\hline Estrutura & $\begin{array}{c}\text { Modelo } \\
\text { proporcional }\end{array}$ & $\begin{array}{c}\text { Modelo } \\
\text { desproporcional }\end{array}$ & $\begin{array}{c}\text { Radiografia } \\
\text { Comum (1) }\end{array}$ & $\begin{array}{c}\text { Radiografia } \\
\text { Obeso (2) }\end{array}$ \\
\hline $\begin{array}{l}\text { Intestino } \\
\text { Grosso }\end{array}$ & 26 & 46 & $\begin{array}{c}25 \\
\text { Ponto A }\end{array}$ & $\begin{array}{c}44 \\
\text { Ponto A }\end{array}$ \\
\hline $\begin{array}{l}\text { Intestino } \\
\text { Delgado }\end{array}$ & 62 & 121 & $\begin{array}{c}65 \\
\text { Ponto C }\end{array}$ & $\begin{array}{c}128 \\
\text { Ponto C }\end{array}$ \\
\hline $\begin{array}{l}\text { Intestino Grosso } \\
\text { + Delgado }\end{array}$ & 76 & 155 & $\begin{array}{c}72 \\
\text { Ponto D }\end{array}$ & $\begin{array}{c}150 \\
\text { Ponto D }\end{array}$ \\
\hline Osso & 70 & 200 & $\begin{array}{c}64 \\
\text { Ponto B }\end{array}$ & $\begin{array}{c}192 \\
\text { Ponto A }\end{array}$ \\
\hline
\end{tabular}

A tabela 4.2 mostra que as estruturas modeladas são representativas e podem ser modificadas caso essa característica seja de interesse do usuário.

\subsubsection{Avaliação das Imagens Radiológicas por Médicos}

Os radiologistas consideraram $60 \%$ das imagens como satisfatórias e $40 \%$ ruins, devido principalmente a não representação das diferenças de composição das estruturas. 


\subsection{Discussões}

Os resultados apresentados nas seções anteriores demonstram a versatilidade proporcionada pela metodologia empregada no desenvolvimento de nossos modelos. Essa versatilidade se refere a possibilidade de variação de parâmetros das estruturas retratadas, a qualidade gráfica de sua representação e a visualização dos modelos sob diferentes perspectivas.

A Figura 4.11 demonstra as possibilidades de variação de parâmetros de nosso modelo, apresentando uma visualização frontal do intestino grosso considerado "normal", em forma de serpente, em forma de "u" e em forma de "v", respectivamente. As Figuras 4.6 e 4.7 demonstram a possibilidade de variação da quantidade de tecido adiposo em nosso modelo. O segundo possui um acréscimo de $45,97 \%$ de tecido adiposo em relação ao modelo considerado proporcional. As possibilidades de variação de parâmetros das estruturas retratadas são ilimitadas e vão muito além das apresentadas aqui. Para tanto, basta um objetivo e os dados necessários para a manipulação das malhas referentes às estruturas investigadas. Essa possibilidade, inexistente em grande parte dos fantomas computacionais modernos e impraticável em fantomas físicos, é um diferencial significativo que amplia consideravelmente a utilização dos modelos e os torna interessantes para utilização em outras universidades e em diferentes grupos de pesquisa. Novas estruturas, ou mesmo patologias, ainda não representadas, podem ser adicionadas aos modelos desenvolvidos e manipuladas livremente.

As Figuras 4.20(a), 4.21(a), 4.22(a) e 4.23(a) apresentam imagens retiradas de um atlas anatômico [Sobotta, 2000] sobrepostas às malhas correspondentes obtidas à partir dos modelos desenvolvidos. A sobreposição de imagens foi realizada à partir de visualizações parciais do sistema ósseo humano e sob diferentes perspectivas, à saber: perspectiva frontal e posterior da caixa torárica, perspectiva frontal dos membros superiores e perspectiva frontal dos membros inferiores, respectivamente. Já as Figuras 4.20(b), 4.21(b), 4.22(b) e 4.23(b) apresentam a subtração entre as imagens retiradas do atlas e as imagens referentes aos modelos, de modo que, os pixels com nível RGB $(0,0,0)$, cor preta, representam os pixels não correspondentes entre o modelo retirado do atlas e o modelo desenvolvido. A não correspondência dos pixels, conforme a tabela 4.2 , varia entre 8 e $12,14 \%$ e se deve a alguns fatores apresentados a seguir:

- A não correspondência parcial entre os pixels referentes aos arcos costais do modelo anatômico e do modelo desenvolvido se deve principalmente à necessidade de se adequar a malha do esqueleto a malha que representa a pele durante o processo de modelagem. Em função dessa necessidade, a espinha dorsal do modelo desenvolvido possui uma curvatura mais acentuada em relação à apresentada no atlas anatômico, o que explica a não 
correspondência parcial dos arcos costais.

- A correspondência entre os pixels do modelo do membro superior e da imagem retirada do atlas é bastante alta, chegando a $92 \%$. Os pixels não correspondentes estão concentrados em maior parte nas regiões da escápula e da clavícula, também em função da necessidade de um reposicionamento dessas estruturas no interior da malha da pele. Existe também, embora em menor quantidade, uma concentração de pixels não correspondentes na região do úmero, cuja visualização evidencia claramente que o problema está relacionado a uma pequena redução na largura da malha referente a representação deste.

- Por fim, a maior quantidade de pixels não correspondentes é encontrada no modelo dos membros inferiores, chegando a 12,14\%. A região mais atingida é a região do pé, uma vez que a imagem do pé disponibilizada no atlas é significativamente maior do que a representação do pé disponível em nosso modelo. Para manter a proporcionalidade do modelo, optamos por não aumentar, ainda mais, o tamanho do pé. A região do fêmur, da fíbula e da tíbia também apresentam, embora em menor quantidade, pixels não correspondentes, devido, assim como no caso dos membros superiores, à necessidade de aplicação de uma operação de escala sobre esses ossos de modo a torná-los compatíveis com a malha da pele, o que causou uma pequena redução na largura destes.

As Figuras 4.24 e 4.26 apresentam visualizações frontal/posterior e lateral, respectivamente, do torso obtidas à partir de um atlas anatômico [Sobotta, 2000]. As Figuras 4.25 e 4.27 apresentam as malhas correspondentes visualizadas sob as mesmas perspectivas. Nessas imagens não foram verificadas as não correspondências dos pixels, em função do grande número de estruturas retratadas, no entanto, visualmente é possível averiguar que a disposição dos órgãos em nosso modelo é compatível com a modelo anatômico obtido no atlas. Alguns detalhes internos às estruturas, visualizados nas imagens retiradas do atlas, não são visualizadas com a mesma riqueza de detalhes nas imagens obtidas a partir de nosso modelo em função da inexistência de uma função de transparência que possa ser aplicada quando as três malhas são visualizadas simultaneamente (pele, esqueleto e órgãos). Pequenas variações de posicionamento se devem a adaptações necessárias para adequar a malha dos órgãos a do esqueleto e da malha do esqueleto a da pele. 


\section{Conclusões}

Na literatura especializada existem basicamente dois tipos principais de fantomas virtuais: os obtidos a partir de simulação computacional e os tomográficos. Ambos apresentam características positivas e negativas.

Os fantomas tomográficos ou "voxel phantoms" possuem boa qualidade gráfica e podem representar todas as estruturas internas e externas do corpo humano, pois são gerados a partir de um processo de reconstrução 3D que utiliza como base uma série de imagens tomográficas de pacientes reais, normalmente fornecidas por hospitais ou projetos de pesquisa. Em função da metodologia empregada em seu desenvolvimento, esse tipo de fantoma é totalmente dependente das imagens tomográficas de referência, o que impossibilita a modificação de parâmetros e características anatômicas de um modelo inicial, afim de que novos modelos, com diferentes características, possam ser criados. Para tanto, seriam necessários novos dados, provenientes de um ou mais pacientes diferentes e fisicamente compatíveis com o modelo inicial.

Já os modelos obtidos através de simulação computacional, possuem como maior contribuição a possibilidade de variação de parâmetros, gerando dessa forma, uma série de modelos diferentes, característica interessante inclusive para a simulação de exames. No entanto, o principal problema relacionado a esse tipo de fantoma é a representação em uma única perspectiva, normalmente a frontal, e em duas dimensões, além da representação gráfica de qualidade inferior em relação aos "voxel phantoms".

De acordo com os resultados apresentados no capítulo anterior, foi possível demonstrar que a metodologia utilizada em nosso trabalho reúne as características positivas dos principais fantomas virtuais encontrados na literatura e sobretudo, não apresenta os problemas encontrados nestes. A representação gráfica dos modelos gerados em nosso trabalho possui qualidade realística e em alguns casos, chega a superar inclusive a qualidade gráfica dos "voxel phantoms". A partir do modelo inicial foram criados novos modelos com características anatômicas distintas, o que demonstra a possibilidade de variação de parâmetros anatômicos do modelo, ainda que dentro da ferramenta de modelagem, e torna a metodologia empregada eficaz também nesse sentido. 
Conforme apresentado no Capítulo 2, a necessidade de variação de parâmetros em fantomas de tecnologia mais recente foi prevista por Xu em um de seus trabalhos [Xu and Shi, 2005]. No entanto, a metodologia proposta pelo autor, apesar de permitir a alteração de parâmetros e a manipulação de pontos de controle das superfícies NURBS, ainda depende de um modelo inicial baseado em imagens tomográficas de referência. Além disso, o propósito da metologia empregada nesse trabalho é apenas aplicar deformações referentes ao funcionamento dos órgãos em função do tempo e não simular exames ou avaliar a quantidade de radiação residual destes. Sendo assim, é possível prever a contribuição da metodologia empregada em nosso trabalho nos objetivos perseguidos por $\mathrm{Xu}$ [Xu and Shi, 2005] ou ainda, em novas necessidades que venham a surgir no futuro.

A qualidade gráfica dos modelos aliada às suas inúmeras possibilidades de alteração de parâmetros, nos permite criar pacientes com variações anatômicas relevantes. As influências da alteração das características dos modelos podem ser investigadas através da simulação de outros tipos de exame baseados em imagem, além dos radiológicos, graças a tridimensionalidade "real" dos modelos.

Um outro fator que merece destaque é o fato de que os fantomas desenvolvidos podem ser distribuídos para utilização de terceiros de maneira extremamente simplicada. Os modelos podem ser fornecidos como arquivos, no formato nativo da ferramenta de desenvolvimento em que foram criados, nesse caso o blender, ou ainda, podem ser fornecidos através da disponibilização de um banco de dados, bastando para tanto, a criação de um script SQL que, quando executado, replica os dados para uma nova base. Todos os softwares necessários para a visualização e edição dos modelos são livres e multi-plataforma, não requerendo dessa forma, a aquisição de nenhum tipo de licença de uso para sua manipulação. O Projeto "The Visible Human" [Spitzer, 2008], por exemplo, possui dois modelos completos, um masculino e um feminino, cada um com aproximadamente 15 gigabytes de dados. Além disso, para visualizar e manipular as imagens de referência, são necessários softwares específicos, o que limita de certo modo sua utilização.

Desse modo, a utilização dos modelos desenvolvidos, bem como do algoritmo para simulação de suas imagens radiológicas, caracterizam uma ferramenta complementar de auxílio ao controle de qualidade convencional com uma grande gama de possibilidades de expansão, uma vez que a metodologia empregada no desenvolvimento do trabalho além de atual, não apresenta uma série de limitações existentes nos fantomas computacionais encontrados na literatura, proporcionando dessa forma, inúmeras possibilidades de exploração em trabalhos futuros. 


\subsection{Sugestões para Trabalhos Futuros}

- Simular diferentes tipos de exame, como a tomografia computadorizada e o ultra-som;

- Modificar os modelos desenvolvidos de modo a representar doenças diagnosticáveis via análise das imagens simuladas, como por exemplo, fraturas;

- Criação de modelos dinâmicos caracterizados pelas variações de tamanho e forma dos órgãos em função do tempo, permitindo desse modo, a simulação de processos presentes na atividade corporal humana, como a respiração e os batimentos cardíacos;

- Criação de um banco de imagens para utilização na radiologia que siga as normas de posicionamento estabelecidas por guias radiográficos de referência, de acordo com o tipo de estrutura investigada;

- Criação de um portal web que possibilite a utilização dos fantomas e dos algoritmos de simulação desenvolvidos via internet. 


\section{Referências Bibliográficas}

[Blender, 2008] Blender (2008). Website: http://www.blender3d.org. Acessado em 06 de abril de 2008.

[Boone and Seibert, 1997] Boone, J. M. and Seibert, J. A. (1997). An accurate method for computer-generating tungsten anode x-ray spectra from 30 to $140 \mathrm{kV}$. Medical Physics, 24:1661-1670.

[Caon, 2004] Caon, M. (2004). Voxel-based computational models of real human anatomy: a review. Radiation and Environmental Biophysics, 42:229-235.

[Chao and $\mathrm{Xu}, 2004$ ] Chao, T. and Xu, G. X. (2004). S-values calculated from a tomographic head/brain model for brain imaging. Physics in Medicine and Biology, 49:4971-4984.

[Chao et al., 2001] Chao, T. C., Bozkurt, A., and Xu, G. X. (2001). Organ dose conversion coefficients for $0 . m e v$ electrons calculated for the vip-man tomographic model. Health Physics, 81, Number 2:203-217.

[Cristy, 1980] Cristy, M. (1980). Mathematical phantoms representing children at various ages for use in estimates of internal dose. Technical report, Oak Ridge National Laboratory.

[Fisher and Snyder, 1967] Fisher, H. L. and Snyder, W. S. (1967). Distribution of dose in the body from a source of gamma rays distributed uniformly in an organ. Technical report, Oak Ridge National Laboratory.

[Fisher and Snyder, 1968] Fisher, H. L. and Snyder, W. S. (1968). Distribution of dose in the body from a source of gamma rays distributed uniformly in an organ. Proceedings 1st International Congress of Radiation Protection, 1:1473-1486.

[Fujita, 1995] Fujita, H. (1995). Automated detection of masses and clustered microcalcifications on mammograms. Proceedings of SPIE - The International Society for Optical Engineering, 2434:682-692.

[Gualdrini, 2005] Gualdrini, G. (2005). Monte carlo simulations for in vivo internal dosimetry (including phantom development). In 11th International Congress of the International Radiation Protection Association, page N/A.

[Hendricks, 1997] Hendricks, J. S. (1997). MCNP4B. Los Alamos National Laboratory.

[Hoydonck and Stefano, 2008] Hoydonck, W. V. and Stefano (2008). Knife Script for Blender. Website: http://www.blender.org/download/python-scripts. Acessado em 06 de abril de 2008 .

[Hughes et al., 1997] Hughes, H. G., Prael, R. E., and Little, R. C. (1997). MCNPX - The LAHET/MCNP Code Merger. Los Alamos National Laboratory. 
[ICRP, 1975] ICRP (1975). Report of the Task Group on Reference Man. ICRP Publication 23. Oxford: Pergamon.

[ICRP, 2003] ICRP (2003). Basic Anatomical and Physiological Data for Use in Radiological Protection: Reference Values. ICRP Publication 89. Oxford: Pergamon.

[ICRU, 1989] ICRU (1989). Tissue Substitutes in Radiation Dosimetry and Measurement. ICRU Report 44. International Commission on Radiation Units and Measurements Methesda.

[Jiang et al., 2005] Jiang, H., Wang, B., Xu, G. X., Suit, H. D., and Paganetti, H. (2005). Simulation of organ-specific patient effective dose due to secondary neutrons in proton radiation treatment. Physics in Medicine and Biology, 50:4337-4353.

[Kitaoka, 2002] Kitaoka, H. (2002). Computational morphology of the lung and its virtual imaging. European Journal of Radiology, 44:164-171.

[Kitaoka and Suki, 1999] Kitaoka, H., T. R. and Suki, B. (1999). A three-dimensional model of the human airway tree. Journal of Applied Physiology, 87:2207-2217.

[Kitaoka and Takaki, 2000] Kitaoka, H., T. S. and Takaki, R. (2000). A three-dimensional model of the human pulmonary acinus. Journal of Applied Physiology, 88:2260-2268.

[Kitware, 2008] Kitware (2008). VTK - The Visualization Toolkit. Website: http://public.kitware.com/VTK/. Acessado em 06 de abril de 2008.

[Kramer et al., 2004] Kramer, R., Khoury, H. J., Vieira, J. W., Loureiro, E. C. M., Lima, V. J. M., Lima, F. R. A., and Hoff, G. (2004). All about fax: a female adult voxel phantom for monte carlo calculation in radiation protection dosimetry. Physics in Medicine and Biology, 49:5203-5216.

[Kramer et al., 2003] Kramer, R., Vieira, J. W., Khoury, H. J., Lima, F. R. A., and Fuelle, D. (2003). All about max: a male adult voxel phantom for monte carlo calculation in radiation protection dosimetry. Physics in Medicine and Biology, 48:1239-1262.

[Kramer et al., 1999] Kramer, R., Zankl, M., Williams, G., and G., D. (1999). The calculation of dose from external photon exposures using reference human phantoms and monte carlo methods: Part 1. the male (adam) and female (eva) adult mathematical phantoms. Technical report, Neuherberg-Muenchen: Institut fuer Strahlenschutz.

[Ligier et al., 1994] Ligier, Y., Ratib, O., Logean, M., and Girard, C. (1994). Osiris: a medical image manipulation system. M. D. Comput. Journal, 11:212-220.

[Make-Human, 2008] Make-Human (2008). Make-Human 0.8a. Website: http://www.dedalo3 d.com/. Acessado em 06 de abril de 2008.

[Nascimento, 2005] Nascimento, M. Z. (2005). Método computacional automático para correção do efeito heel. PhD thesis, EESC-USP.

[Nelson et al., 1985] Nelson, W. R., Hirayama, H., and Rogers, D. W. O. (1985). The EGS4 code system. Stanford, CA: Stanford Linear Accelerator Center. 
[Neves, 2005] Neves, L. A. (2005). Modelagem computacional das estruturas torácicas, pulmonares e simulação de suas imagens radiográficas. PhD thesis, EESC - USP.

[Oliveira, 1999] Oliveira, H. J. Q. (1999). Otimização da obtenção de imagens mamográficas para digitalização e processamento. $\mathrm{PhD}$ thesis, IFSC - USP.

[Prael and Lichtenstein, 1989] Prael, R. E. and Lichtenstein, H. (1989). User guide to LCS: The LAHET code system. Los Alamos, NM: Los Alamos National Laboratory.

[Rhinoceros, 2008] Rhinoceros (2008). Nurbs Modeling For Windows. Website: http://www.rhino3d.com. Acessado em 06 de abril de 2008.

[Santos, 2003] Santos, C. E. (2003). Sistema virtual para auxiliar a avaliação dos equipamentos radiológicos. Master's thesis, EESC - USP.

[Sobotta, 2000] Sobotta, J. (2000). Atlas de anatomia humana. Guanabara Koogan.

[Spitzer, 2008] Spitzer, V. (2008). The University of Michigan Visible Human Project. Website: http://www.nlm.nih.gov/reserach/visible. Acessado em 06 de abril de 2008.

[Stabin et al., 1995] Stabin, M., Watson, E., Cristy, M., Ryman, J., Eckerman, K., Davis, J., Marshall, D., and K., G. (1995). Mathematical models and specific absorded fractions of photon energy in the nonpregnant adult female and at the end of each trimester of pregnancy. Technical report, Oak Ridge National Laboratory.

[Supertech, 2008] Supertech (2008). The Lawrence Livermore Realistic Phantom. Calibration Phantoms For In Vivo Whole Body Counters. Website: http://www.supertechxray.com/a1170-r.htm. Acessado em 06 de abril de 2008.

[vtkEditor, 2008] vtkEditor (2008). Website: http://www.esat.kuleuven.ac.be/vtkedit. Acessado em 06 de abril de 2008.

[Wang et al., 2005] Wang, B., Goorley, J. T., Bozkurt, A., and Xu, X. G. (2005). Issues related to the use of monp code for an extremely large voxel model vip-man. In The Monte Carlo Method: Versatility Unbounded in a Dynamic Computing World, pages 17-21. American Nuclear Society.

[Winslow et al., 2004] Winslow, M., Huda, W., Xu, X. G., Chao, T. C., Shi, C. Y., Ogden, K. M., and Scalzetti, E. M. (2004). Use of the vip-man model to calculate energy imparted and effective dose for X-ray examinations. Health Physics, 86, Number 2.

[Wolbarst, 1993] Wolbarst, A. B. (1993). Physics of Radiology. Norwalk, Appleton \& Lange.

[XCOM, 2008] XCOM (2008). Photon Cross Sections Database, NIST Standard Reference Database 8 (XGAM). Website: http://physics.nist.gov/PhysRefData/Xcom/Text/XCOM. Acessado em 06 de abril de 2008.

[Xu, 2005a] Xu, G. X. (2005a). The latest data on effective dose (equivalent) for hot particles on the skin. Radiation Protection Dosimetry, 115:289-293.

[Xu, 2005b] Xu, X. G. (2005b). The effective dose equivalent and effective dose for hot particles on the skin. Health Physics, 89, Number 1:53-70. 
[Xu, 2005c] Xu, X. G. (2005c). Stylized vs tomographic: An experience on anatomical modeling at rpi. In The Monte Carlo Method: Versatility Unbounded in a Dynamic Computing World.

[Xu and Chao, 2003] Xu, X. G. and Chao, T. C. (2003). Calculations of specific absorbed fractions of the gastrointestinal tract using a realistic whole body tomographic model. Cancer Biotherapy \& Radiopharmaceuticals, 18, Number 3:431-436.

[Xu et al., 2000] Xu, X. G., Chao, T. C., and Bozkurt, A. (2000). Vip-man: An image-based whole-body adult male model constructed from color photographs of the visible human project for multi-particle monte carlo calculations. Health Physics, 78, Number 5:476-486.

[Xu and Shi, 2005] Xu, X. G. and Shi, C. (2005). Preliminary development of a 4d anatomical model for monte carlo simulations. In The Monte Carlo Method: Versatility Unbounded in a Dynamic Computing World. American Nuclear Society.

[Zankl and Wittmann, 2001] Zankl, M. and Wittmann, A. (2001). The adult male voxel model "golem" segmented from whole-body ct patient data. Radiation and Environmental Biophysics, 40, Number 2:153-162.

[Zubal et al., 1995] Zubal, I. G., Harrell, C. R., Smith, E. O., and Smith, A. L. (1995). Two dedicated software, voxel-based, anthropomorphic (torso and head) phantoms. 